\title{
WestVirginiaUniversity
}

THE RESEARCH REPOSITORY @ WVU

Graduate Theses, Dissertations, and Problem Reports

2006

\section{Filter weighing procedure for 2007 and newer heavy duty diesel engines}

Eric Taylor

West Virginia University

Follow this and additional works at: https://researchrepository.wvu.edu/etd

\section{Recommended Citation}

Taylor, Eric, "Filter weighing procedure for 2007 and newer heavy duty diesel engines" (2006). Graduate Theses, Dissertations, and Problem Reports. 1747.

https://researchrepository.wvu.edu/etd/1747

This Thesis is protected by copyright and/or related rights. It has been brought to you by the The Research Repository @ WVU with permission from the rights-holder(s). You are free to use this Thesis in any way that is permitted by the copyright and related rights legislation that applies to your use. For other uses you must obtain permission from the rights-holder(s) directly, unless additional rights are indicated by a Creative Commons license in the record and/ or on the work itself. This Thesis has been accepted for inclusion in WVU Graduate Theses, Dissertations, and Problem Reports collection by an authorized administrator of The Research Repository @ WVU. For more information, please contact researchrepository@mail.wvu.edu. 


\title{
Filter Weighing Procedure for 2007 and Newer Heavy Duty Diesel Engines
}

\author{
Eric Taylor \\ Thesis submitted to the \\ College of Engineering and Mineral Resources \\ at West Virginia University \\ in partial fulfillment of the requirements \\ for the degree of \\ Master of Science \\ in \\ Mechanical Engineering \\ Gregory J. Thompson, Ph.D., Chair \\ Nigel Clark, Ph.D. \\ Mridul Gautam, Ph.D. \\ Department of Mechanical and Aerospace Engineering \\ Morgantown, West Virginia \\ 2006
}

Keywords: Cleanroom, Diesel Particulate Matter Procedures 


\section{ABSTRACT}

\section{Filter Weighing Procedure for 2007 and Newer Heavy Duty Diesel}

\section{Engines}

\section{Eric Taylor}

The 2007 heavy-duty on road diesel engine particulate matter standards will require that the particulate matter (PM) levels being emitted from the exhaust will be less than $0.01 \mathrm{~g} / \mathrm{bhp}$-hr. This ten-fold decrease in the existing regulations created the need for changes in the PM filter-weighing environment and procedures. The Code of Federal Regulations Title 40, Part 86 Subpart N (40 CFR 86) has stated that a weighing environment must meet Federal Standard 209E class 1000 classification. This regulation required a new cleanroom facility in the West Virginia University Center for Alternative Fuels, Engines and Emissions laboratories.

Weighing procedures were determined by the specifications of 40 CFR 86, conducting experiments and by varying procedures to determine the procedure that yielded the lowest variation. The Society of Automotive Engineers (SAE) documentation and Center for Alternative Fuels, Engines and Emissions laboratory procedures for particulate matter filter handling and weighing were also reviewed to assist in the evaluation of procedures that will yield the smallest error. This study compares the particulate matter collection on two types of filter media, dual $70 \mathrm{~mm}$ and single $47 \mathrm{~mm}$ T60A20 and $47 \mathrm{~mm}$ Teflo filter. The average difference between the $70 \mathrm{~mm}$ T60A20 and the $47 \mathrm{~mm}$ Teflo was determined to be $0.259 \mathrm{~g} /$ testphase. The average difference between the $70 \mathrm{~mm}$ T60A20 and the $47 \mathrm{~mm}$ T60A20 was determined to be 0.205 g/testphase. 


\section{ACKNOWLEDGEMENTS}

I thank Dr. Thompson for giving me the opportunity in giving me a position at the ERC and allowing me to work to graduate quickly. I would also like to thank the committee members for their input. I would also like to thank John Nuszkowski for assisting me in completing my course work and in my thesis work. I want to thank Nathaniel Moles for his help in our classes as we pressed on to finish. His help and oftenfunny stories helped to make the time spent in the classroom and ERC proceed quickly. I have to thank Mahesh and Reddy for educating me on engine testing and working with me to learn about the test cell. I also want to thank everyone at the ERC for the help that they had provided me with and for the sometimes-interesting working environment.

I also want to thank my family for assisting me during my time at West Virginia University. I would like to thank my wife for supporting me and putting up with me throughout my college career. My mom has helped in providing support and funding throughout my entire collegiate career and many many thanks must be given to her for all of the sacrifices she has made for both my sister and I in our collegiate careers. I also have to thank my mother in law for all the excellent food, and support that she has given to me while working to attain my degrees at WVU. Finally, I would like to thank God for giving me the opportunities and the drive to make it through my collegiate career. 


\section{TABLE OF CONTENTS}

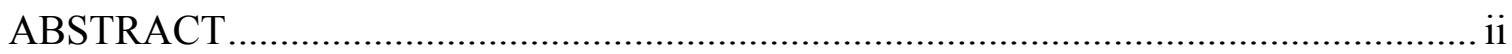

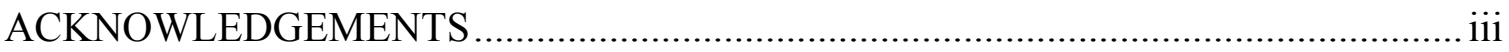

TABLE OF CONTENTS ............................................................................... iv

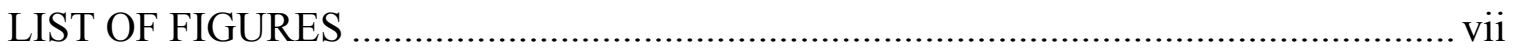

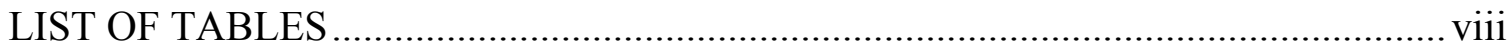

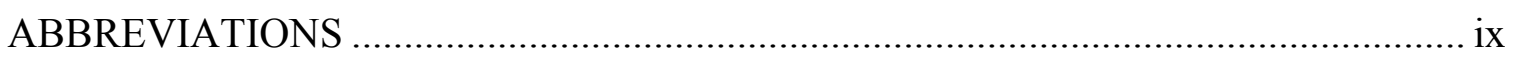

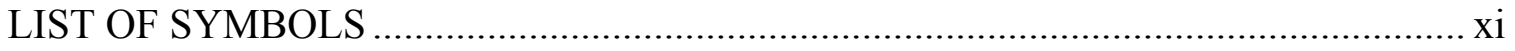

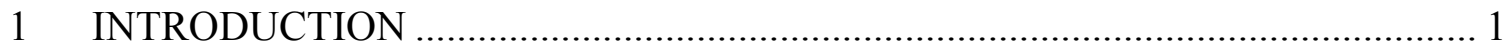

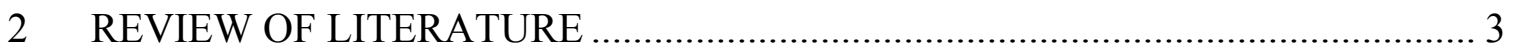

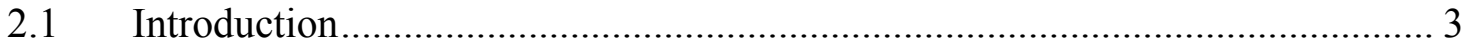

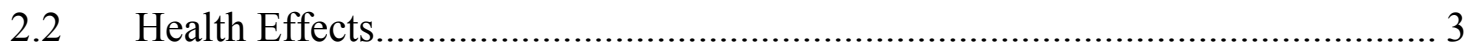

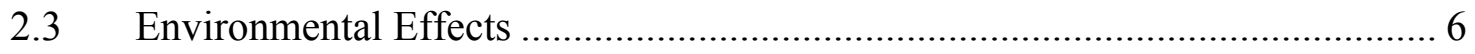

2.4 Diesel Particulate Matter Composition ...................................................... 7

2.4.1 Composition of Solid Fraction of Particulate Matter ................................. 8

2.4.2 Composition of Soluble Organic Fraction of Particulate Matter............... 8

2.4.3 Sulfate Particulates................................................................................... 9

2.5 Particulate Matter Measurement Procedures ............................................... 10

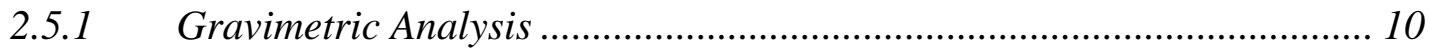

2.5.2 Tapered Element Oscillating Microbalance ............................................ 17

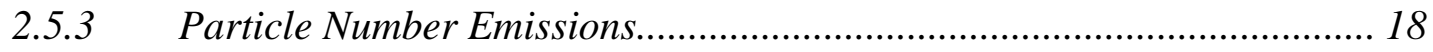

2.5.4 Thermal Mass Analysis .......................................................................... 20

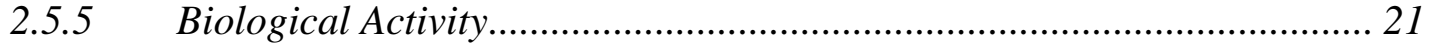

2.6 ISO 14644-1: Classification of Air Cleanliness [38] ..................................... 21

2.6.1 Determination of ISO Cleanroom Classes............................................... 22

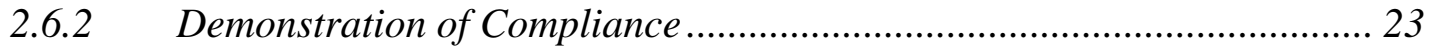

2.6.3 Amount of Sampling Locations ................................................................ 24

2.6.4 Determination of Single Sample Volume per Location.............................. 24 
2.6.5 Recording the Results ....................................................................... 25

2.6.6 Interpretation of the Results.................................................................. 25

2.7 ISO 14644-2: Maintaining Compliance with ISO 14644-1 [39] ...................... 26

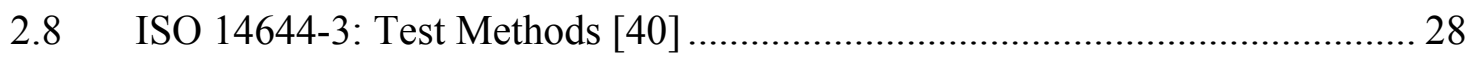

2.9 ISO 14644-4: Design, Construction and Start-up [41] .................................. 30

2.10 ISO 14644-5: Cleanroom Operations [42] ................................................... 30

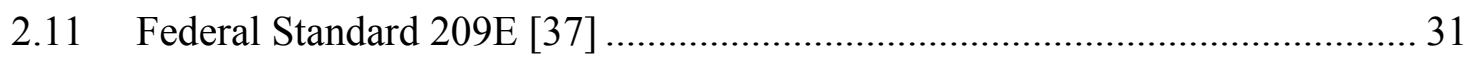

2.11.1 Airborne Particulate Cleanliness Classes ............................................... 31

2.11.2 Verification and Monitoring Of Airborne Particulate Cleanliness ........... 32

2.12 Differences between the FED STD 209 \& ISO 14644 .................................. 34

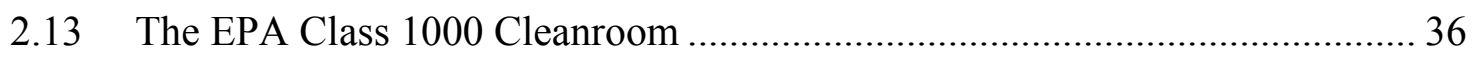

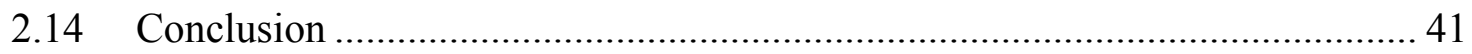

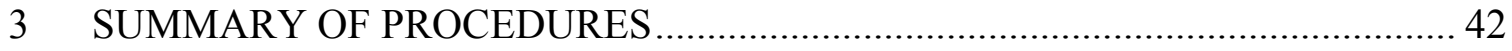

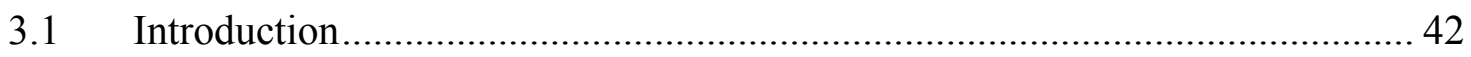

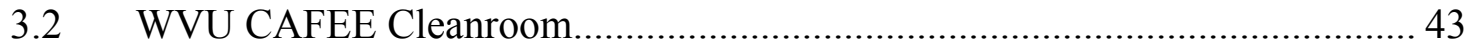

3.3 Developing Cleanroom Cleaning Procedures .................................................... 47

$3.4 \quad$ Weighing Procedures ............................................................................... 48

3.4.1 Procedures to Enter the Cleanroom …………….................................... 48

3.4.2 Operation of Ultra-Microbalance............................................................ 49

3.4.3 Determining Weighing Procedures.......................................................... 50

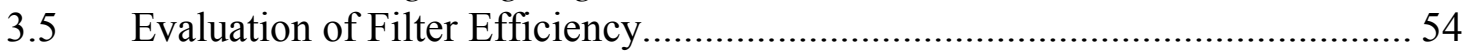

3.5.1 Experimental Setup ......................................................................... 54

3.5.2 Filter Comparison........................................................................... 56

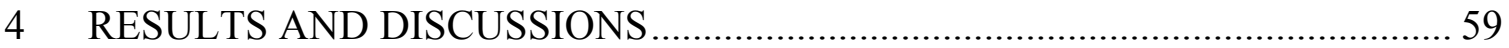

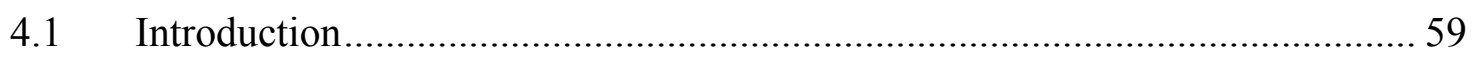

4.2 Cleanroom Cleaning Procedures................................................................ 59

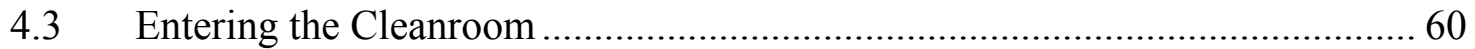

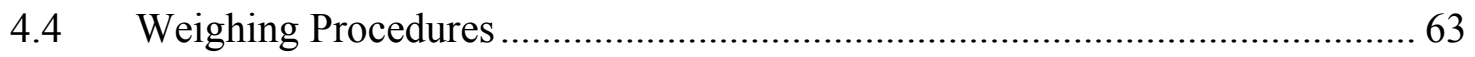

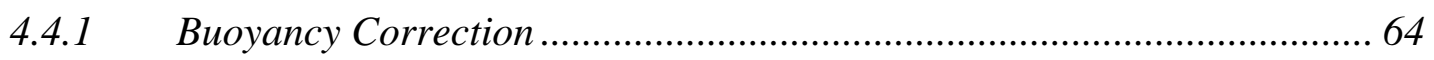

4.4.2 Evaluation of Average Filter Weight ....................................................... 76

4.4.3 Standard Deviations for Sartorius Microbalance ……………………...... 77

4.4.4 Linearization of Sartorius Microbalance.............................................. 78

4.5 Filter Comparison Results..................................................................... 80 
5.1 Cleanroom Cleaning Procedures.............................................................. 83

5.2 Determination of Weighing Procedures..................................................... 83

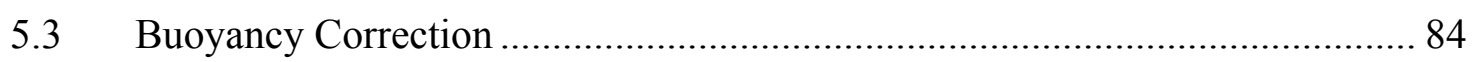

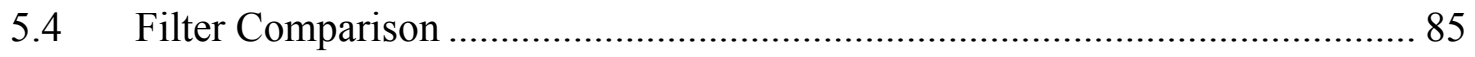

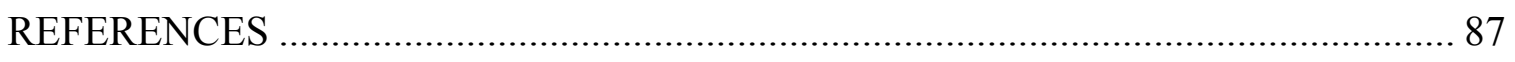

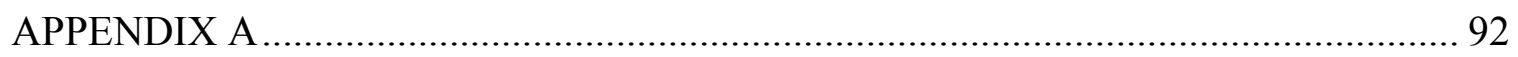

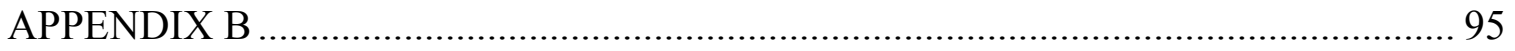

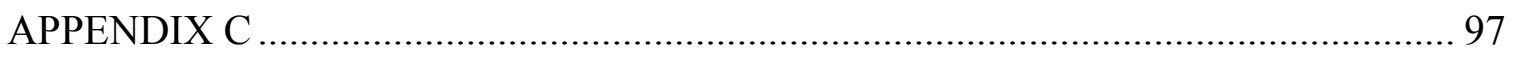

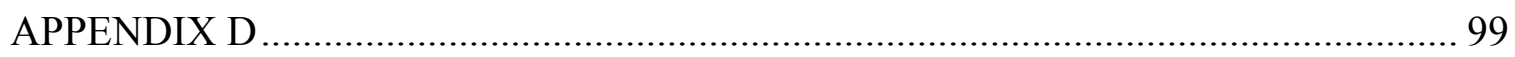




\section{LIST OF FIGURES}

Figure 2-1: Composition of PM [10].............................................................................. 7

Figure 2-2: Changes of mass deposition onto a particulate filter over time [15]............ 10

Figure 2-3: Accuracy of gravimetry as a function of the mass emission [15] .................. 12

Figure 2-4: Illustrates the equation above and how each ISO class is determined [38] . 23

Figure 2-5: Illustration of unidirectional airflow [41] .................................................. 28

Figure 2-6: Illustration of non-unidirectional flow [41] ................................................ 29

Figure 2-7: EPA cleanroom................................................................................ 38

Figure 2-8: EPA weighing environment ....................................................................... 39

Figure 2-9: Weighing environment of EPA cleanroom ................................................... 41

Figure 3-1: View from entrance into gowning room ......................................................... 43

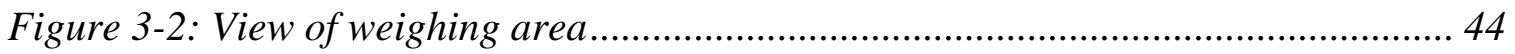

Figure 3-3: Shelves containing pre-weighed filters and conditioning filters................... 45

Figure 3-4: Outside view of cleanroom and gowning room............................................. 46

Figure 3-5: Schematic of primary components of an ultra-microbalance [47] ................ 50

Figure 3-6: View of the WVU CAFEE cleanroom........................................................ 52

Figure 3-7: Comparison view of the Mettler Toledo and Sartorius microbalances......... 52

Figure 3-8: Pass through between cleanroom and gowning room ................................. 55

Figure 3-9: Location of $70 \mathrm{~mm}$ and $47 \mathrm{~mm}$ filter holders during transient testing.......... 56

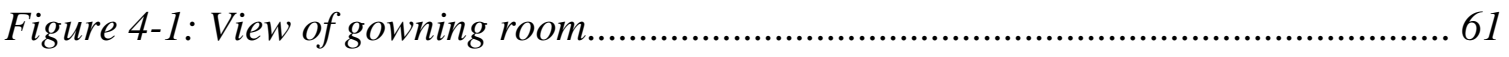

Figure 4-2: Illustrating the change in weight with the change in barometric pressure... 72

Figure 4-3: Demonstrates the buoyancy correction on a larger weighing sample.......... 73

Figure 4-4: Buoyancy corrected weight for $47 \mathrm{~mm}$ Teflo filter compared to barometric

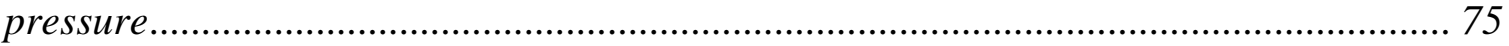

Figure 4-5: Uncorrected weight for $47 \mathrm{~mm}$ Teflo filter compared to barometric pressure

Figure 4-6: Results from running linearity test .......................................................... 79

Figure 4-7: Results when a single $47 \mathrm{~mm}$ Teflo filters are compared with dual $70 \mathrm{~mm}$

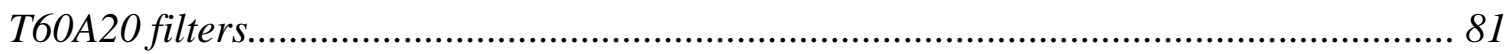

Figure 4-8: Comparison of results from single $47 \mathrm{~mm}$ and dual $70 \mathrm{~mm}$ T60A20 ............ 82 


\section{LIST OF TABLES}

Table 2-1: Schedules of testing to demonstrate compliance with particle concentration

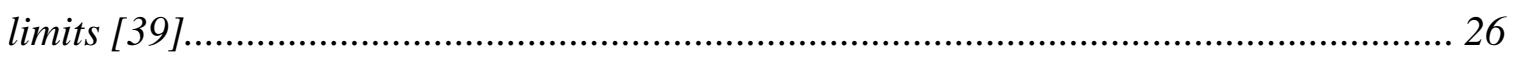

Table 2-2: Schedules of additional tests for all classes [39] ........................................... 26

Table 2-3: Schedules of optional tests [39] ............................................................... 27

Table 2-4: Upper confidence level factor for 95\% upper confidence limit [37] .............. 34

Table 2-5: FED-STD 209E air cleanliness classes [37] ............................................... 36

Table 2-6: Selected airborne particulate cleanliness classes for cleanrooms and clean

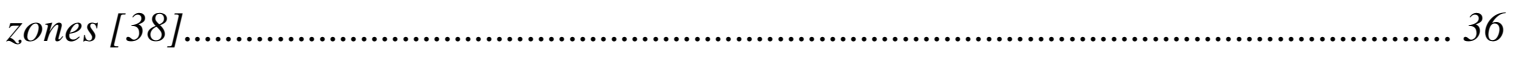

Table 4-1: Values to be used in error propagation .......................................................... 65

Table 4-2: Values used to find error terms for Equation 4-6 ......................................... 67

Table 4-3: Error associated with each instrument used in the buoyancy correction [55,

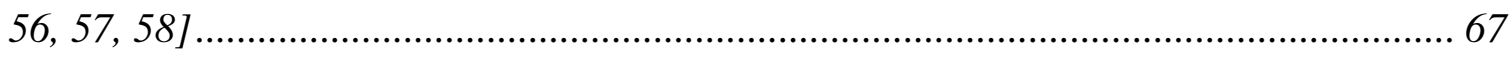

Table 4-4: Error terms for different filter media and diameters ..................................... 70

Table 4-5: Total error values for each calculated term in the buoyancy correction

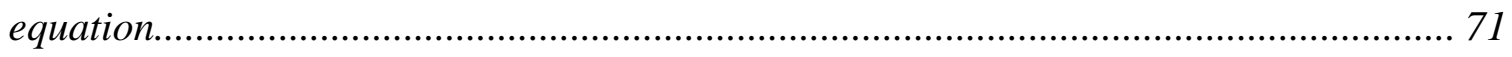

Table 4-6: Values used to determine buoyancy correction and buoyancy corrected values 71

Table 4-7: Illustrates the difference between maximum and minimum values................. 74 Table 4-8: Evaluation of average $47 \mathrm{~mm}$ T60A20 and Teflo filter weighing compared to

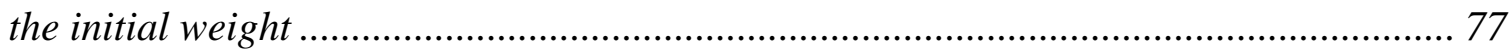
Table 4-9: Illustrates the precision of the microbalance when the tare key is not used... 77 Table 4-10: Demonstrating the precision of the microbalance when the tare key is used 77 Table 4-11: Determination of percent difference by using Equation 4-6 .......................... 78

Table 4-12: Results obtained from linear testing of Sartorius microbalance ................... 79 


\section{ABBREVIATIONS}

\begin{tabular}{|c|c|}
\hline $\mathrm{BC}$ & Buoyancy Corrected \\
\hline bhp & Brake Horse Power \\
\hline BET & Brunauer, Emmett, and Teller method \\
\hline CAFEE & Center for Alternative Fuels, Engines and Emissions \\
\hline CARB & California Air Resources Board \\
\hline CFR & Code of Federal Regulations \\
\hline $\mathrm{CO}$ & Carbon Monoxide \\
\hline $\mathrm{CO}_{2}$ & Carbon Dioxide \\
\hline $\mathrm{COV}$ & Coefficient of Variance \\
\hline DF & Dilution Factor \\
\hline DPC & Discrete Particle Counter \\
\hline DPM & Diesel Particulate Matter \\
\hline EPA & Environmental Protection Agency \\
\hline FED-STD & Federal Standard \\
\hline $\mathrm{HC}$ & Hydrocarbon \\
\hline HD & Heavy Duty \\
\hline HDD & Heavy Duty Diesel \\
\hline $\mathrm{Hg}$ & Mercury \\
\hline $\mathrm{H}_{2} \mathrm{SO}_{4}$ & Sulfuric Acid \\
\hline $\mathrm{H}_{2} \mathrm{O}$ & Water \\
\hline ISF & Insoluble Fraction \\
\hline ISO & International Standards Organization \\
\hline $\mathrm{NO}_{\mathrm{x}}$ & Oxides of Nitrogen \\
\hline $\mathrm{N}_{2}$ & Nitrogen \\
\hline OV & Organic Vapor \\
\hline PAH & Polynuclear Aromatic Hydrocarbons \\
\hline PDP & Positive Displacement Pump \\
\hline PM & Particulate Matter \\
\hline $\mathrm{PM}_{2.5}$ & Particulate Matter less than 2.5 Micrometers \\
\hline $\mathrm{PM}_{10}$ & Particulate Matter less than 10 Micrometers \\
\hline ppm & Parts Per Million \\
\hline SD & Standard Deviation \\
\hline SE & Standard Error \\
\hline SOL & Solid Fraction \\
\hline SOF & Soluble Organic Fraction \\
\hline $\mathrm{SO}_{2}$ & Sulfur Dioxide \\
\hline $\mathrm{SO}_{3}$ & Sulfur Trioxide \\
\hline $\mathrm{SO}_{4}$ & Sulfate \\
\hline TEOM & Tapered Element Oscillating Microbalance \\
\hline THC & Total Hydrocarbons \\
\hline TPM & Total Particulate Matter \\
\hline PTFE & PolyTetraFluoroEthylene \\
\hline & Uncorrected \\
\hline
\end{tabular}




$\begin{array}{ll}\text { UCL } & \text { Upper Confidence Level } \\ \text { US } & \text { United States } \\ \text { VOC } & \text { Volatile Organic Compounds } \\ \text { VOF } & \text { Volatile Organic Fraction } \\ \text { WVU } & \text { West Virginia University }\end{array}$




\title{
LIST OF SYMBOLS
}

\author{
A Area of the cleanroom, $\left(\mathrm{ft}^{2}\right),\left(\mathrm{m}^{2}\right)$ \\ $\mathrm{C}_{\mathrm{n}} \quad$ Maximum permitted concentration of airborne particles that are equal to or larger \\ than the considered particle size, (particles per cubic meter of air) \\ $\mathrm{C}_{\mathrm{n}, \mathrm{m}} \quad$ Class limit for the largest considered particle size specified for the relevant class, \\ (particles per cubic meter) \\ D Particle size, $(\mu \mathrm{m})$ \\ d Threshold particle size, $(\mu \mathrm{m})$ \\ DF Dilution factor, (-) \\ M Buoyancy corrected mass, (mg) \\ $\mathrm{N} \quad$ ISO classification number, which shall not exceed a value of 9, (-) \\ $\mathrm{N} \quad$ Number of revolutions of the PDP during the test phase, (rev) \\ $\mathrm{N}_{\mathrm{L}} \quad$ Minimum number of sampling locations, rounded to a whole number, (-) \\ L Number of sampling locations, (-) \\ $\mathrm{P} \quad$ Measured barometric pressure, $(\mathrm{kPa})$ \\ $\mathrm{P}_{\mathrm{B}} \quad$ Barometric pressure, $(\mathrm{mm} \mathrm{Hg}),(\mathrm{kPa})$ \\ $\mathrm{P}_{\mathrm{bf}} \quad$ Net weight of particulate on the background particulate filter, $(\mathrm{g})$ \\ $\mathrm{P}_{\mathrm{f}} \quad$ Mass of particulate on the sample filter, (g/test phase) \\ $\mathrm{P}_{\mathrm{ib}} \quad$ Pressure elevation above ambient measured at the inlet to the background gas \\ meter or flow instrumentation, $(\mathrm{mm} \mathrm{Hg})$ \\ $\mathrm{P}_{\text {is }} \quad$ Pressure elevation above ambient measured at the inlet to the dilute exhaust \\ sample gas meter or flow instrumentation, $(\mathrm{mm} \mathrm{Hg})$ \\ $\mathrm{P}_{\text {mass }} \quad$ Mass of particulate emitted per test phase, $(\mathrm{g} /$ test phase) \\ $\mathrm{P}_{\mathrm{W}} \quad$ Vapor pressure of water, $(\mathrm{kPa})$ \\ $\mathrm{P}_{4} \quad$ Pressure depressions below atmospheric measured at the inlet to the positive \\ displacement pump, $(\mathrm{mm} \mathrm{Hg}),(\mathrm{kPa})$ \\ $\mathrm{R} \quad$ Uncorrected filter weight, $(\mathrm{mg})$ \\ SD Standard deviation, $(\mathrm{mg})$ \\ SE Standard error, (-) \\ $\mathrm{S}_{\mathrm{L}} \quad$ Number of sampling locations, (-) \\ $\mathrm{T} \quad$ Measured temperature, $\left({ }^{\circ} \mathrm{C}\right)$ \\ $\mathrm{T}_{\mathrm{dp}} \quad$ Dew point temperature, $\left({ }^{\circ} \mathrm{C}\right)$ \\ $\mathrm{T}_{\mathrm{ib}} \quad$ Average temperature of the dilute exhaust sample at the inlet to the gas meter or \\ flow instrumentation, $\left({ }^{\circ} \mathrm{R}\right)$ \\ $\mathrm{T}_{\text {is }} \quad$ Average temperature of the background sample at the inlet to the gas meter or \\ flow instrumentation, $\left({ }^{\circ} \mathrm{R}\right)$ \\ $\mathrm{T}_{\mathrm{P}} \quad$ Average temperature of dilute exhaust entering the positive displacement, $\left({ }^{\circ} \mathrm{R}\right)$ \\ UCL Upper confidence level, (-) \\ $\mathrm{V}_{\mathrm{ab}} \quad$ Actual volume of primary dilution air sampled by background particulate \\ sampler, $\left(\mathrm{ft}^{3}\right)$ \\ $\mathrm{V}_{\mathrm{as}} \quad$ Actual volume of dilute sample removed from the primary dilution tunnel, $\left(\mathrm{ft}^{3}\right)$ \\ $\mathrm{V}_{\mathrm{bf}} \quad$ Total volume of sample removed from the primary dilution air sampled by \\ background particulate sampler, $\left(\mathrm{ft}^{3}\right)$
}


$\mathrm{V}_{\mathrm{s}} \quad$ Minimum single sample volume per location, (1)

$\mathrm{V}_{\text {sf }} \quad$ Total volume of sample removed from the primary dilution tunnel, $\left(\mathrm{ft}^{3}\right)$

$\mathrm{V}_{\text {nux }}$ Total dilute exhaust volume corrected to standard conditions, $\left(\mathrm{ft}^{3} /\right.$ test phase)

$\mathrm{V}_{\mathrm{o}} \quad$ Volume of gas pumped by the positive displacement pump, $\left(\mathrm{ft}^{3} / \mathrm{rev}\right),\left(\mathrm{m}^{3} / \mathrm{rev}\right)$

$\rho_{\mathrm{A}} \quad$ Determined air density, $\left(\mathrm{kg} / \mathrm{m}^{3}\right)$

$\rho_{\mathrm{S}} \quad$ Density of filter material used to sample particulate emissions, $\left(\mathrm{kg} / \mathrm{m}^{3}\right)$

$\rho_{\mathrm{W}} \quad$ Density of calibration weight used to adjust the balance, $\left(\mathrm{kg} / \mathrm{m}^{3}\right)$ 


\section{INTRODUCTION}

Diesel engines produce good fuel economy when compared to similar gasoline engines. This makes the diesel engine a very attractive power plant. However, the diesel combustion process yields higher particulates and oxides of nitrogen compared to its gasoline counterpart [1]. The California Air Resources Board (CARB) 2001 estimated annual average emissions show that on a statewide basis all on-road diesel vehicles contribute $32 \%$ of on-road mobile $\mathrm{PM}$ and $\mathrm{PM}_{10}$ emissions [2]. CARB hopes to cut diesel particulate emissions by $75 \%$ by 2010 and $85 \%$ by 2020 [3]. Recently PM emissions from diesel engines have been considered one of the most important issues concerning human health and impact on the environment [4].

The Environmental Protection Agency is continually enacting more stringent regulations due the increasing health concerns of diesel particulates. The 2007 heavyduty diesel engine particulate matter standards will require that the PM levels being emitted from the exhaust will be less than $0.01 \mathrm{~g} / \mathrm{bhp}-\mathrm{hr}$ [5]. The previous PM requirement, set in 1994, was $0.10 \mathrm{~g} / \mathrm{bhp}-\mathrm{hr}$ [6]. This decease in the limit has created the need for changes in the PM filter-weighing environment. Therefore, the EPA has stated that diesel particulate matter weighing should take place in a weighing environment that must meet Federal Standard 209E class 1000 classifications [2].

This requirement was developed to ensure ambient contaminants will not influence the PM filter weight and to have greater control of the environmental conditions. Along with class 1000 requirement, the cleanroom must maintain a five minute unweighted average of temperature and dew point at $22^{\circ} \pm 1{ }^{\circ} \mathrm{C}$, and $9.5^{\circ} \pm 1{ }^{\circ} \mathrm{C}$, respectively, in which the averages are calculated by sampling once per second [7]. The 
40 CFR 86 Subpart $\mathrm{N}$ has described that a microbalance should have a precision (standard deviation) of 0.25 micrograms $(\mu \mathrm{g})$ or better for a repeated weighing of a calibration weight, a precision $2.5 \mu \mathrm{g}$ or better for repeated weighing of particulate filter and a readability of $0.1 \mu \mathrm{g}$.

The objective of this study was to determine how changes in the weighing environments will affect the repeatability and precision of weighing in the West Virginia University Center for Alternative Fuels, Engines and Emissions (CAFEE) class 1000 weighing environment and the procedures that should be developed to minimize the error in weighing. These procedures include weighing procedures and cleanroom cleaning procedures. Both sets of procedures are important in minimizing contamination of filters, which could yield invalid results. A Sartorius SE2-F was procured to be compliant with the 2007 regulations in which the standard deviation of repeated weighings are to be determined. 


\section{REVIEW OF LITERATURE}

\subsection{Introduction}

This section will discuss the importance of measuring total particulate matter (TPM) due to health effects and environmental effects. The formation and composition of particulate matter and its affects on the collected PM are important for the 2007 standards due to minimal amount of collected solid fraction of PM. The lowered PM emission requirements have also required the EPA to set weighing environment requirements. These requirements were initially set to follow the Federal Standard 209E but this standard has since been superseded by ISO 14644. Both documents will be reviewed and their differences will be discussed.

\subsection{Health Effects}

The EPA has included diesel exhaust in its list of mobile sources of air toxics whose emissions may be further regulated. CARB has reviewed the risk of exposure to diesel exhaust as well and has designated diesel PM as a toxic air contaminant for which additional control measures may be needed [2, 8]. In 1989, the International Agency for Research on Cancer found that diesel particulates are possibly a human carcinogen while the National Institute for Occupation Safety and Health determined that it is a probable occupational carcinogen [9]. The soluble organic fraction constituents, particularly the polynuclear aromatic hydrocarbons $(\mathrm{PAH})$ and the nitro-PAH, are strong contributors to the overall mutagenicity and is also known to increase the risk of heart respiratory disease 
$[10,11]$. Organic compounds tend to undergo reactions in ambient air that may render them more toxic [8].

The diameter of the PM being expelled from the exhaust is known as a trimodal distribution by aerodynamic diameter of particles, $\mathrm{D}$ (diameter) $<10 \mu \mathrm{m}$; fine particles, $\mathrm{D}$ $<2.5 \mu \mathrm{m}$; ultra fine particles, $\mathrm{D}<0.10 \mu \mathrm{m}$; and nanoparticles $\mathrm{D}<0.05 \mu \mathrm{m}$ or $50 \mathrm{~nm}$. $\mathrm{PM}_{2.5}$ is dominated by emissions from combustion processes. $\mathrm{PM}_{10}$ has a much higher proportion of particles generated by mechanical processes from a variety of noncombustion sources [8]. The EPA designates national air quality standards that are considered a danger to the public, in which the standard states there should be an arithmetic mean of $50 \mu \mathrm{g} / \mathrm{m}^{3}$ or less, annually for the $\mathrm{PM}_{10}$. The EPA standard states there should be an arithmetic mean of $15 \mu \mathrm{g} / \mathrm{mg}^{3}$ or less, annually for the $\mathrm{PM}_{2.5}$ [7].

The size of the diameter of the particulates has created much concern in the health community. The EPA proposed fine particle standards that are based on studies that link fine particles with adverse health effects. Many studies show that the correlation between health effects and atmospheric particle concentration is improved when fine particle concentration rather than the concentration of $\mathrm{PM}_{10}$ is used. Adverse health effects seem to be linked with smaller diameter particles. The number of particles and particle surface area per unit mass increases with decreasing particle size. The smaller particle diameter increases the efficiency of deposition in the human respiratory tract [12]. A number of epidemiological and experimental studies have found that effects of short-term exposure to diesel exhaust particles on the respiratory and immune systems, particularly in the individuals with asthma and other allergic diseases, may be of concern [8]. 
Long-term bioassays conducted in rats were shown to have an increase in lung tumors only at high levels of exposure (several milligrams of diesel exhaust PM per cubic meter). While PM studies with mice and hamsters have shown little to no effect. The rat studies have shown that high levels of both diesel exhaust and carbon black particles (lacking gases and PM-associated organic compounds) caused lung tumors. "These results suggest that the mechanisms of carcinogenesis in rats are likely to be related to exposure to high doses of the particles themselves and to possible lung overload of particles, rather than to the adsorbed organic compounds or gases" [8].

Both the EPA and the California EPA have determined that results of animal studies can be used to reason that PM is a hazard for humans. However, these groups found the results were too uncertain to be used in quantitative risk assessment for human lung cancer because the mechanisms operating at high dose exposures in animals may not be relevant to humans exposed to low ambient concentrations. The California EPA concluded that the studies "provide evidence consistent with a causal relationship between occupational diesel exhaust exposure and lung cancer." The diesel engines that were used in the animal study and the worker study were engines that were built before the mid-1990s. The EPA acknowledged that it is uncertain "whether the health hazards identified from studies using emissions from older engines can be applied to present-day environmental emissions and related exposures, as some physical and chemical characteristics of the emissions from certain sources have changed over time" [8]. "Due to the introduction of future diesel engine and fuel technologies, it was confirmed that health effects of PM showed an improving tendency in comparison with the current state, provided the mutagenicity in Ames test was used as an index" [13]. 
Another study looked at railroad workers and truck drivers and it showed a relatively consistent, though weak association between exposure to diesel exhaust and lung cancer. However, most studies were unable to properly account for possible cofounders, and lacked sufficient data for estimating exposure across the full work experience. A different study has concluded that after following population subgroups for long periods of time, they reported an association between long term PM exposure and increased rates of death due to cardiovascular disease and cancer [8].

\subsection{Environmental Effects}

Diesel engines emit low levels of hydrocarbons and carbon monoxide that do not require after treatment to comply with current standards. However, hydrocarbons are now joined together with oxides of nitrogen and thus reduces the total amount oxides of nitrogen that can be emitted. Diesel engines also enjoy $25 \%$ to $40 \%$ higher thermal efficiency over their gasoline-fueled counterparts [11]. However, regulatory officials are concerned about diesel vehicle emissions, oxides of nitrogen and PM. Ozone, which is a byproduct of oxides of nitrogen, hydrocarbons, and nitrogen dioxide, remains a persistent air pollution problem around the world. The use of diesel vehicles are thought to combat the effects of global warming because of their substantial fuel economy benefits and $\mathrm{CO}_{2}$ advantage over their gasoline burning counterparts. However, this fact could be overshadowed by recent studies that indicate that diesel engines produce a substantial fraction of atmospheric particles that may be reducing cloud cover and rainfall $[13,14]$. 


\subsection{Diesel Particulate Matter Composition}

It has become more important to understand the detailed characteristics of diesel particulate matter as diesel emissions have been continually reduced and as more regulations push for further reduction [9]. The EPA defines diesel particulate matter as the mass collected on a filter from exhaust that has been diluted and cooled to $52^{\circ} \mathrm{C}$ or below $[12,15]$. The basic fractions of diesel particulate matter are elemental carbon, heavy hydrocarbons derived from unburned fuel and lubricating oil, and hydrated sulfuric acid derived from the fuel sulfur [12]. PM is traditionally divided into three main components, which can be further sub-categorized as follows; solid fraction (elemental carbon, ash), soluble organic fraction (organic material derived from engine lubricating oil, organic material derived from fuel), and sulfate particulates (sulfuric acid, water), as shown in Figure 2-1 $[6,10]$. The composition of exhaust particles depends upon where and how they are collected, engine technology, conditions of the dilution air, fuel properties, the rate of dilution and after treatment, therefore Figure 2-1 does not hold true in all PM. As the exhaust is diluted and cooled, nucleation, condensation, and adsorption transform volatile materials to solid and liquid particulate matter $[12,16]$.

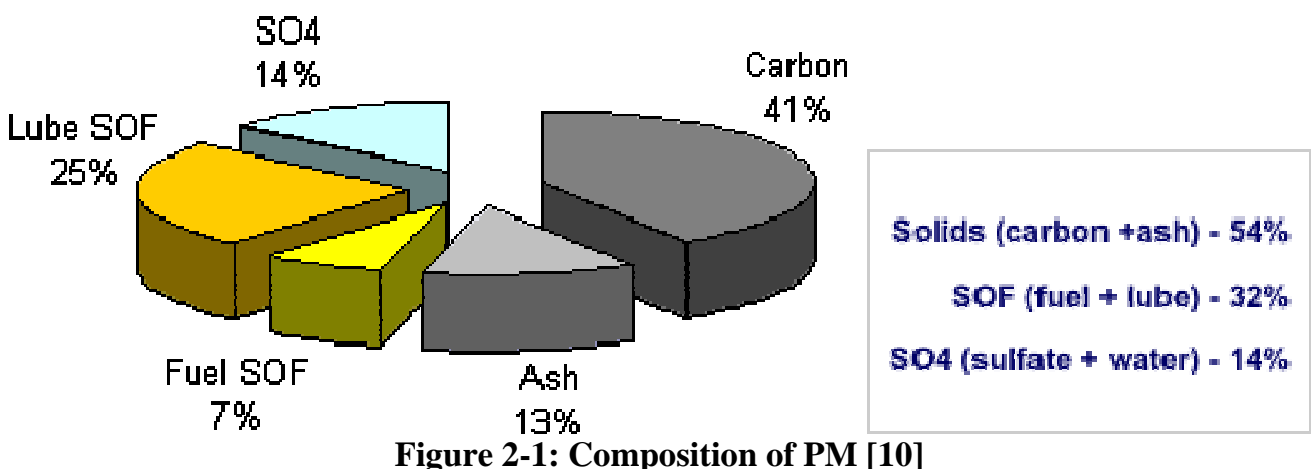

Figure 2-1: Composition of PM [10] 


\subsubsection{Composition of Solid Fraction of Particulate Matter}

The solid fraction of diesel particulates is composed primarily of elemental carbon that also contains sulphate and nitrate. The carbonaceous PM fraction results from the heterogeneous combustion process in diesel engines, where solid particle precursors are formed in both diffusion and premixed flame [10].

Another important component of the solid fraction of PM is metallic ash. Diesel exhaust ash consists of a mixture of the following components: metals that are formed in the engine's combustion chamber from burning of additives in the engine lubricating oil, metal oxide impurities resulting from the engine wear, and iron oxides resulting from corrosion of the engine exhaust manifold and other exhaust system components. Particulate matter from US post 1994 HDD engines may contain as much as 10\% or more $\operatorname{ash}[10]$.

\subsubsection{Composition of Soluble Organic Fraction of Particulate Matter}

The soluble organic fraction portion of the PM is derived from the unburned fuel and the engine lubricating oil that is adsorbed into the carbonaceous material of the particulate [17]. The dominant component in SOF is paraffin hydrocarbon and second is polycyclic aromatic hydrocarbon $[18,19]$. The heavy hydrocarbon will condense or adsorb onto the surface of the carbon particles forming the organic portion of PM. The hydrocarbons will nucleate forming increased numbers of volatile nuclei mode particles if the carbon particles are unable to adsorb all of the heavy hydrocarbons [10].

The amount of SOF varies with engine design and operating condition. It can range from less than 10 percent to more than 90 percent by mass. SOF values are highest 
at light engine loads when exhaust temperatures are low [18]. PM with low SOF content is called "dry" particulate and PM of high SOF content is called "wet" particulate [10].

\subsubsection{Polycyclic Aromatic Hydrocarbon Content in SOF}

The dominant components of PAH emissions are phenanthrene and naphthalene. PAH contains a small percentage of linear and branched paraffin hydrocarbon and a very small fraction of alkene and ester. The amount of PAH measured in the diesel exhaust is orders of magnitude lower in comparison to the primary PM components and typically constitutes a fraction of a percent of the total PM emission. Diesel fuel contains PAH with a concentration level varying between $1.5 \%$ and $2.5 \%$. Diesel fuel appears to be the dominant source of PAH in diesel exhaust [10].

\subsubsection{Sulfate Particulates}

Sulfate particulates are formed in the dilution tunnel through a heteronucleation process from the molecules of $\mathrm{H}_{2} \mathrm{SO}_{4}$ and water. Sulfate particulates are primarily composed of liquid hydrated sulfuric acid. Most of the sulfur in the fuel is oxidized to $\mathrm{SO}_{2}$, but a small fraction is oxidized to $\mathrm{SO}_{3}$ that leads to sulfuric acid and sulfates in the exhaust particles [12]. Formation of sulfate particles in the dilution tunnel depends on $\mathrm{H}_{2} \mathrm{SO}_{4}$ and $\mathrm{H}_{2} \mathrm{O}$ vapor pressures, which are functions of fuel sulfur levels, conversion of fuel sulfur to $\mathrm{SO}_{3}$, air/fuel ratio, dilution tunnel temperature, and dilution tunnel humidity. During PM measurements, sulfate particulates are deposited on the filters together with the carbonaceous material [10]. 


\subsection{Particulate Matter Measurement Procedures}

There are many other ways of determining PM properties, such as composition, surface area and biological assays. The largest source of error in all collecting techniques is the unstable character of the collected PM sample. Particles may change considerably during their deposition onto a filter or during analysis. Therefore, their properties might be different than those from airborne particulates. Phase transitions will allow material to evaporate from the particulate filter, or allow initially gaseous material to condensate on the filter. Figure 2-2 demonstrates how these phase transitions alter the mass deposition on a particulate filter [15].

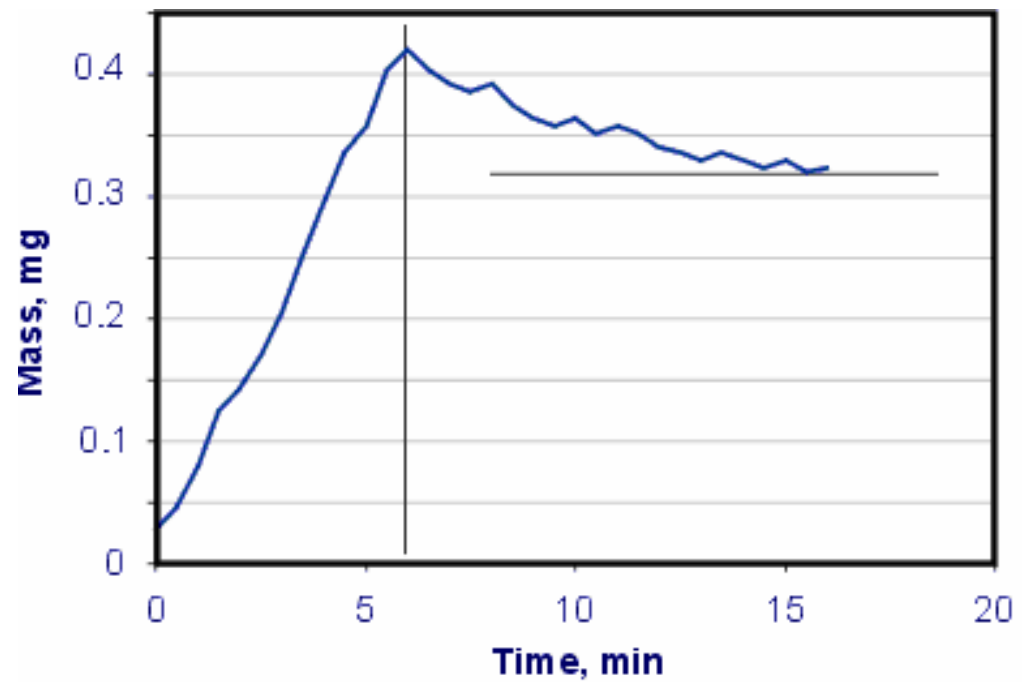

Figure 2-2: Changes of mass deposition onto a particulate filter over time [15]

\subsubsection{Gravimetric Analysis}

The current method of PM measurement used for EPA certification testing is based on gravimetric analysis. Gravimetric analysis is completed by drawing a sample of diluted exhaust from the dilution tunnel through a dual (primary and secondary) or a single Teflon coated fiberglass filter, in which the exhaust gas temperature is not to exceed $52^{\circ} \mathrm{C}$ at the filter face $[12,15]$. Filters are pre- and post-weighed using a high 
precision microbalance after they have been conditioned within a temperature and humidity controlled room $[4,15,20]$.

Current EPA regulations of $0.1 \mathrm{~g} / \mathrm{bhp}$-hr allow for repeatable results where PM composition is mainly solid particles that are not strongly affected by changes of dilution parameters such as dilution ratio, dilution temperature, residence time [15]. The current gravimetric analysis faces many challenges when applied to the low emissions of 0.01 $\mathrm{g} / \mathrm{bhp}-\mathrm{hr}$ for the 2007 regulations. The sensitivity of gravimetric analysis is becoming too low for the reduced amount of mass emission, as shown in Figure 2-3 [4, 15, 22]. The gravimetric analysis must measure $100 \mu \mathrm{g}$ or less, in net weight, of particulate matter on a filter that ranges in gross weight from 60 to $150 \mathrm{mg}$ with a resolution of $0.1 \mu \mathrm{g}$. This means that the sampling and handling procedure must be accurate within $\pm 25 \mathrm{ppm}$ by mass [23]. The EPA has chosen to adjust the filter face temperature to $47^{\circ} \mathrm{C} \pm 5^{\circ} \mathrm{C}$, to ensure laboratory-to-laboratory variance is minimized, to meet the challenges of the 2007 PM standard. The EPA has also made changes to the secondary dilution tunnel, CVS, and to filter handling, weighing chamber, and filter media. These procedural alterations have been demonstrated by the EPA to achieve a coefficient of variance of less than $10 \%$ [21]. 


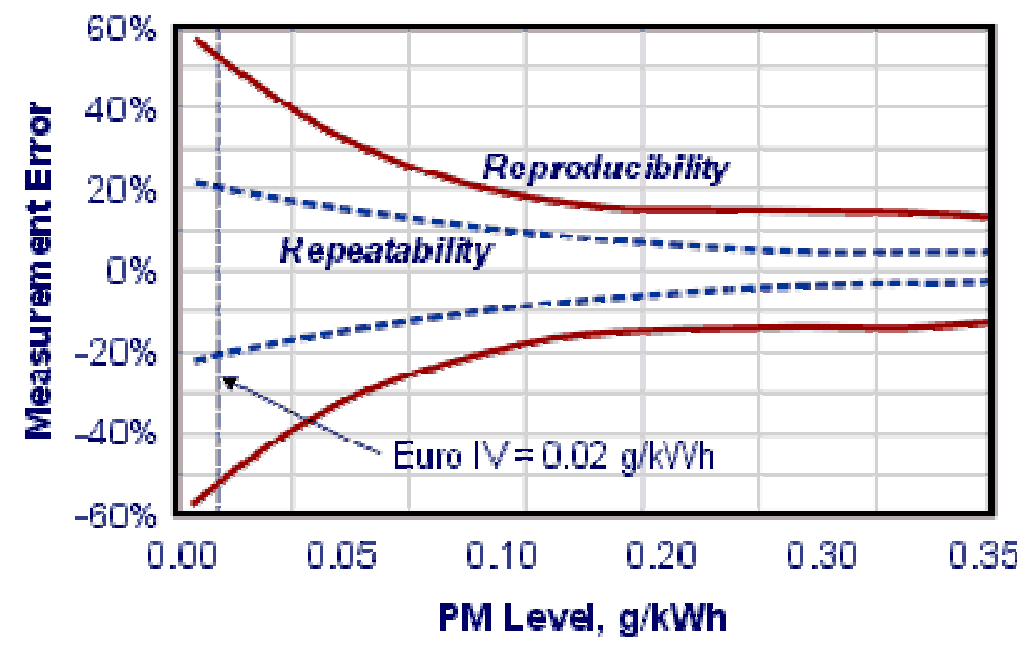

Figure 2-3: Accuracy of gravimetry as a function of the mass emission [15]

There are other analyses that can take place by using the PM samples that are collected on the filter media. These analyses can determine the SOF, water-soluble reaction, sulfates, and the insolubles. The SOF is usually measured through the extraction of the PM sample with dichloromethane in a Soxhlet extractor. Further analysis of SOF can be used to determine the amount of PAH. The addition of alcohols to the dichloromethane solvent allows some extraction of sulfates. The sample for sulfate analysis is obtained in a second extraction by using an isopropanol/water mixture to extract the water-soluble fraction. An ion chromatograph calibrated with a standard potassium sulfate solution is used to analyze a filtered extract for sulfates. The remaining portion of PM on the filter represents the insolubles. The VOF is found by using vacuum evaporation [15].

\subsubsection{Reducing the Variability of Gravimetric PM Measurement}

The 2007 heavy-duty diesel standard for PM levels, $0.01 \mathrm{~g} / \mathrm{bhp}-\mathrm{hr}$, are enough that a small amount of variation in weight could have a significant effect on the outcome of the test. A number of weighing factors can greatly affect errors when handling filters 
with small weight gains. The following sources of error contribute to uncertainties in filter handling and weighing: filter contamination, vibration of the balance, electrostatic charges, and fluctuations in temperature and relative humidity in the filter conditioning environment [25]. Therefore exploration is needed in determining ways to minimize variability in the data. A significant cause of variability is neutralization of the PM filter. A study by Chase et al. determined that there is also a considerable amount of variability in using the Teflo filters compared to the TX40 filters, meaning that filters will not provide equivalent measurements [15].

\subsection{Reducing Variability by Minimizing Static Charge}

Triboelectric charging is the most common method of producing static charge. This occurs when there is friction, movement, separation of materials and fluid flow over a material. When two surfaces in close contact are separated, one surface loses an electron to become positively charged, while the other surface gains an electron to become negatively charged [26]. This process describes a filter being removed from a Petri dish to be placed onto the microbalance. The triboelectric charging creates the need for static control and this is the reasoning for research into ways of minimizing static charge.

A study conducted by Chase et al. had observed several outliers in PM results, when levels were reaching $1 \mathrm{mg} / \mathrm{mile}$. They had examined their weighing process to determine that the most likely culprit in causing the outliers was their neutralization procedure. A study by Hanninen et al. determined that if static charge was not removed between two weight measurements, it added random variance on the order of 20-40 $\mu \mathrm{g}$ to the differential masses [27]. 
Neutralization of the charge accumulated on filters is a challenge because of the disposable, low mass, efficient inert PM filters are insulators. Charge will not readily flow from where it is deposited to points of the filter that are brought into contact with ground. Past methods used to minimize static charges were maintaining elevated humidity to facilitate charge dissipation and providing a source of ions in the vicinity of the filter to promote neutralization. Ionizers are currently used in the CAFEE cleanroom due to the tighter control of humidity. There are two types of ionizers in use: Polonium 210 produces alpha particles by radioactive decay which then creates ions in the air and corona discharge devices that use alternating high voltage applied to pointed electrodes to ionize the air. Both sides of the filter should be exposed to the ionizer to ensure that the filter will be neutrally charged [28].

\subsection{Exercising Microbalance to Reduce Variability}

The study by Chase et al. observed that exercising the balance with weight similar to the weight of the PM filters would be a good practice because it places the balance's electromagnetic coil in a known thermal condition that will be repeated for each subsequent measurement. This is because a microbalance uses an electromagnetic coil to oppose the pull of gravity and to keep the balance pan in a known position. Thus the current through the coil is measured to determine the balance reading. It was found that reading the balance when it first becomes stable would help to minimize the effects of drifting [28]. 


\subsection{Filter Media Effects on Variability}

Previously, organic vapor (OV) deposition onto filter media was a negligible contribution to the total PM. This is no longer true under new 2007 HDD regulations. These regulations allow two types of filter media, which are the Teflo and TX40 filters. However, filer media is able to adsorb (positive artifact) or desorb (negative artifact) gas

phase species depending upon their characteristics and therefore the results that are attained by different filter media will not be equal [21]. The OV accounts for $10-20 \%$ of the total PM measurement for the Teflo filters and $30-50 \%$ for the TX40 filter. This OV adsorption by the TX40 filter could mask variations in the PM emissions that occur as a result of engineering changes to the engine or after treatments [24].

\subsection{Effect on Variability of Removing Backup Filter}

A study by Anderson et al. found that PM is reduced by $25 \%$ when the backup filter is removed. The primary filter efficiency is initially low when a test starts, but the efficiency increases as the filter loads with PM. It was also determined that the standard deviation is reduced by $50 \%$ when the backup filter is removed. Day-to-day and within a single day repeatability was higher when only a single filter was used. These results justify the move of 2007 regulations to a single, more efficient, Teflo filter that will be used instead of the primary and secondary T60A20 Teflon covered fiberglass filters [29]. It has also been determined that the collected PM on the backup filter is extremely low at low PM emission levels [21]. 


\subsection{Influence of Multiple Weighings on Variability}

A study by Zervas et al. reviewed the weighing process in the gravimetric analysis of PM with the use of $47 \mathrm{~mm}$ T60A20 and $47 \mathrm{~mm}$ Teflo filters. They first looked at the difference in using a microbalance with the readability of $1 \mu \mathrm{g}$ and $0.1 \mu \mathrm{g}$. It had been determined that $1 \mu \mathrm{g}$ microbalance would be sufficient for type-approval purposes. This conclusion has been reached because of its comparison of balance readability with the 0.1 $\mu \mathrm{g}$ microbalance in which it was found that the mean difference, through repeated weighings, between the two balances is $2.4 \%$ [21].

Their experiment weighed a filter five times and took the average of the five readings. This reading was then compared to the first reading to determine that in the case of the $1 \mu \mathrm{g}$ microbalance, there was a difference in the PM mass of only $1.4 \%$. This is compared to the $0.16 \%$ mean difference of PM mass for the $0.1 \mu \mathrm{g}$ microbalance. However, the mean difference is much lower when the mass of the filter is taken into account to yield a mean difference of $0.005-0.007 \%$. These low differences suggest that multiple weighings are unnecessary [21].

\subsection{Buoyancy Correction Used to Reduce Variability}

The buoyant force on an object is equal to the weight of the fluid or gas that is displaced by this object. This buoyancy force is used in determining the buoyancy correction. Chase et al. found buoyancy correction to vary from 185.8 to $181.8 \mu \mathrm{g}$ between two consecutive days. This weight would be significant at low PM levels and would equate to about $1 / 3$ of the mass loading at $1 \mathrm{mg} / \mathrm{mile}$. It was determined that air 
buoyancy was shown to be a noteworthy source of error in filter weighing in an experiment by Hanninen et al. [26].

\subsection{Effect of Pre-baking Filters}

Southwest Research Institute conducted a study of the amount of negative artifact or positive artifact of a Teflo filter when placed into a vacuum oven for 24 hrs at a temperature of $52{ }^{\circ} \mathrm{C}$. This was done to desorb materials from the filter media that may otherwise be desorbed during certification testing, which would then contribute to filter negative artifact. Seven Teflo primary and secondary filters were pre-baked and seven pairs were left unbaked to draw a comparison. The filters were placed into a conditioning environment for $24 \mathrm{hrs}$ in which the difference between maximum and minimum average filter weight was $0.4 \mu \mathrm{g}$ for Teflo filters [21].

After pre-baked and unbaked filters were used alternatively in transient emissions tests, it was determined that there was no significance between pre-baked and unbaked filters. Average collected PM was $0.0073 \mathrm{~g} / \mathrm{bhp}-\mathrm{hr}$ with a COV of $4 \%$. The primary filter weight gain was on the order of $60 \mu \mathrm{g}$. The backup filter weight gain ranged \pm 3 $\mu \mathrm{g}$, which is near the variability of clean filter weight, $\pm 2.5 \mu \mathrm{g}$. The backup filter weight gain was negligible and was within the uncertainty of filter weighing method and therefore suggests that the positive artifact collected by the primary filter was also negligible [21].

\subsubsection{Tapered Element Oscillating Microbalance}

Other methods to collect particulate matter includes the Tapered Element Oscillating Microbalance, a device that measures captured particle mass continuously on a small filter held on an oscillating element. The TEOM utilizes a hollow tapered, 
cantilever element, which is forced to oscillate at its natural frequency via a feedback system in which an internal volumetric flow controller maintains a constant sample flow rate of diluted exhaust gas through the TEOM filter. A study by WVU mobile emissions laboratory has found that TEOM results were on average of $6 \%$ lower than results obtained by standard gravimetric analysis. This was attributed to variation in organic fraction of the PM and differences in filter face temperatures. Therefore it was determined to set the TEOM temperature close to the conventional PM filter temperature for best agreement [30].

\subsubsection{Particle Number Emissions}

Internal combustion engines emit a wide range of particle sizes, from less than 10 $\mathrm{nm}$ to more than $1 \mu \mathrm{m}[31]$. Currently, $\mathrm{PM}$ is measured by mass through a gravimetric process but does not address particle size [12]. Newer technologies to control emissions are expected to result in a significant decrease in the particle size. These particles have insignificant mass but are present in large numbers and these large numbers can contribute large surface areas for biological interaction [32,33].

There is ongoing research to develop standardized measuring methods based on particle number emissions, which would allow for reliable quantification of particle number emissions and size distributions $[10,15]$. Due to differences in particulate sampling and the variety of measuring methods, test results differ from each laboratory. The determination of the total number of particles and median diameter depends upon the repeatability of the engine, the driving conditions or engine operation and the total particle number emitted [31]. 
Microscopy is a process that could be used to determine the size, shape and morphology of particles. Some of these tools include transmission electron microscopy and scanning electron microscopy. If these tools are equipped with energy dispersive $\mathrm{x}$ ray or electron energy loss spectroscopy, the tools can give information on the elemental composition. These methods are extremely useful for basic studies, but could not be used for regulatory testing [15].

The Brunauer, Emmett, and Teller (BET) method measures the amount of a gas, such as $\mathrm{N}_{2}$, that can be adsorbed on the particle surface. This process is used to measure the amount of surface area. The BET analysis is time consuming and a large amount of material is needed [15].

A newly available instrument utilizes electrical aerosol techniques to measure particulate mass. This instrument is called the Dekati mass monitor. It requires a secondary dilution tunnel where the diluted vehicle exhaust sample passes through a corona discharge to positively charge particles. The particles then pass through an electrical mobility analyzer and then onto a cascade impactor that records aerodynamic size. This information can then determine an average effective particle density. The size and average particle density is then used to find the particle mass.

The electrical low pressure impactor and the scanning mobility particle sizer work off of the same principle as the Dekati, by using the corona discharge and impactor to determine aerodynamic diameter. A study by Chase et al. found that these aerosol instruments, based on electrical detection or counting provide a better estimate of PM mass than filters at emission levels below $0.01 \mathrm{~g} / \mathrm{bhp}-\mathrm{hr}$ [15]. 


\subsubsection{Thermal Mass Analysis}

Coulometric carbon analysis is a quantitative analysis of the carbon dioxide generated by thermal oxidation of the PM sample under controlled conditions, which can reveal the components of the PM mass. Coulometry is commonly used in Europe to determine elemental carbon and organic carbon fractions of PM. This process involves burning the carbon to produce $\mathrm{CO}_{2}$ by using a filter sample that is heated in an oxygen flow. The $\mathrm{CO}_{2}$ concentration is then measured by a coulometric technique. The organic fraction is extracted and thermally desorbed into a $\mathrm{N}_{2}$ flow to produce a reliable determination of elemental carbon. However, this process is time consuming and therefore very expensive [15].

Different methods of analysis of filter samples for total, elemental and organic carbon were compared in a round robin test in which the tests showed a relatively small variance, standard deviation of less than $9 \%$, for the total carbon analysis, but up to $46 \%$ variance for elemental carbon between laboratories. The distinction between elemental and organic carbon causes problems. These methods of elemental carbon and total carbon analysis are used more in ambient air analysis for occupational health settings and remains uncommon in engine tailpipe emission measurements [15].

Thermal TPM analysis uses analyzers that can determine the total mass of particulate matter based on thermal oxidation principle. After PM has accumulated on clean quartz filters in the same manner as traditional filters, the filters are placed into a high temperature furnace where the semi-volatiles organic fraction and sulfates are removed by flowing nitrogen $[15,23]$. After a suitable amount of time, addition of oxygen causes the organic volatiles, soot and the sulfates to convert to $\mathrm{CO}_{2}$ and $\mathrm{SO}_{2}$. 
Downstream analyzers are used to determine the concentrations of $\mathrm{CO}_{2}$ and $\mathrm{SO}_{2}$, in which software is used to convert these concentrations into masses of SOF, sulfates and inorganic carbon. This process is able to obtain very good correlation with the gravimetric process, but does not account for ash [15]. There is a significant advantage of thermal TPM analysis over gravimetric analysis because it allows speciation of the PM into soot and SOF [23].

\subsubsection{Biological Activity}

The Ames bacteria test is used to determine the biological activity of the SOF. This test was developed by Bruce Ames from the Biochemistry Department of the University of California, Berkeley. Selected strains of salmonella bacteria are exposed to the tested material to determine the amount of bacteria that will mutate as the result of the exposure. The Ames test will calculate the mutagenicity of a test sample by determining the number of mutated strains. There is a correlation between the Ames mutagenicity and the longer-term carcinogenicity in higher animals and humans although this is not entirely understood or precisely explained [15].

\subsection{ISO 14644-1: Classification of Air Cleanliness [38]}

The Federal Standard 209E was originally written in 1962. It designated ways in which air cleanliness could be verified and proposed a plan be established to monitor air cleanliness. However, The FED-STD 209E was only a standard set for the US. Therefore, the rest of the world wanted a more global standard. This global standard was the ISO 14644 and was based off of standards from three different documents, FED-STD 209E, prEN 1633-1, and JIS B 9920 from the US, European Union, and Japan, respectively $[34,35]$. 
The 40 CFR 86 states that the cleanroom be built to the FED-STD 209E standards but the US General Services Administration canceled FED-STD 209E on November 29, $2001[35,36,37]$. Therefore, both the Federal Standard 209E and the ISO 14644 standards were examined to determine the proper procedures for maintaining the cleanroom and for proper cleanroom attire. There are five sections of the ISO 14644 cleanrooms and associated environments.

This section describes the classification of air cleanliness and associated controlled environments in terms of concentration of airborne particles. Only particle populations having cumulative distributions based on threshold sizes ranging from 0.1 to $5 \mu \mathrm{m}$ are considered for classification purposes.

\subsubsection{Determination of ISO Cleanroom Classes}

A discrete particle counter should be used to determine the class and to ensure that cleanliness is being maintained. Equation 2-1 is used to determine the ISO class value.

$$
C_{n}=10^{N} \times\left(\frac{0.1}{D}\right)^{2.08}
$$

The value obtained for $C_{n}$ is the maximum permitted concentration of airborne particles that are equal to or larger than the considered particle size. The value calculated for $C_{n}$ is rounded to the nearest whole number, using no more than three significant figures. The value of 0.1 is a constant, with a dimension of micrometers. The proper designation will have $\mathrm{N}$ as the classification number, such as ISO Class " $\mathrm{N}$ " and this should illustrate what particle sizes were considered when establishing the ISO Class value. A graphical 
interpretation of Equation 2-1 and Table 2-6 is shown in Figure 2-4. Each ISO class has the tested particle size shown in Figure 2-4.

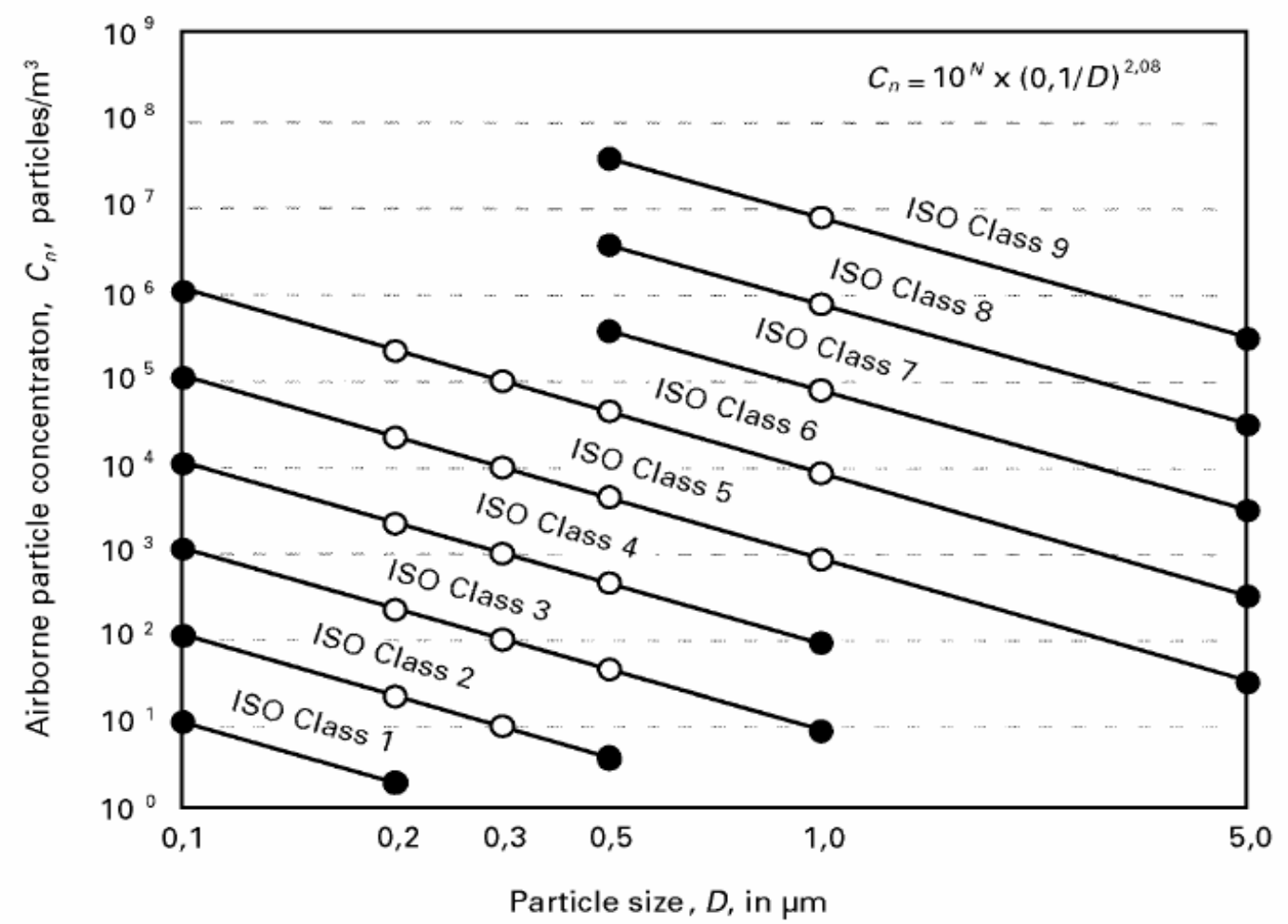

Figure 2-4: Illustrates the equation above and how each ISO class is determined [38]

\subsubsection{Demonstration of Compliance}

The test method for maintaining compliance should be the use of a particle cleanliness classification using a discrete particle counting, light scattering instrument. A discrete particle counting, light scattering instrument is used to determine the concentration of airborne particles, equal to and larger than the specified sizes, at designated sampling locations. The discrete particle counter (DPC) should be able to display or record the count and size of discrete particle in the air. The DPC should have a size discrimination capability to detect the total particle concentration in the appropriate particle size ranges for the class under consideration and a suitable sampling system. The DPC should have a valid calibration certificate in which the frequency and method of 
calibration should be based on current accepted practice and is to be completed by using ASTM F328-98 (2003).

The room should be checked to verify that all aspects of the cleanroom are up to operational integrity and functioning in accordance with performance specifications. The following pretests should be performed: airflow volume or velocity, air pressure difference, containment leakage, and installed filter leakage tests.

\subsubsection{Amount of Sampling Locations}

The minimum number of sampling point locations will be derived from Equation $2-2$.

$$
N_{L}=\sqrt{A}
$$

Equation 2-2

The sampling locations need to be evenly distributed throughout the area of the cleanroom and positioned at the height of the work activity.

\subsubsection{Determination of Single Sample Volume per Location}

Each sampling location must sample a sufficient volume of air that a minimum of 20 particles would be detected if the particle concentration for the largest considered particle size were at the class limit for the designated ISO class. The single sample volume $\mathrm{V}_{\mathrm{s}}$ per location is determined by using Equation 2-3.

$$
V_{s}=\frac{20}{C_{n, m}} * 1000
$$

Equation 2-3

The time required for sampling could be substantial when the $\mathrm{V}_{\mathrm{s}}$ is very large. The minimum sampling volume will be at least 2 liters and the sampling time should be at least 1 minute. The sampling time will come from the flow rate of the DPC light scattering instrument. The sampling probe should be positioned so that it will be pointing 
into the airflow. In the case of the WVU CAFEE, the sampling probe should be pointed up because the air flows down from the ceiling panels with air return ducts located at the floor level.

\subsubsection{Recording the Results}

The concentration of each considered particle size should be recorded appropriate to the relevant classification of air cleanliness. The average should be taken when two or more single sample volumes are taken at a location. This average will be used to compute the average particle concentration for each considered particle size from the individual sample particle concentrations. A 95\% upper confidence level must be found when the number of locations sampled is less than ten and more than one.

\subsubsection{Interpretation of the Results}

The cleanroom is considered to have met the specified air cleanliness classification if the averages of the particle concentrations measured at each of the locations and the $95 \%$ confidence level do not exceed the concentration limits determined in accordance with Equation 2-1. If the results of the testing fail to meet the specified air cleanliness classification, testing may be performed at additional, evenly distributed sampling locations. The results of recalculation and the data from the added locations shall be definitive. An outlier can be excluded from the calculation if it is found to cause failure of compliance with the 95\% UCL at a specified ISO class designation, provided that, the calculation is repeated, including all remaining sampling locations, at least three measurement values remain in the calculation, not more than one measurement value is excluded from the calculation, and the suspected cause of the erroneous measurement or low particle concentration is documented. The results from each test within the 
cleanroom shall be recorded and submitted as a comprehensive report, along with a statement of compliance or noncompliance with the specified designation of airborne particulate cleanliness classification.

\subsection{ISO 14644-2: Maintaining Compliance with ISO 14644-1 [39]}

The continued compliance with air cleanliness requirements specified for the installation is verified by performing specified tests and by documenting the results. The monitoring of data is used as an indication of installation status and may determine the frequency with which tests are carried out. Table 2-1 shows the reference test method and the maximum time intervals between such tests to prove continued compliance with the designated ISO class. The WVU CAFEE cleanroom is ISO Class 6 and it can be determined from Table 2-1 that the particle concentration tests from ISO 14644-1 should be conducted every 12 months. Table 2-2 illustrates tests that WVU CAFEE can decide to conduct, in addition to the particle concentration test, at the given time frame.

Table 2-1: Schedules of testing to demonstrate compliance with particle concentration limits [39]

\begin{tabular}{|c|c|c|}
\hline Classification & Maximum time interval & Test method \\
\hline$\leqslant$ ISO Class 5 & 6 months & Annex B in ISO 14644-1:1999 \\
\hline$>$ ISO Class 5 & 12 months & Annex B in ISO 14644-1:1999 \\
\hline
\end{tabular}

Table 2-2: Schedules of additional tests for all classes [39]

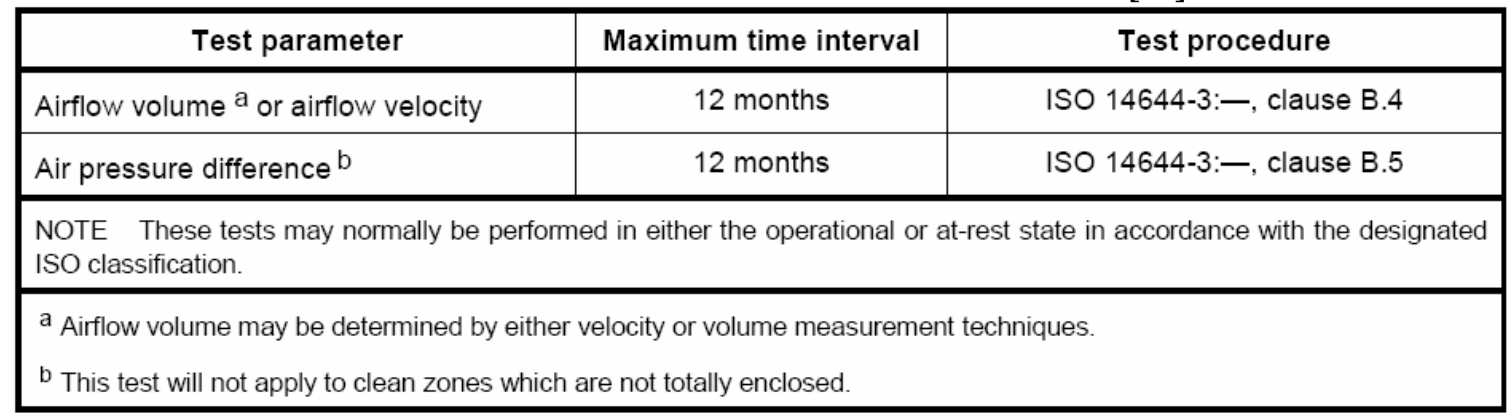


If deemed necessary, there are more tests beyond Table 2-1 and Table 2-2 that can be conducted to ensure the cleanroom is running at the highest efficiency. Table 2-3 shows the optional tests and provides a suggested time interval for the test parameter to be checked.

Table 2-3: Schedules of optional tests [39].

\begin{tabular}{|l|c|c|c|}
\hline \multicolumn{1}{|c|}{ Test parameter } & Class & $\begin{array}{c}\text { Suggested maximum time } \\
\text { interval }\end{array}$ & Test procedure \\
\hline Installed filter leakage & All classes & 24 months & ISO 14644-3:-, clause B.6 \\
\hline Airflow visualization & All classes & 24 months & ISO 14644-3:-, clause B.7 \\
\hline Recovery & All classes & 24 months & ISO 14644-3:-, clause B.13 \\
\hline Containment leakage & All classes & 24 months & ISO 14644-3:-, clause B.14 \\
\hline
\end{tabular}

The routine monitoring of airborne particle concentration and other parameters shall be performed according to a written plan. This plan shall consist of the predetermined amount of sample locations, minimum volume of air per sample, duration of measurements, time interval between measurements, particle size or sizes to be counted, and count acceptance limits, as well as count alert, action and excursion limits. If the monitored results exceed the specified limits, then the installation shall be considered non-compliant and appropriate remedial action shall be taken. After the action has been taken, the room shall be retested as in ISO14644-1, Demonstration of Compliance. The test results from monitoring should be properly documented and the test report should include the following:

a) Name and address of the testing organization

b) Operator identification and the date on which the test was performed

c) Reference to this part of ISO 14644

d) Clear identification of the physical location of the installation tested and specific designations for coordinates of all sampling locations

e) Specified designation criteria for the installation, including the ISO classification and considered particle size, relevant occupancy states, airflow volume or velocity and air pressure difference

f) Measuring instruments used and proof of calibration 
g) Test results, including particle concentration data for all sampling location coordinates

h) Date of the preceding test to prove continued compliance

\subsection{ISO 14644-3: Test Methods [40]}

This part of ISO 14644 specifies test methods for designated classification of airborne particulate cleanliness and for characterizing the performance of cleanrooms and clean zones. Performance tests are specified for two types of cleanrooms and clean zones: those with unidirectional flow and those with non-unidirectional flow, in three possible occupancy states: as built, at-rest and operational.

Examples of unidirectional flow and non-unidirectional flow are shown in Figure 2-5 and Figure 2-6, respectively. The unidirectional flow has a venting system to remove the return air, below the floor in which the floor is vented. This allows the supply air to flow straight from ceiling to floor as demonstrated in Figure 2-5. The non-unidirectional has return air vents located at the base of the wall and thus the flow is not a straight flow, as illustrated in Figure 2-6.

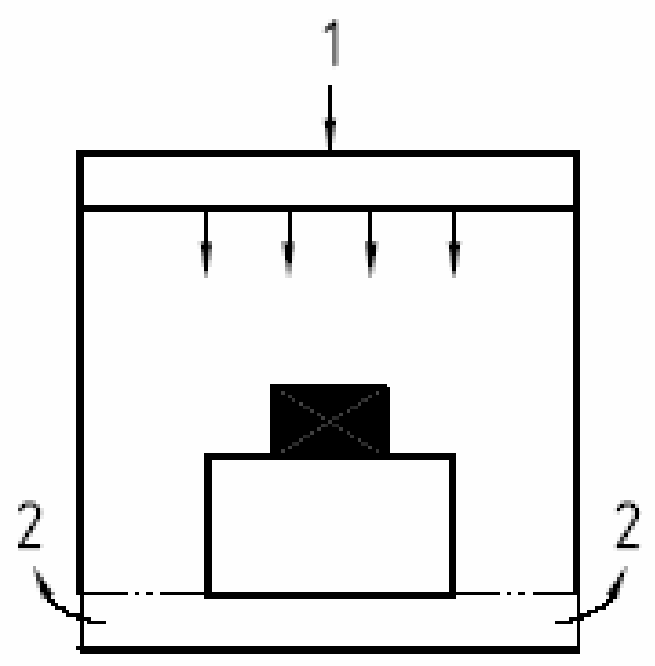

Figure 2-5: Illustration of unidirectional airflow [41] 


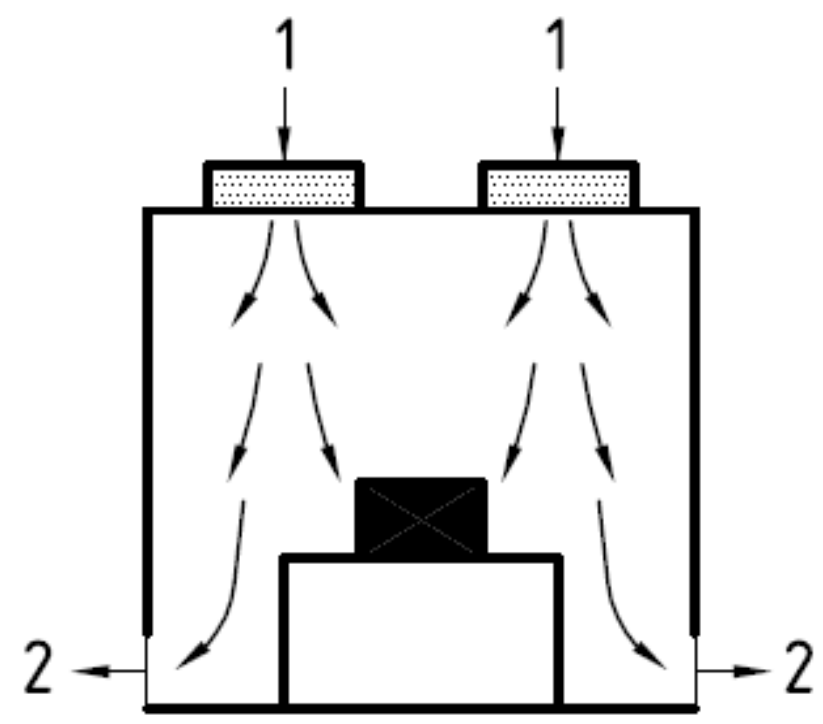

Figure 2-6: Illustration of non-unidirectional flow [41]

The first required test is that previously mentioned in 2.6.2 in which the amount of particles for a given ISO designation is measured and the results reported as shown in Error! Reference source not found. The test method for particle collection was mentioned earlier but will go into greater depth here. The number of sampling points and the volume of air to be sampled is determined from Equation 2-2 and 2-3.

The following gives a description of the designation classification procedures as presented in ISO 14644-3. Install the DPC intake at the specified sampling location, and set up the DPC flow rate and select the particle size thresholds in accordance with section 2.6.4 [38]. A sampling probe should be selected to permit close to isokinetic sampling in areas with unidirectional flow. The sample probe velocity should not differ from sampled air velocity by more than $20 \%$. If this is not possible, set the sampling probe inlet facing into the predominant direction of the airflow. The transit tube from the sample probe inlet to the DPC sensor should be as short as possible. For sampling of particles larger than and equal to $1 \mu \mathrm{m}$, the transit tube length should not exceed the manufacturer's recommended length and diameter. Sampling errors due to small particle 
loss by diffusion and large particle loss by sedimentation and impaction should be no great than $5 \%$.

\subsection{ISO 14644-4: Design, Construction and Start-up [41]}

This part of ISO 14644 specifies requirements for the design and construction of cleanroom installations but does not prescribe specific technological or contractual means to meet these requirements. It is intended for use by purchasers, suppliers and designers of cleanroom installations and provides a checklist of important parameters of performance. Application of this part of ISO 14644 is restricted to the following:

- User requirements are represented by purchaser

- Specific processes to be accommodated in the cleanroom installation are not specified

- Fire and safety regulations are not considered specifically; the appropriate national and local requirements should be respected

- Process media and utility services are only considered with respect to their routing between and in the different zones of cleanliness

- Regarding initial operation and maintenance, only cleanroom construction specific requirements are considered

\subsection{ISO 14644-5: Cleanroom Operations [42]}

This portion of the ISO 14644 defines basic requirements for cleanroom operations. The ISO 14644-5 document is intended for those operating the cleanroom. This section defines how objects are to be thoroughly cleaned upon being taken into the cleanroom. It also describes how personnel should dress and the order in which they should dress to minimize contamination.

The cleanroom clothing should be made of materials that will resist breakdown and therefore not shed contamination. This clothing should be put on and taken off in such a way that the spread of contamination is avoided or minimized. Some 
consideration should be given to the comfort of personnel wearing the cleanroom clothing.

Personnel working in the cleanroom should remove items that are not intended for cleanroom use. A policy concerning jewelry, cosmetics and similar materials that can cause contamination problems should be determined. Personnel should be trained to conduct themselves in a manner that minimizes generation of contamination, which can be transferred or deposited onto the product.

Any objects entering into the cleanroom should be thoroughly cleaned, ranging from stationary equipment to tools that will be used to maintain the cleanroom. The cleanroom should also have procedures that should be specified to routinely clean the cleanroom. These schedules should be defined and carried out at effective frequencies to ensure that specified cleanliness level is maintained.

\subsection{Federal Standard 209E [37]}

Federal Standard 209E was originally written in 1962. It designated ways in which air cleanliness could be verified and proposed a plan be established to monitor air cleanliness. The FED-STD 209E was only a standard set for the US.

\subsubsection{Airborne Particulate Cleanliness Classes}

A discrete particle counter, or other particle count method or equipment that demonstrates the same accuracy as a discrete particle counter should be used to determine the class and to ensure that cleanliness is being maintained. The counter should verify air cleanliness by measuring at one or more of the particle sizes listed in Table 2-5. Equations 2-4 and 2-5 are used to determine the particle concentration per cubic meter 
and per cubic foot, respectively. $\mathrm{C}_{\mathrm{N}}$ is the particle concentration per cubic meter, or per cubic foot, $\mathrm{N}$ is the class designation.

$$
\begin{aligned}
& C_{N}=10^{N}(0.5 / d)^{2.2} \\
& C_{N}=N(0.5 / d)^{2.2}
\end{aligned}
$$

Equation 2-5

After the initial verification of the cleanroom is carried out, tests shall be performed at periodic intervals or as otherwise specified between the users and contracting agency. The verification should take place by measuring particle concentrations at specified operating conditions. There are other environmental factors that can be tested and these are air velocity, air volume change rate, room pressurization, makeup air volume, unidirectional airflow parallelism, air turbulence, air temperature, humidity or dew point and room vibration.

\subsubsection{Verification and Monitoring Of Airborne Particulate Cleanliness}

Non-unidirectional flow sampling locations should be uniformly spaced horizontally. Vertical locations should be agreed upon by the users and contracting agency.

The minimum number of sample locations required for verification in a cleanroom with non-unidirectional flow is found by using Equations 2-6 and 2-7. Equation 2-6 is given in SI units, while Equation 2-7 is given in English units. The values obtained by these equations should be rounded to the next higher integer. The sample must be taken by at least two different locations. The number of sampling locations distributed to permit a definition of the cleanroom classification that accounts for some minor variability in point to point conditions [34]. 


$$
\begin{aligned}
& S_{L}=\frac{(A) 64}{\left(10^{M}\right)^{0.5}} \\
& S_{L}=\frac{A}{\left(N_{C}\right)^{0.5}}
\end{aligned}
$$

More than one sample may be taken at each location, and different numbers of samples may be taken at different locations. There must be a total of at least five samples taken at each sampling location. Sampling at more locations than the required minimum will result in greater precision in the mean of the location averages and its upper confidence limit.

The sample of air test at each location should be of sufficient volume such that at least 20 particles would be detected for the particle concentration at the class limit for each specified particle size. Equation 2-8 demonstrates the minimum volume of air that should be sampled as a function of the number of particles per unit volume as listed in Table 2-5.

$$
V_{S}=\frac{20 \text { Particles }}{[\text { Class Limit }(\text { Particles } / V)]}
$$

The results from Equation 2-8 should not be rounded down. The minimum volume of air sampled should be $0.00283 \mathrm{~m}^{3}$ or $0.1 \mathrm{ft}^{3}$. The sampling of a larger volume than the required minimum will result in greater precision in the mean of the location averages and its upper confidence level.

Monitoring of airborne particulate cleanliness should be monitored while the cleanroom is operational. Other environmental factors should also be monitored to indicate trends in variables that may be related to airborne particulate cleanliness. This monitoring schedule is to be decided by the user and the contracting agency. 
The average is found after the five samples have been taken at each sampling location. The mean of the averages is then found. A standard deviation is found of the averages. The standard error of the mean of the averages is found by Equation 2-9.

$$
S E=\frac{S D}{\sqrt{L}}
$$

The $95 \%$ upper confidence level of the mean of averages is found by adding the mean to the product of the appropriate upper confidence level factor. The upper confidence level factor is found in Table 2-4. Equation 2-10 illustrates how the UCL is determined.

Table 2-4: Upper confidence level factor for $95 \%$ upper confidence limit [37]

\begin{tabular}{|l|c|c|c|c|c|c|c|c|c|}
\hline No. of locations L & 2 & 3 & 4 & 5 & 6 & 7 & 8 & 9 & $>9$ \\
\hline $95 \%$ UCL factor & 6.31 & 2.92 & 2.35 & 2.13 & 2.02 & 1.94 & 1.9 & 1.86 & NA \\
\hline
\end{tabular}

$$
U C L=M+(U C L \text { Factor } \times S E)
$$

Equation 2-10

The UCL value is then compared to the value given in Table 2-5, for the desired class. The cleanroom meets the specifications if the UCL is less than the value given in Table 2-5. It is the UCL that determines whether or not the cleanroom passes the specifications given in Table 2-5, even though individual readings might be higher than the specifications.

\subsection{Differences between the FED STD 209 \& ISO 14644}

ISO 14644-1 and FED-STD 209E are similar in many ways. However, there are some differences in the documents and must be reviewed since 40 CFR 86 requires the cleanroom to be built to FED-STD 209E requirements, and the requirements have since been superseded by ISO 14644. The class 1000 specifications of Federal Standard 209 state that the room shall not have more than 1000 particles of size $0.5 \mu \mathrm{m}$ or larger per 
cubic foot and shall not have more than 7 particles of size $5 \mu \mathrm{m}$ or larger per cubic foot. The ISO calculations are determined for number of particles per cubic meter and therefore the class 1000 room in Federal Standards 209 would then become ISO class 6 in the ISO standards $[35,36]$.

The FED-STD 209E uses both metric and English units, shown in Table 2-5. The ISO 14644-1 uses only metric units. The air cleanliness standards are derived from a formula in ISO 14644-1, as shown in Equation 2-1. There are nine standards in the ISO 14644-1 as opposed to the thirteen classes listed in FED-STD 209E. The additional particle size, $1 \mu \mathrm{m}$, was added to the ISO 14644-1 table of air cleanliness classes, as shown in Table 2-6 $[34,36]$. The maximum particles allowed for ISO class 5 is within $0.3 \%$ of the FED-STD 209E class M 3.5 at $0.5 \mu \mathrm{m}$ even though the FED-STD 209E uses a different formula than ISO $14644[35,36]$.

ISO 14644-1 states that if measurements are made at more than one considered particle size, each larger particle diameter shall be at least 1.5 times greater than the next small diameter. The $95 \%$ confidence limit shall be performed for 2 to 9 sample locations in which the number of sampling test locations is found by using Equation 2-2 [35, 36]. 
Table 2-5: FED-STD 209E air cleanliness classes [37]

\begin{tabular}{|c|c|c|c|c|c|c|c|c|c|c|c|}
\hline \multirow{3}{*}{\multicolumn{2}{|c|}{ Class Name }} & \multicolumn{10}{|c|}{ Class Limits } \\
\hline & & \multicolumn{2}{|c|}{$0.1 \mu \mathrm{m}$} & \multicolumn{2}{|c|}{$0.2 \mu \mathrm{m}$} & \multicolumn{2}{|c|}{$0.3 \mu \mathrm{m}$} & \multicolumn{2}{|c|}{$0.5 \mu \mathrm{m}$} & \multicolumn{2}{|c|}{$5 \mu \mathrm{m}$} \\
\hline & & \multicolumn{2}{|c|}{ Volume Units } & \multicolumn{2}{|c|}{ Volume Units } & \multicolumn{2}{|c|}{ Volume Units } & \multicolumn{2}{|c|}{ Volume Units } & \multicolumn{2}{|c|}{ Volume Units } \\
\hline SI & English & $\left(m^{3}\right)$ & $\left(\mathrm{ft}^{3}\right)$ & $\left(m^{3}\right)$ & $\left(\mathrm{ft}^{3}\right)$ & $\left(m^{3}\right)$ & $\left(\mathrm{ft}^{3}\right)$ & $\left(m^{3}\right)$ & $\left(\mathrm{ft}^{3}\right)$ & $\left(m^{3}\right)$ & $\left(\mathrm{ft}^{3}\right)$ \\
\hline M 1 & & 350 & 9.91 & 75.7 & 2.14 & 30.9 & 0.875 & 10 & 0.283 & - & - \\
\hline M 1.5 & 1 & 1240 & 35 & 265 & 7.5 & 106 & 3 & 35.3 & 1 & - & - \\
\hline M 2 & & 3500 & 99.1 & 757 & 21.4 & 309 & 8.75 & 100 & 2.83 & - & - \\
\hline M 2.5 & 10 & 12400 & 350 & 2650 & 75 & 1060 & 30 & 353 & 10 & - & - \\
\hline M 3 & & 35000 & 991 & 7570 & 214 & 3090 & 87.5 & 1000 & 28.3 & - & - \\
\hline M 3.5 & 100 & - & - & 26500 & 750 & 10600 & 300 & 3530 & 100 & - & - \\
\hline M 4 & & - & - & 75700 & 2140 & 30900 & 875 & 10000 & 283 & - & - \\
\hline M 4.5 & 1000 & - & - & - & - & - & - & 35300 & 1000 & 247 & 7 \\
\hline M 5 & & - & - & - & - & - & - & 100000 & 2830 & 618 & 17.5 \\
\hline M 5.5 & 10000 & - & - & - & - & - & - & 353000 & 10000 & 2470 & 70 \\
\hline M 6 & & - & - & - & - & - & - & $1 E+06$ & 28300 & 6180 & 175 \\
\hline M 6.5 & 100000 & - & - & - & - & - & - & $4 E+06$ & 100000 & 24700 & 700 \\
\hline M 7 & & - & - & - & - & - & - & $1 \mathrm{E}+07$ & 283000 & 61800 & 1750 \\
\hline
\end{tabular}

Table 2-6: Selected airborne particulate cleanliness classes for cleanrooms and clean zones [38].

\begin{tabular}{|c|c|c|c|c|c|c|}
\hline \multirow{2}{*}{$\begin{array}{l}\text { ISO } \\
\text { classification } \\
\text { number }(N)\end{array}$} & \multicolumn{6}{|c|}{$\begin{array}{l}\text { Maximum concentration limits (particles } / \mathrm{m}^{3} \text { of air) for particles equal to and larger } \\
\text { than the considered sizes shown below (concentration limits are calculated in } \\
\text { accordance with equation (1) in 3.2) }\end{array}$} \\
\hline & $0,1 \mu \mathrm{m}$ & $0,2 \mu \mathrm{m}$ & $0,3 \mu \mathrm{m}$ & $0,5 \mu \mathrm{m}$ & $1 \mu \mathrm{m}$ & $5 \mu \mathrm{m}$ \\
\hline ISO Class 1 & 10 & 2 & & & & \\
\hline ISO Class 2 & 100 & 24 & 10 & 4 & & \\
\hline ISO Class 3 & 1000 & 237 & 102 & 35 & 8 & \\
\hline ISO Class 4 & 10000 & 2370 & 1020 & 352 & 83 & \\
\hline ISO Class 5 & 100000 & 23700 & 10200 & 3520 & 832 & 29 \\
\hline ISO Class 6 & 1000000 & 237000 & 102000 & 35200 & 8320 & 293 \\
\hline ISO Class 7 & & & & 352000 & 83200 & 2930 \\
\hline ISO Class 8 & & & & 3520000 & 832000 & 29300 \\
\hline ISO Class 9 & & & & 35200000 & 8320000 & 293000 \\
\hline
\end{tabular}

\subsection{The EPA Class 1000 Cleanroom}

An onsite visit was conducted at the Environmental Protection Agency located in Ann Arbor, Michigan during March 2006. The following information was gained from the visit. The EPA is currently measuring PM by 2007 standards as stated in the Code of 
Federal Regulations Part 86 Subpart N. The standard states that a cleanroom must be built to class 1000 specifications as found in Federal Standard 209E. However, this document has since been canceled and now the EPA follows ISO 14644. This room had met the class 1000 cleanroom specifications upon building completion but has not since been retested to determine if it still meets the class 1000 status. The temperature and humidity control can permit three or four people in the room before exceeding dry bulb temperature and dew point requirements of $22^{\circ} \pm 1^{\circ} \mathrm{C}$ and $9.5^{\circ} \pm 1{ }^{\circ} \mathrm{C}$, respectively.

The EPA cleanroom has tacky mats before entering the cleanroom to remove particles from the bottom of shoes. Frocks and booties were not worn into the cleanroom, as shown in Figure 2-7. The cleaning procedure that is used to maintain cleanliness of their cleanroom is as follows, once a week janitors mop the floor with a specific cleaner. Their rubber floor is designed to hold dirt and therefore a specially designed cleaner is used. 


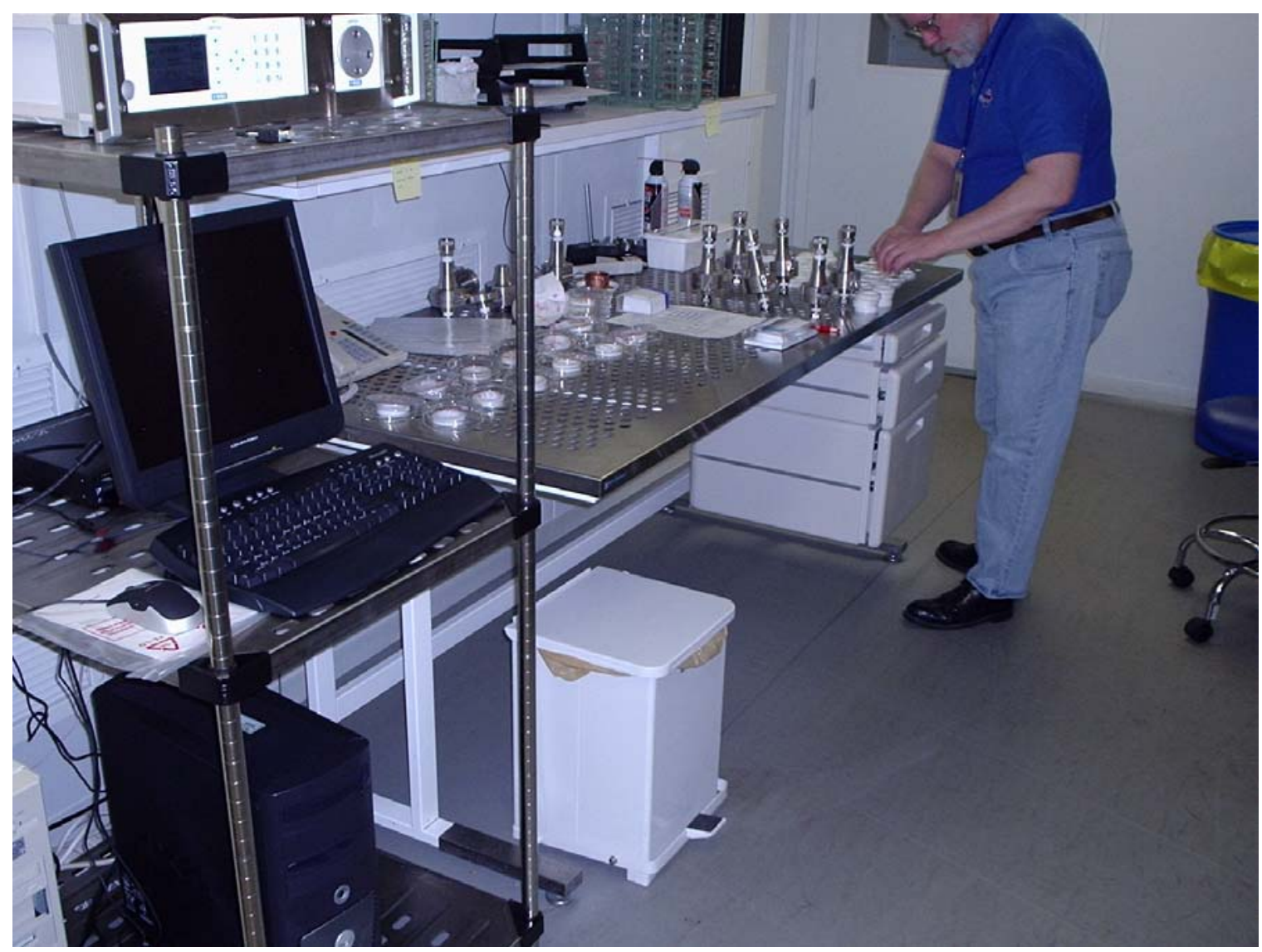

Figure 2-7: EPA cleanroom

The EPA uses the Mettler Toledo UMT2 microbalance [43]. The weighing process begins by verifying that the cleanroom is within specifications and that the balance is level. The next step involves calibrating the balance in which, the calibration involves an internal calibration and linearization [44]. The scale is then zeroed. Weighing can then start after the previous processes have been completed. The EPA uses Whatman Teflo $47 \mathrm{~mm}$ filters. Filters are left an hour to stabilize after testing. However, EPA Engineer Brian Olsen had weighed filters at five-minute intervals to determine the amount of time that is required for a filter to stabilize. He had found stabilization time to be within 20 minutes after being removed from a test cell. Filters are only weighed once. An outlier is not corrected in anyway. Instead, the test is rerun. The weighing environment can be seen in Figure 2-8. 
The filters are loaded into the cassettes while in the cleanroom when certification testing is taking place. Filters are loaded into Petri dishes to be transported from cleanroom to test cells where they will be loaded into the filter holder when certification testing is not taking place. The filters are to be returned to the cleanroom as soon as possible, but not later than one hour after the filters have been removed from the filter holder [45]. An example of the cassettes and Petri dishes used can be viewed in Figure $2-7$.

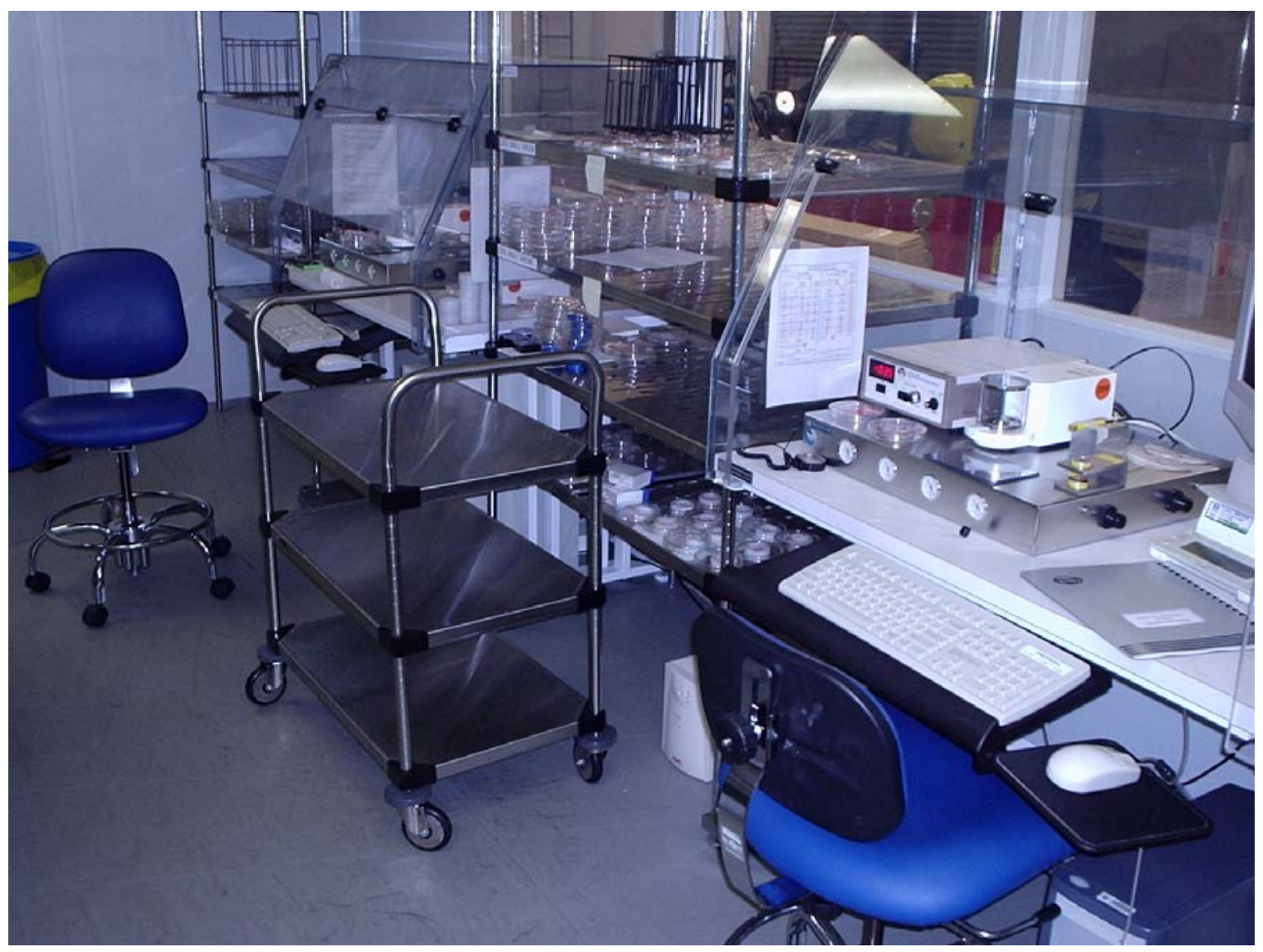

Figure 2-8: EPA weighing environment

The microbalance sat upon $200 \mathrm{lb}$ air tables that are used to isolate the microbalance from vibrations. Two nuclespots are used to neutralize the filter. The nuclespots are located on a "C" shaped metal carrier, in which one is on the top and one 
is on the bottom to ensure that both sides of the filter will be neutralized. A filter is held 0.5 inches from a TREK Model 323 Electrostatic Voltmeter static meter to ensure that filters are static free before being placed on the microbalance [43]. A convective antistatic draft shield is used to reduce the effect of body heat on the microbalance and to shield the microbalance from convective air current, as shown in Figure 2-9. Anti-static chairs and wristband were used to minimize the amount of static charge buildup.

It was stressed that the overall cost effectiveness of the cleanroom should be maintained. EPA did not use booties, frocks, or any other cleanroom clothing to minimize the operating cost of their cleanroom. The cleaning schedule did not require wiping the walls to minimize cost. EPA Engineer Brian Olsen stated that their cleanroom had met the class 1000 cleanroom status after building completion but there would not be any further testing of the cleanroom to verify that it was maintaining the class 1000 standard. He described the current cleanroom as being "order of magnitudes better than the previous weighing environment" and therefore would not need to be continually tested to ensure compliance with the class 1000 standard. 


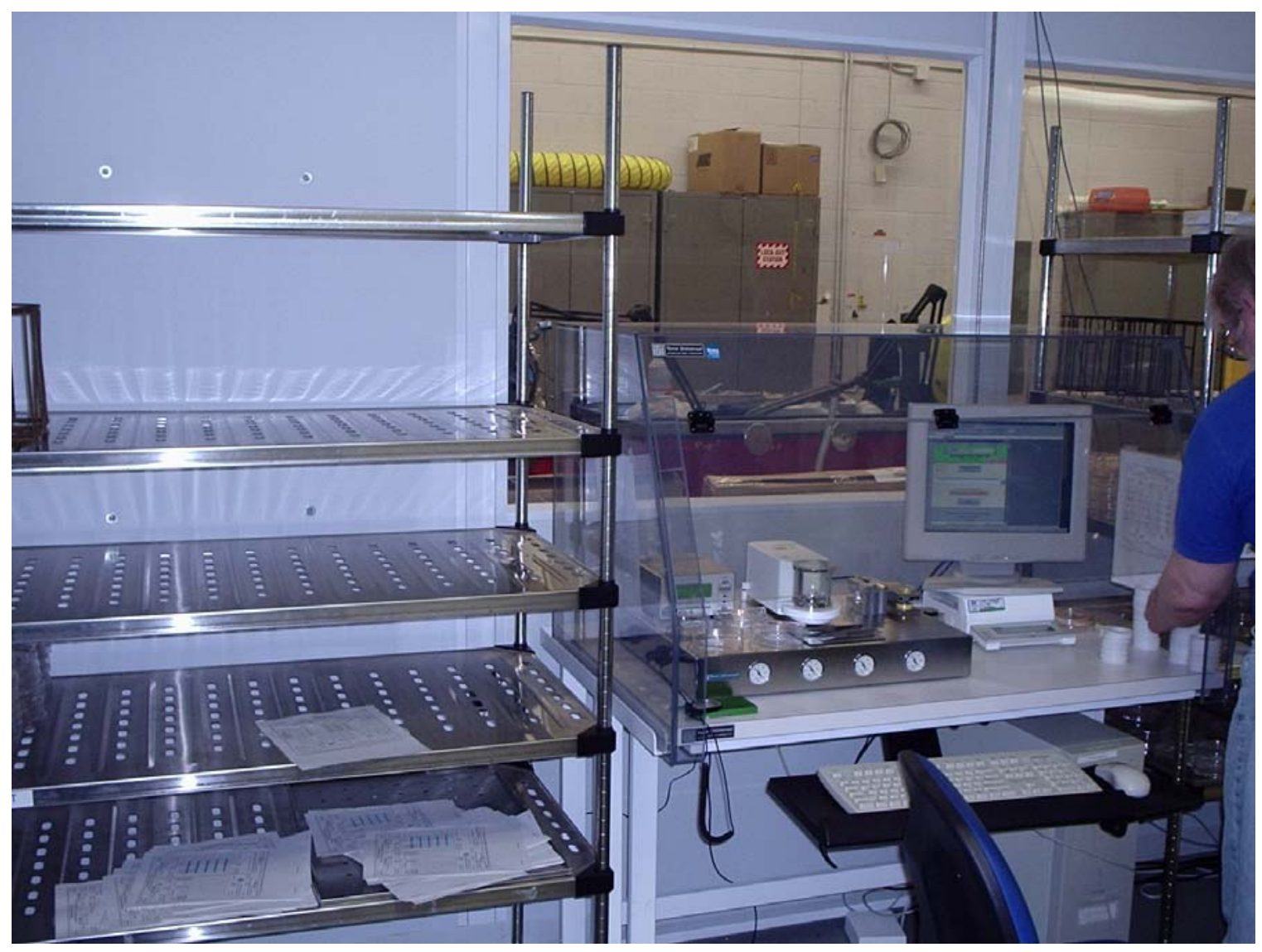

Figure 2-9: Weighing environment of EPA cleanroom

\subsection{Conclusion}

This chapter introduced the health and environmental effects which presents the need for PM testing. A review of PM composition and the causes for variations was completed because variations in PM composition will affect the accuracy of the gravimetric process. The 40 CFR 86 regulations require a class 1000 cleanroom due to the low amount of collected PM for 2007 standards in which this class 1000 requirement was required to reduce other variables that have an effect on the gravimetric process. A review of the EPA cleanroom was completed to ensure that WVU CAFEE cleanroom meets or exceeds the EPA cleanroom cleaning and weighing procedures. 


\section{SUMMARY OF PROCEDURES}

\subsection{Introduction}

Many resources were evaluated to determine the best cleaning procedures for the West Virginia University Center for Alternative Fuels, Engines and Emissions cleanroom. The Federal Standard 209E and ISO documents were reviewed to determine the cleaning procedures to maintain a non-contaminating working environment. A visit to the EPA cleanroom was also used to compare cleanroom cleaning procedures.

Weighing procedures were created to minimize the amount of error introduced in weighing with the Sartorius SE2-F scale for the 2007 standards. The error is minimized by ensuring the filter is neutrally charged. The weighing area is wiped prior to weighing to minimize the error introduced by particulates being displaced from one filter to another and to ensure no other particulates will come in contact with the filter. Day-to-day changes of filter weights are addressed by the usage of $47 \mathrm{~mm}$ filters and the buoyancy correction shown in the 40 CFR 86.

The difference between pre-2007 primary and backup $70 \mathrm{~mm}$ T60A20, single 47 mm Teflo and T60A20 filters are examined to determine the effects of different filter media, flow rates, and surface area. Preliminary results were obtained by running transient engine testing through a pre-2007 dilution tunnel. It is noted that these results are not applicable to 2007 standards due to the dilution tunnel not meeting 2007 standards and the use of an older technology engine but did provide data that can be used to compare single $47 \mathrm{~mm}$ Teflo, T60A20 to pre-2007 dual $70 \mathrm{~mm}$ T60A20 filters. 


\subsection{WVU CAFEE Cleanroom}

The gowning room is entered before accessing the cleanroom. The gowning room air is filtered and conditioned the same as the cleanroom and therefore acts as a buffer between the outside and the cleanroom air conditions. The gowning room provides an area for removing particles from shoes before booties are placed over the shoes, in which the user will then access the cleanroom. A view from the entrance into the gowning room is shown in Figure 3-1, in which the pass through and entrance into cleanroom can be seen (both on the right-hand side of the picture). The figure does not show two tacky mats that are walked across to remove particles before placing booties over shoes.

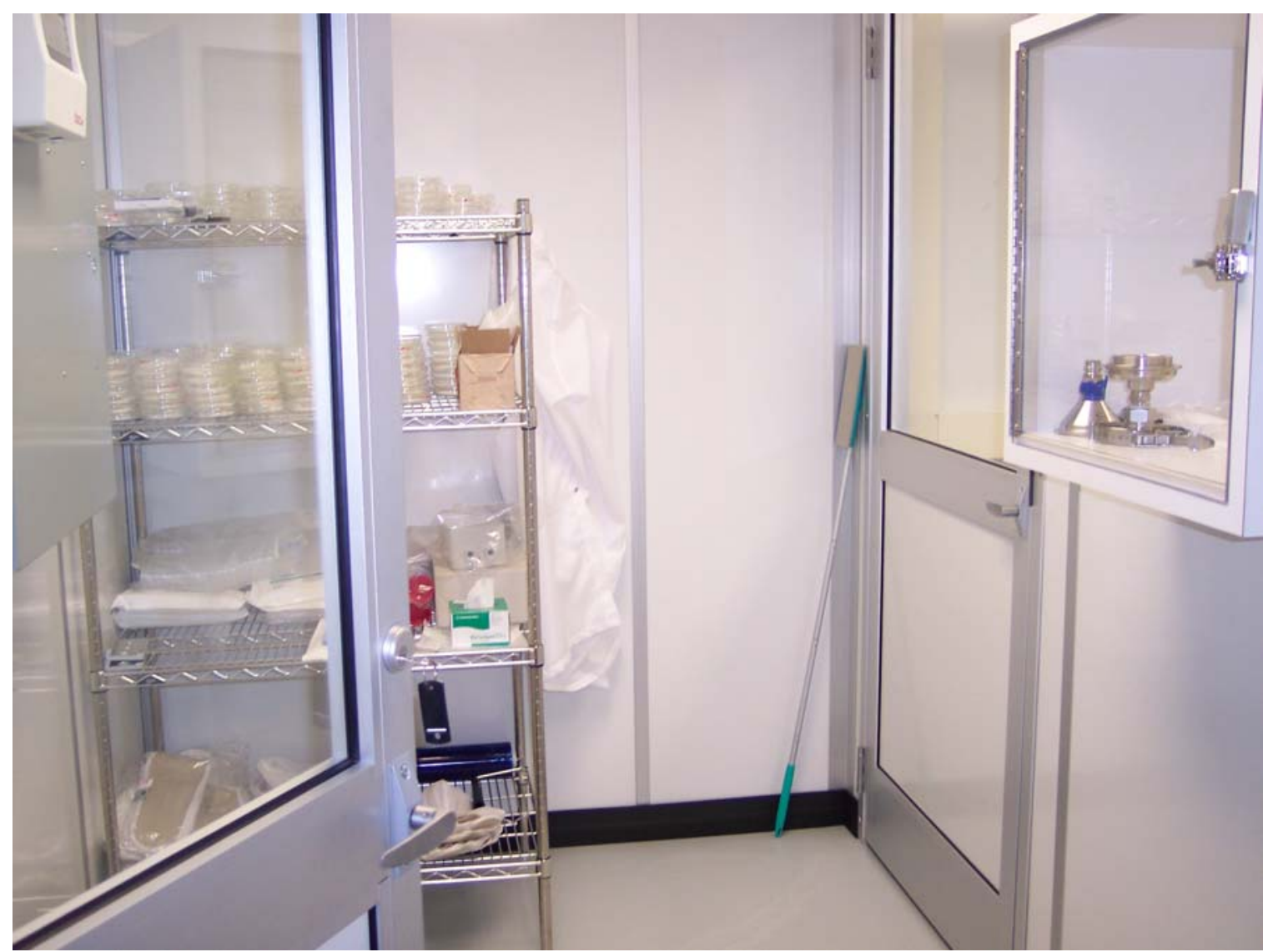

Figure 3-1: View from entrance into gowning room 
As previously mentioned, the WVU CAFEE cleanroom is a class 1000 cleanroom that must maintain a five minute unweighted average of temperature and dew point at $22^{\circ}$ $\pm 1{ }^{\circ} \mathrm{C}$, and $9.5^{\circ} \pm 1{ }^{\circ} \mathrm{C}$, respectively, in which the averages are calculated by sampling once per second [7]. This is completed by maintaining an air velocity of $10 \mathrm{fpm}$. The WVU CAFEE cleanroom is currently in an operational state and has a non-unidirectional flow as shown in Figure 2-6. Figure 3-2 and Figure 3-3 demonstrate the weighing area of the cleanroom and the filters being conditioned prior to being pre-weighed, and filters that have been pre-weighed. A detailed view and description of the weighing area is found in Figure 3-6 and Figure 3-7.

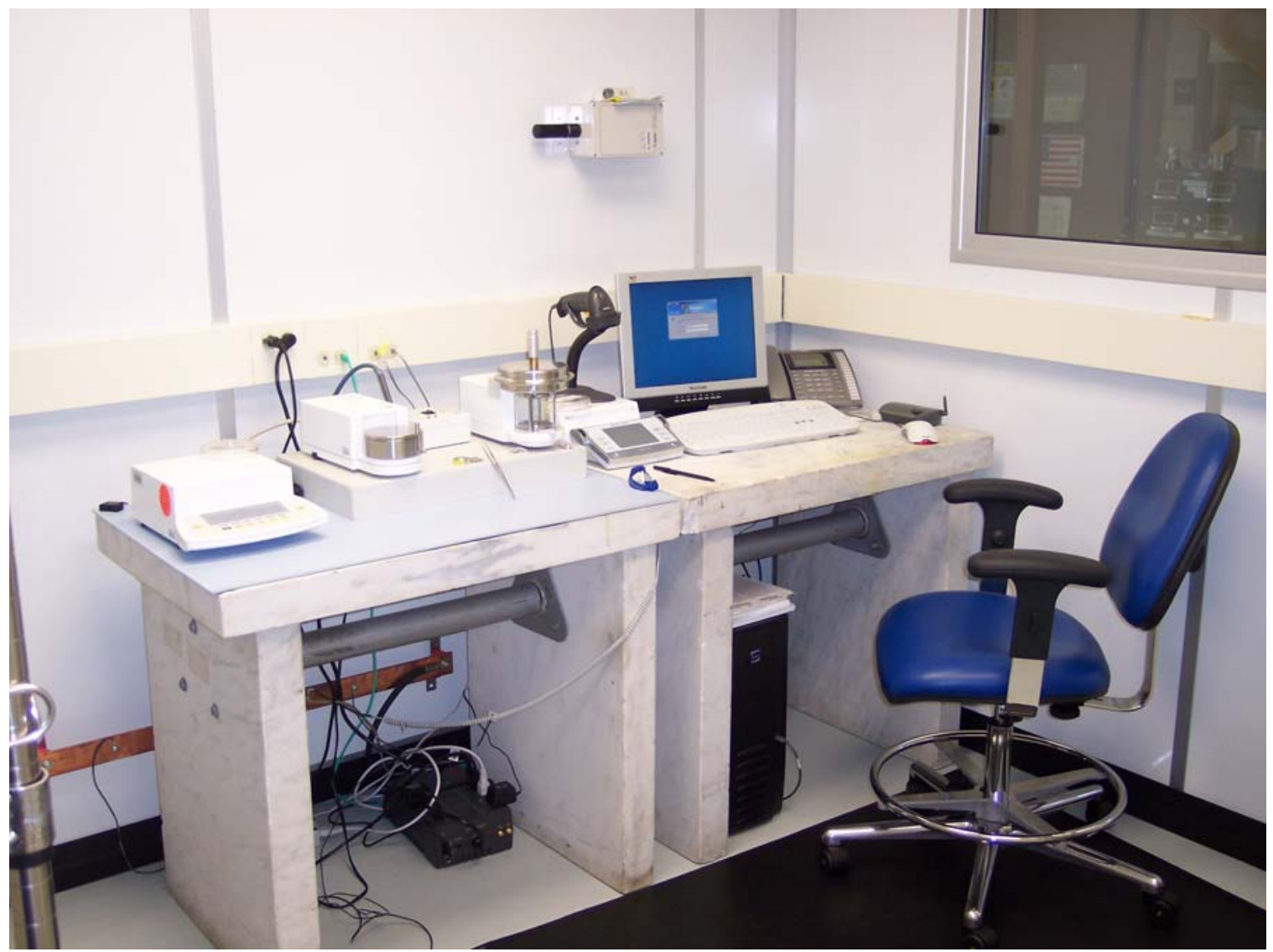

Figure 3-2: View of weighing area 


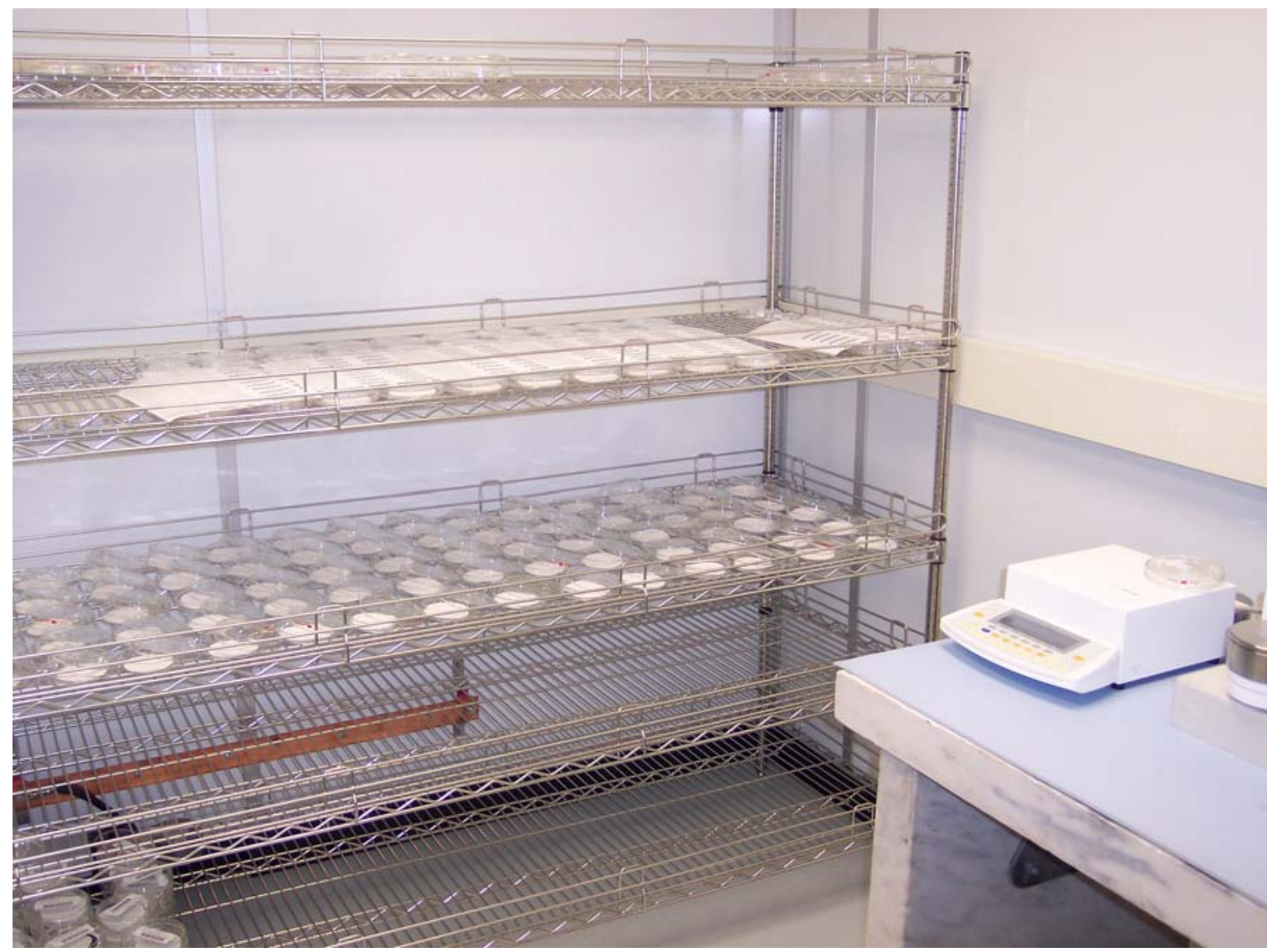

Figure 3-3: Shelves containing pre-weighed filters and conditioning filters

The WVU CAFEE cleanroom was constructed by TourAndoverControls. The cleanroom has a $10 \mathrm{ft}$. $x 10 \mathrm{ft}$. floor area and was designed to allow two personnel to be present. The gowning room is $6 \mathrm{ft} . \mathrm{x} 10 \mathrm{ft}$. An outside view of the cleanroom and gowning room can be viewed in Figure 3-4. Four filters are used to reduce particles in the air. The entrance to the air-handling unit contains a $30 \%$ efficient pre filter, $95 \%$ efficient post filter, a carbon filter and the outlet contains a 99.99\% efficient HEPA filter. 


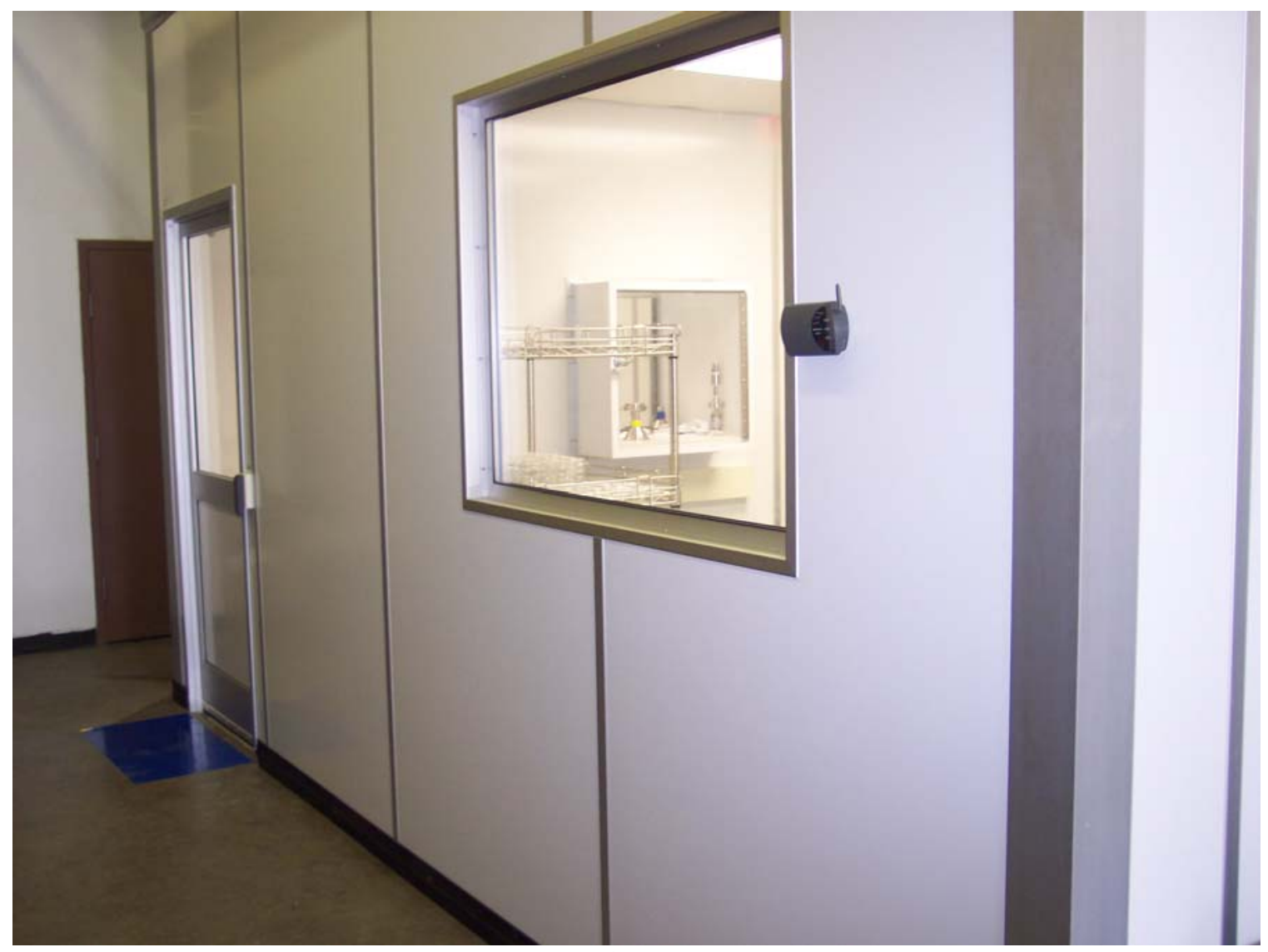

Figure 3-4: Outside view of cleanroom and gowning room

The following tests were completed to ensure that the cleanroom met the design and class 1000 specifications, after cleanroom building completion: particulate test, temperature, dew point, laboratory pressure, supply air velocity and lighting. The class 1000 classification specifies that particle sizes 0.5 and $5.0 \mu \mathrm{m}$ be tested, however TourAndoverControls tested for particle sizes $0.3,0.5$ and $5.0 \mu \mathrm{m}$. The WVU CAFEE cleanroom met the class 1000 specifications with an average of 540 particles at $0.5 \mu \mathrm{m}$ and 2 particles at $5.0 \mu \mathrm{m}$, with the class 1000 specified average particles being less than 1000 particles at $0.5 \mu \mathrm{m}$ and 7 particles at $5.0 \mu \mathrm{m}$. However, this was only taken at one location and through Equation 2-7, from FED-STD 209E, this test should have been taken from four, uniformly spaced horizontally, locations. The cleanroom was 
commissioned for use in December 2005 as a result of the cleanroom meeting the design and 40 CFR 86 requirements.

Temperature and dew point are constantly being monitored due to 40 CFR 86 , but passed the initial inspection by monitoring the dew point and temperature for 24 hours. The differential pressure was tested by using a differential pressure probe of a calibrated Solomat and it was determined that the differential pressure was 0.06 in. water column. The design air volume was $650 \mathrm{cfm}$ but the actual duct velocity was $750 \mathrm{fpm}$ which results in a $750 \mathrm{cfm}$ flow through a square foot duct. The lighting was able to pass the design requirements of 100 foot candles.

\subsection{Developing Cleanroom Cleaning Procedures}

The Federal Standard 209E, ISO 14644-5, and Operation \& Maintenance Manual "Lab Dressing Procedure," by TourAndoverControls were reviewed to determine the best cleaning procedures for the WVU CAFEE cleanroom. An onsite visit to the EPA facility in Ann Arbor, Michigan was conducted to determine their procedures and how their cleanroom is conducted. EPA Engineer Brian Olsen stated that the cleanroom is to be run as cost effective as possible therefore the cleanroom had to meet the class 1000 requirements upon completion of being built but would not require further testing to ensure that the cleanroom is maintaining the class 1000 status. Some of the EPA's cleaning procedures have been adopted for use in the WVU CAFEE cleanroom, as well as the cleaning procedures specified in the ISO documents. The cleaning procedures were developed to be easily maintained but also to minimize the amount of particles in the cleanroom. 


\subsection{Weighing Procedures}

The weighing procedures begin with entering the gowning room to remove particles from shoes and then to place booties over the shoes before entering the cleanroom. Once inside the cleanroom, the weighing procedures are modeled from the previous CAFEE laboratory procedures version 20051227 for PM filter handling and weighing, and determined from prior tests, of which some of the tests are included herein [43]. The outcome from previous studies in minimization of errors in the gravimetric process were evaluated to determine if the results could be implemented at the WVU CAFEE.

An understanding of the microbalance will help to build procedures that will minimize error. The procedures will explain what measures have been taken to minimize errors that could occur in the weighing process. The procedures address the oscillating temperature and dew point conditions upon entering the room to ensure that these variations are not affecting the gravimetric process, as the balance is very sensitive to temperature fluctuations and therefore could cause weighing errors if the weighing process is started immediately upon entering the cleanroom. The WVU CAFEE cleanroom has a Mettler Toledo UMX2 and a Sartorius SE2-F, in which the following weighing procedures are constructed in reference to the Sartorius SE2-F ultramicrobalance.

\subsubsection{Procedures to Enter the Cleanroom}

Entering the cleanroom, from the gowning room, is the first step to the weighing process. This step minimizes the amount of particles that are entering the cleanroom. This therefore minimizes the amount of particles that can affect the weighing process. It 
is recommended that only door (entrance to the gowning room, entrance to the cleanroom, or pass through) be open at any one time so as to avoid gross contamination of the cleanroom or pass through. The Federal Standard 209E, ISO 14644, and Operation \& Maintenance Manual "Lab Dressing Procedure," by TourAndoverControls were evaluated to determine the best procedures for minimizing the amount of particles that are introduced into the WVU CAFEE cleanroom.

\subsubsection{Operation of Ultra-Microbalance}

An ultra-microbalance has an electromagnetic coil that is used to oppose the pull of gravity to maintain the balance pan at a know position. This process is completed by using a compensation coil that contains a permanent current flow and is inserted into a permanent magnetic field. Current regulation maintains the zero position of the balance when the balance is in an unloaded condition. An opt electronic position sensor is used to control the coil position to an accuracy better than one thousandth of a millimeter. The balance records vertical positional changes when the scale is loaded and this information from the controller is used to generate a compensation current in the coil to return the weighing system to zero. The current is directly proportional to the loaded weight. The current is digitalized and then sent to the display $[28,47]$. Figure 3-5 illustrates the interior of an ultra-microbalance and assists in the understanding of where each part is located and to explain the process of each part during a weighing. 


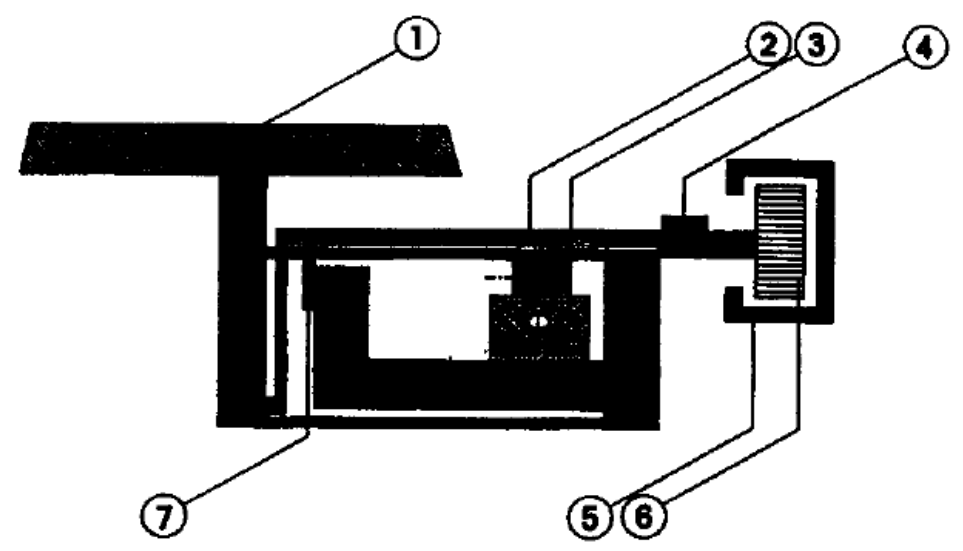

$\begin{array}{ll}\text { 1. } & \text { Weighing pan } \\ \text { 2. } & \text { Beam } \\ \text { 3. } & \text { Detection } \\ \text { 4. } & \text { Counterweight } \\ \text { 5. Permanent-magnet } \\ \text { 6. Coil } \\ \text { 7. Flexible bearing }\end{array}$

Figure 3-5: Schematic of primary components of an ultra-microbalance [47]

\subsubsection{Determining Weighing Procedures}

A nominal $200 \mathrm{mg}$ calibration weight was used to determine the standard deviation by four consecutive repeated weighings. The process used to determine the weighing process involved calibrating the balance before the gravimetric process began. Twelve weighings of the nominal $200 \mathrm{mg}$ calibration weight were conducted. The calibration and linearization function of the scale were then utilized to determine the effects of adding the linearization to the calibration function. Twelve consecutive repeated weighings of the nominal $200 \mathrm{mg}$ calibration weight were conducted at the linearization and calibration condition. The next weighing session alternated these conditions, in which the internal calibration and linearization were completed first and twelve consecutive repeated weighings of the $200 \mathrm{mg}$ calibration weight which was followed by the recalibration of the balance and completing another twelve consecutive 
weighings. This process was alternated each day due to the fluctuations in the temperature and humidity when first entering the cleanroom and to ensure that these fluctuations were not affecting the results.

\subsubsection{Anti Static Measures}

Weighing errors can result from weighing statically charged objects [48]. To ensure that a static charge is not imparted onto the filters, the person weighing the filters is grounded with respect to the microbalance by a wrist strap, an anti-static chair mat, and anti-static tabletop mat. These are grounded to earth via grounding bar as shown in Figure 3-6. The microbalance is grounded to the grounding bar to ensure it will not become statically charged. Electrostatic dissipative chairs are used to ensure that a static charge is not imparted onto the filters. The anti static wrist strap has a 1-megohm resistor installed in series to prevent electrical shock. A small cylindrical Polonium 210 source is located next to the microbalance and is used to neutralize charges on the filters before each weighing. There is an option to use the Sartorius stat pen device to neutralize the static charge on filters. The stat pen is a corona discharge device that uses alternating high voltage applied to pointed electrodes to ionize the air around the filter. The Sartorius SE2-F has no further charge neutralizers once the filters are placed on the weighing platform and the lid is closed. However, the Sartorius SE2-F has draft shield that is made of stainless steel to minimize the effects of static electricity during the weighing process, as shown in Figure 3-7 [49]. 


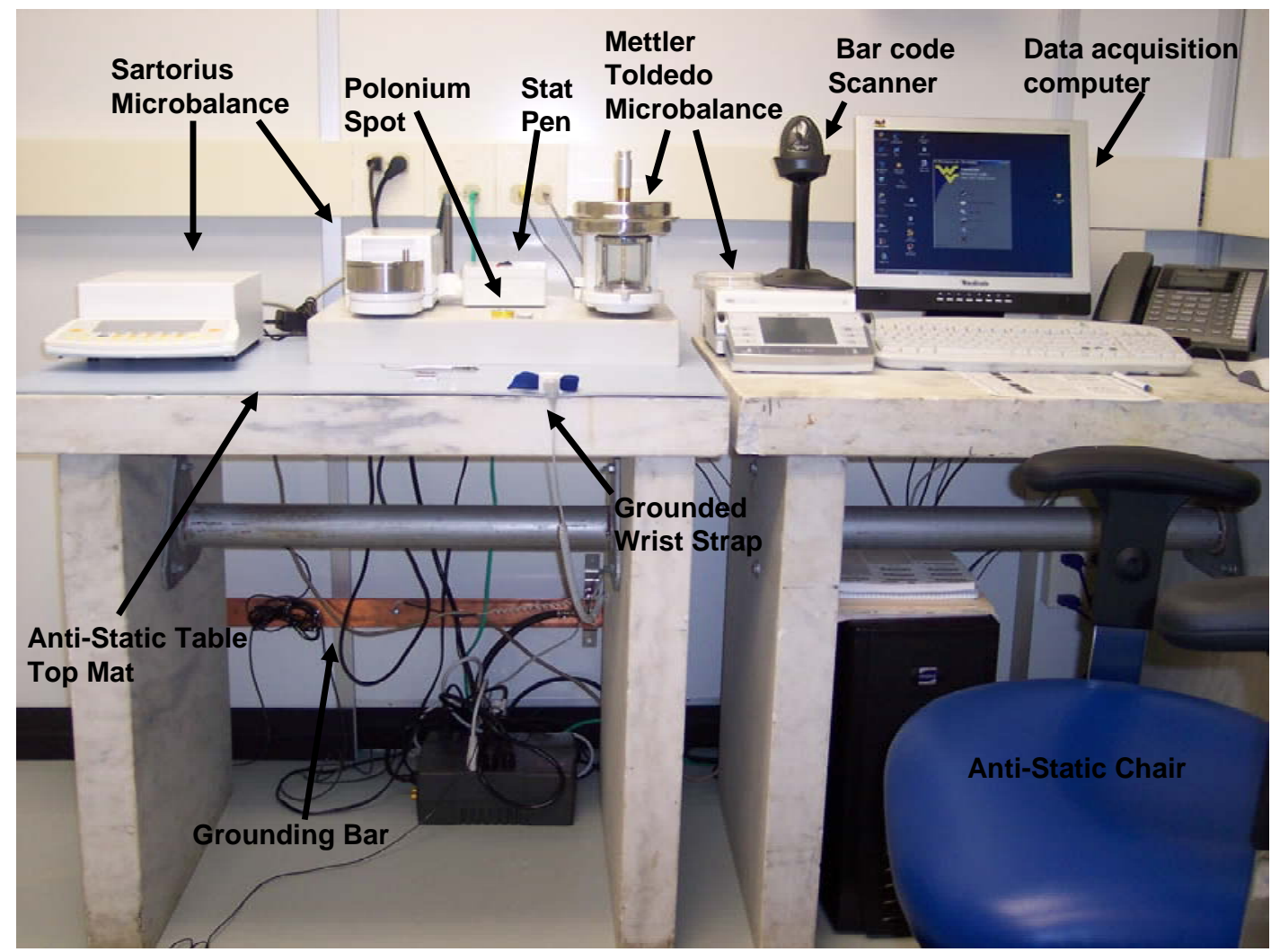

Figure 3-6: View of the WVU CAFEE cleanroom

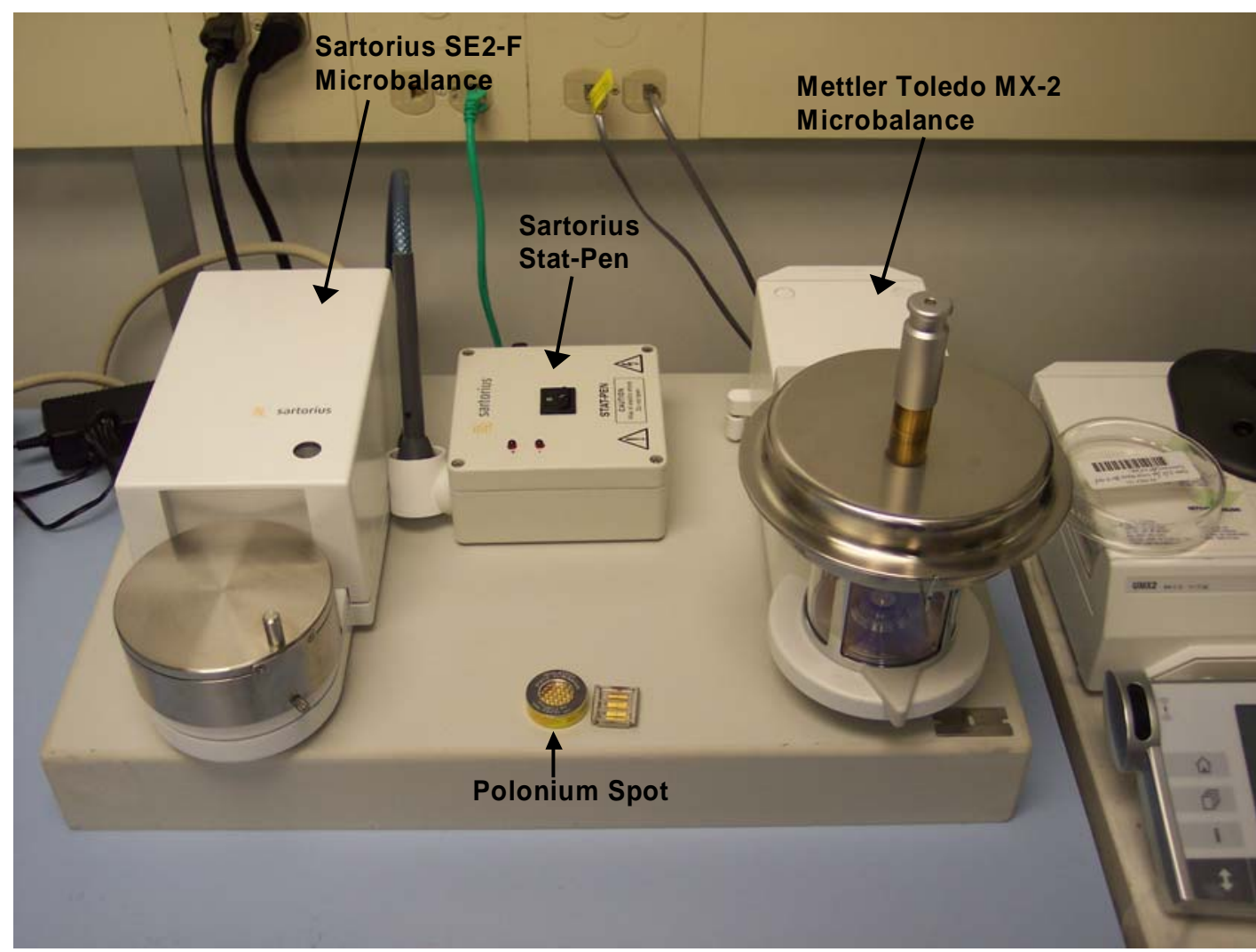

Figure 3-7: Comparison view of the Mettler Toledo and Sartorius microbalances 


\subsubsection{Determining Standard Deviation of Sartorius Microbalance}

Four consecutive weighings were used to determine the standard deviation. The value that must be obtained for a calibration weight must be less than $0.25 \mu \mathrm{g}$ as stated in the $40 \mathrm{CFR} 86$, Subpart N. However, this number ranged from $0.44 \mu \mathrm{g}$ to $0.05 \mu \mathrm{g}$. These values were obtained by two different methods; the first method was by weighing the calibration weight and then zeroing the scale by selecting the tare key, the second method was by weighing the calibration weight, then check the zero, record the zero value, and then reweigh the calibration weight. These methods were repeated four consecutive times to obtain a standard deviation value. The highest value was found immediately after entering the cleanroom, which indicates that the unstable temperature and dew point affect the weighing process. The lowest occurred after sixteen weighings of the $200 \mathrm{mg}$ calibration weight.

\subsubsection{Determining Linearization of Sartorius Microbalance}

The linearization method specified by Sartorius is completed by increasing the weight in $500 \mathrm{mg}$ increments from zero to $1500 \mathrm{mg}$ [50]. This spans the allowable weights to be evaluated by this microbalance, which ranges from zero $\mathrm{mg}$ to $2000 \mathrm{mg}$. The linearization procedure, listed in List of Tolerances for Testing Metrological Specifications Supplement, was completed by adding a $500 \mathrm{mg}$ weight and then pressing the tare key. The $500 \mathrm{mg}$ weight was then removed from the weighing pan for 5 seconds and then replaced onto the weighing pan. The balance was then allowed to stabilize and this value was taken as the deviation. This process was repeated for separate weights consisting of the $1000 \mathrm{mg}$ and $1500 \mathrm{mg}$ calibration weight. However, lower calibration weights were used to determine the linearity of the Sartorius SE2-F since the WVU 
CAFEE filter weights are most often less than $500 \mathrm{mg}$. Class U weights were used in the linearity testing of the Sartorius Microbalance.

\subsection{Evaluation of Filter Efficiency}

The progression from $70 \mathrm{~mm}$ filters to $47 \mathrm{~mm}$ filters was examined to determine the amount of PM that was captured and to evaluate the causes of differing PM measurements. These causes are a result of different filter media, flow rates, and surface area. Therefore the results obtained by running transient engine testing were compared between a primary and backup $70 \mathrm{~mm}$ T60A20 filter set, a single $47 \mathrm{~mm}$ Teflo filter and a single $47 \mathrm{~mm}$ T60A20 filter in which a pre-2007 dilution tunnel was used and therefore results cannot be applied to 2007 standards. It is noted that these results may not be representative of 2007 trap-equipped engine results but were the only available data for this work.

\subsubsection{Experimental Setup}

The evaluation of filters was examined by placing a $70 \mathrm{~mm}$ T60A20 primary and backup filter into a filter holder. A single $47 \mathrm{~mm}$ Teflo and T60A20 filters were placed into the $47 \mathrm{~mm}$ filter holder because the filter holder was designed for a single filter. This only allowed the comparison between the set of $70 \mathrm{~mm}$ filters and a single $47 \mathrm{~mm}$ filter. The $70 \mathrm{~mm}$ T60A20 filter set and $47 \mathrm{~mm}$ were placed in separate secondary dilution tunnels so that a different flow rate could be used for each filter type. Each filter or filter set was loaded into the filter holder while inside the pass through located inside the cleanroom as shown in Figure 3-8. 


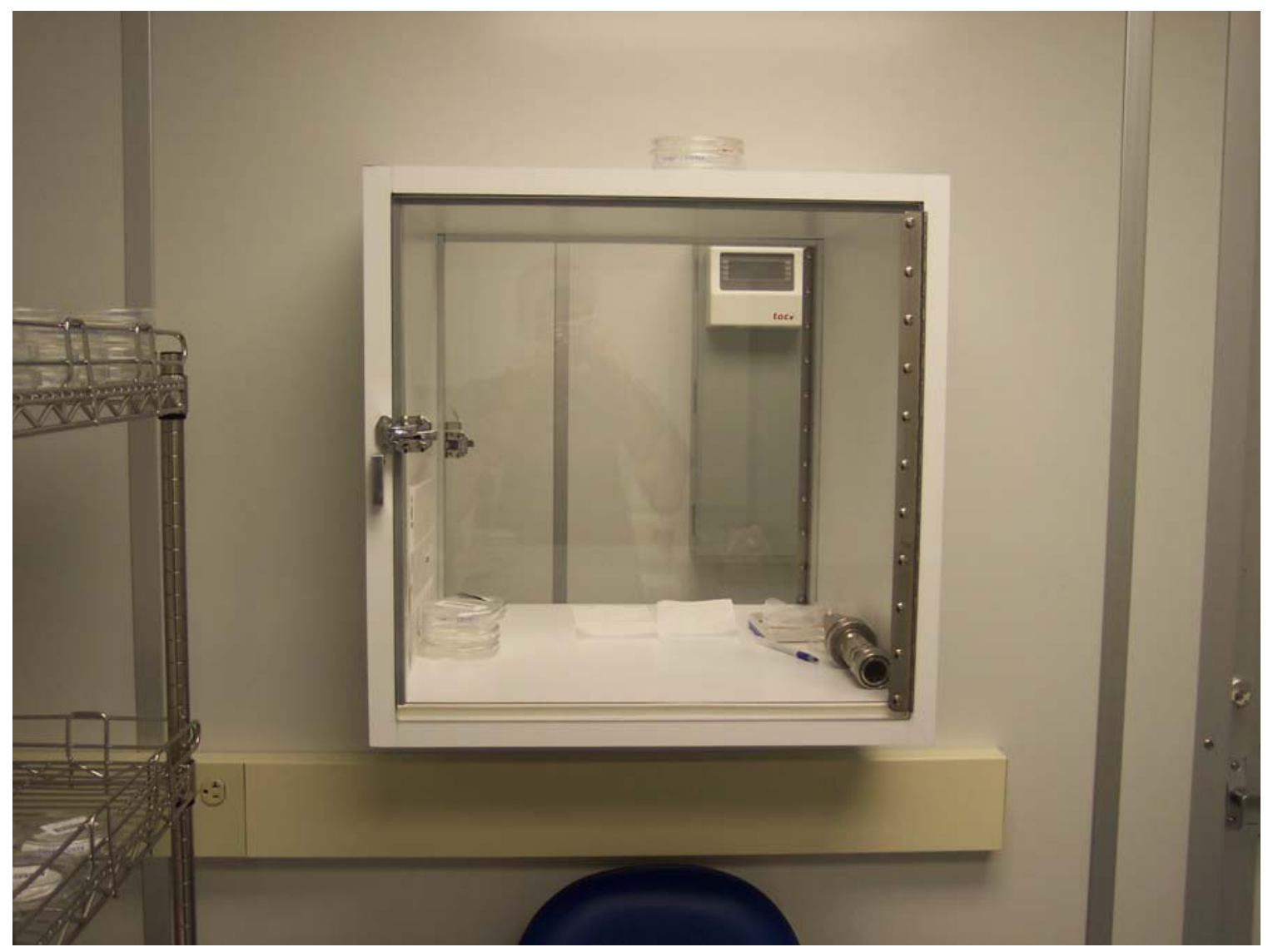

Figure 3-8: Pass through between cleanroom and gowning room

A piece of para-film was pulled over the top of each filter holder to ensure that particulates would not be introduced to the filter before the test was conducted or during the transport from the cleanroom to the test cell. Each filter holder was then taken to the test cell where each filter holder was plugged into the setup as shown in Figure 3-9. 


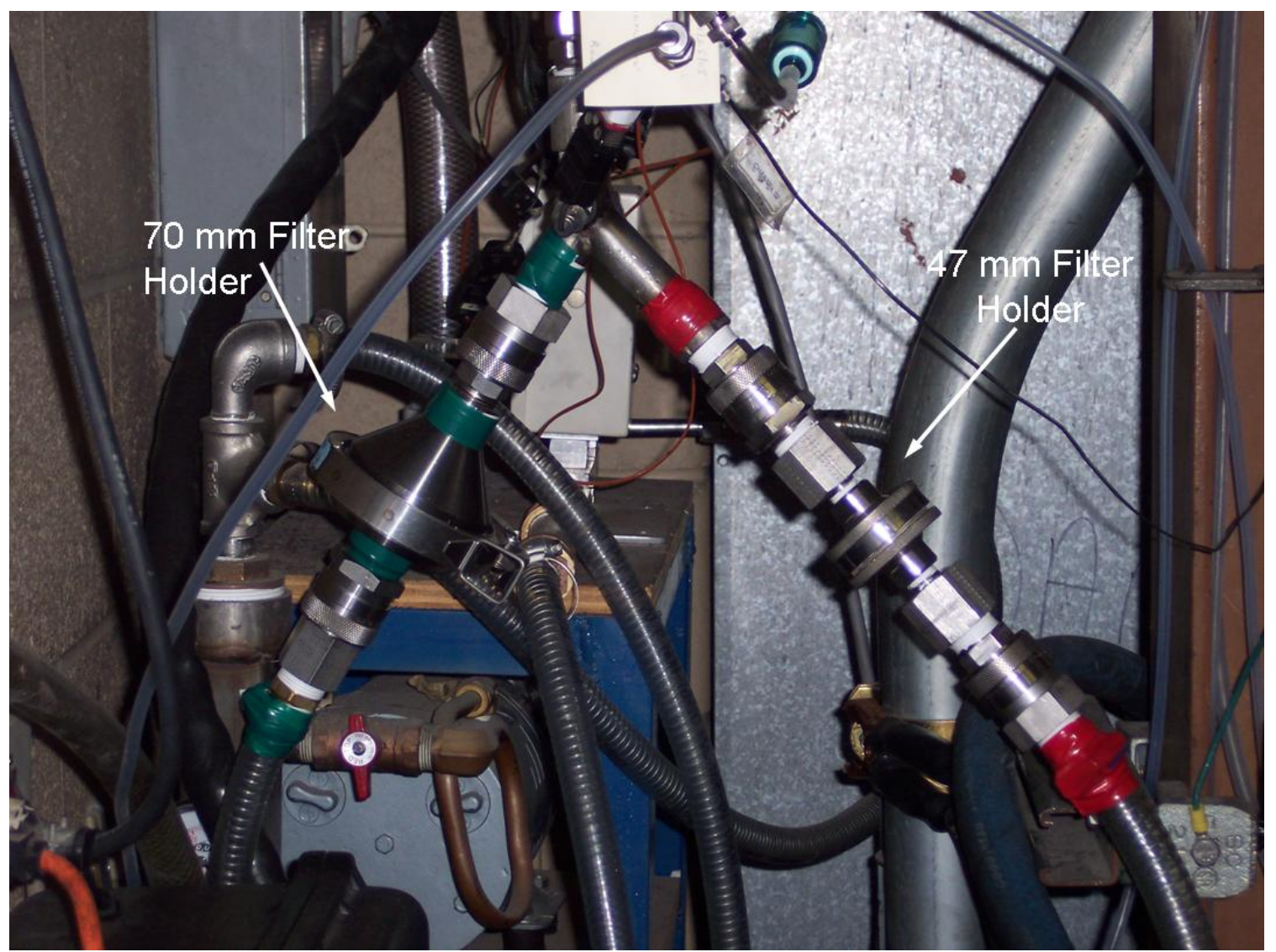

Figure 3-9: Location of $70 \mathrm{~mm}$ and $47 \mathrm{~mm}$ filter holders during transient testing

A transient test was conducted in which the flow through a $70 \mathrm{~mm}$ filter was set to $2 \mathrm{cfm}$ and the flow through the $47 \mathrm{~mm}$ filter was set to $1 \mathrm{cfm}$. After the transient testing, each filter holder was removed from the setup and then taken immediately to the pass through located in the cleanroom. The filters were removed and placed into Petri dishes. The filters were then placed inside the cleanroom for at least an hour to allow the filter media to reach the cleanroom temperature and humidity level. The filters were then weighed using the procedure that is outlined in Section 4.4.

\subsubsection{Filter Comparison}

The filters were compared by using 40 CFR 86, Subpart N, 86.1343. The following equations were used to calculate PM mass in grams per hot phase for a CFV- 
CVS system as shown in Equation 3-1. The dilution factor is calculated by using Equation 3-2, where it is assumed that 13.4 is the Stoichiometric ratio for all diesel fuels.

$$
\begin{gathered}
P_{\text {mass }}=\left(V_{\text {mix }}+V_{s f}\right) \times\left[\frac{P_{f}}{V_{s f}}-\left(\frac{P_{b f}}{V_{b f}} \times[1-(1 / D F)]\right)\right] \\
D F=\frac{13.4}{\left.C O_{2}+\left(H C_{e}+C O_{e}\right) * 10^{-4}\right]}
\end{gathered}
$$

Values were obtained for these equations by using the reduced data from each transient test. A background test was not completed for the $47 \mathrm{~mm}$ filters and therefore a value is not used for the background weight in the calculation of particulate mass.

Once this initial study was completed, another study was used to determine the standard deviation, the buoyancy correction, and the mean difference of each type of filter with and without PM collected on the filter face. This study was completed by weighing a group of $47 \mathrm{~mm}$ Teflo and a group of $47 \mathrm{~mm}$ T60A20 filters. Each group consisted of filters of which a set of five was loaded with PM and a set of five was unloaded. A weighing session included the weighing of each group five times, and therefore each weighing session had fifty weighings. Four weighing sessions were conducted over four days and therefore 200 weighings were conducted for the $47 \mathrm{~mm}$ Teflo filters. The $47 \mathrm{~mm}$ T60A20 filters also had 50 weighings per weighing session, but only three weighing sessions were conducted for a total of 150 weighings.

This study was used to gain averages of the weight for each filter and to determine if the average weight should be used, or if the first initial weighing would be sufficient. The precision was found to compare to the $2.5 \mu \mathrm{g}$ standard stated in the 40 CFR 86 Subpart N, 86.1312. 
Weighings were carried out at various barometric pressures to determine fluctuation in weights after the buoyancy correction was applied. The buoyancy correction was examined to determine the largest source of error in an error propagation study. Equation 3-3, Equation 3-4, and Equation 3-5 illustrate the buoyancy equations that are stated in 40 CFR 86 Subpart N.

$$
\begin{gathered}
P_{W}=0.6113 * 10^{\frac{7.5 * T_{d p}}{237.3+T_{d p}}} \\
\rho_{A}=\frac{3.484 * P-1.317 * P_{W}}{T+273.15} \\
M=R * \frac{\left(1-\frac{\rho_{A}}{\rho_{W}}\right)}{\left(1-\frac{\rho_{A}}{\rho_{S}}\right)}
\end{gathered}
$$

Equation 3-3

Equation 3-4

Equation 3-5 


\section{RESULTS AND DISCUSSIONS}

\subsection{Introduction}

The purpose of this study was to develop cleaning procedures, weighing procedures and filter handling procedures. This chapter examines the error from buoyancy correction and determines the difference between the $47 \mathrm{~mm}$ filters and $70 \mathrm{~mm}$ filter set.

\subsection{Cleanroom Cleaning Procedures}

The following cleanroom cleaning procedures were formulated after reviewing the ISO 14644-5, TourAndoverControls, and reviewing the EPA's cleaning procedures. The EPA spoke of their cleaning procedures consisting of a janitor coming into the cleanroom once a week to clean the floor with a special cleaning solution since their floor was designed to hold dirt. The ISO 14644-5 specifies a cleaning schedule that is determined by risk assessment of the area. A cleaning schedule is not defined by TourAndoverControls, however it is stated that the frequency of cleaning is determined by the amount of activity in a cleanroom and the classification of the cleanroom. Therefore the cleaning procedures that are defined in this section are based off of the assessment of the amount of activity in the cleanroom and classification number, but also to maintain the EPA's idea of cost effectiveness.

The cleanroom is to be cleaned every week to ensure that there is no a gross particle contamination of filters. This should be done by wiping the walls with saturated cleanroom wipes by working from the ceiling down to the floor and by using 
unidirectional, overlapping strokes. The floor should be cleaned with the saturated cleanroom wipes and then a tacky roller is to be used to collect any remaining particles. The person cleaning should pay close attention to corners and cracks to ensure that all of the particles are removed. The chair should also be wiped from top to bottom. The ceiling panels should be removed once a month to wipe down the upper side of the panels and panel tracks to ensure that no dust is being pushed into the room. This process should only be completed in between weighing periods to allow the room to properly filter the air to ensure no particle contamination of reference filters. Any ladder or stool, used to assist in removing the ceiling panels, should be wiped with saturated cleanroom wipes before being taken into the cleanroom. This should be done by working from the top of the ladder or stool to the base. The wiper should be replaced as necessary to avoid distributing contaminants to other parts of the cleanroom surface [42].

It is the responsibility of the person upon leaving the cleanroom to look at the sticky mats and determine if the sticky mats are dirty and to remove the dirty sheet. The person can then remove the loose particles from their shoes more effectively the next time the gowning room and cleanroom are accessed. The procedures are described in Appendix B, Appendix C, and Appendix D for monthly cleaning of cleanroom and gowning room and weekly cleaning of cleanroom and gowning room.

\subsection{Entering the Cleanroom}

Entering the cleanroom is limited to qualified personnel in which key cards regulate access into the gowning room. Upon entering the gowning room, a person must walk on the tacky mats to remove lose particles from their shoes. It is recommended that a person take off all jewelry before entering the cleanroom. A person should then sit 
down on the bench to place the booties over their shoes, as shown in Figure 4-1. This ensures that the particles not removed by the sticky mats will then be kept inside the bootie. This is considered the first line of defense in controlling contamination of the cleanroom [47].

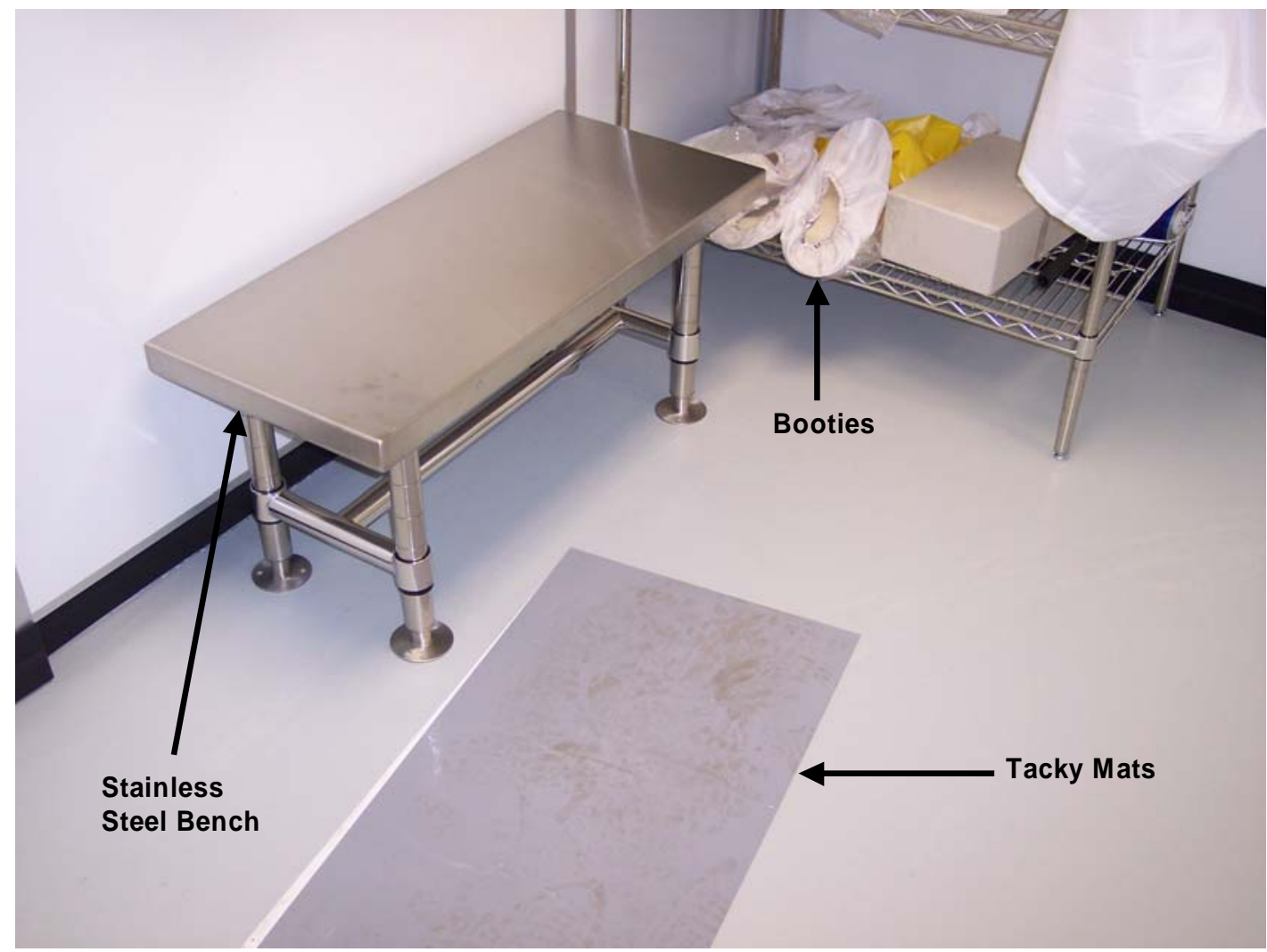

Figure 4-1: View of gowning room

The following procedures are outlined in the standard operating procedures, SOP0270-A, in Appendix A. A program used in the WVU CAFEE cleanroom will assist the user in completing the following procedures to ensure that every user is completing the same procedures. The cleanroom conditions should be checked to ensure that the room meets the five minute unweighted average temperature and dew point requirements of $22^{\circ} \pm 1{ }^{\circ} \mathrm{C}$ and $9.5^{\circ} \pm 1{ }^{\circ} \mathrm{C}$, respectively. The microbalance should be examined to ensure that it is still level and this is completed by viewing the bubble on the top of the microbalance and making sure it is within the circle. Ten minutes should be allowed to 
elapse before weighing begins to allow the temperature and dew point oscillations to stabilize to ensure that this will not affect the weighing process. The internal calibration key should be pressed once the room conditions are stabilized. This allows for an internal adjustment to take place. The internal linearization key should be pressed to allow the microbalance check its internal linearization. The person should then put the anti-static wrist strap on to control static discharge. The zero value should then be checked and saved.

The weight of calibration weights and filters should be saved as soon as the scale reaches stability to minimize the effects from drifting [28]. The $200 \mathrm{mg}$ weight should be placed onto the weighing platform to verify that the scale is working properly, in which this value is to be saved. The microbalance should display the $200 \mathrm{mg}$ weight being within $\pm 0.25 \mu \mathrm{g}$ of its value. The $200 \mathrm{mg}$ weight is then removed and the zero value is checked to ensure that the scale is returning to a near zero value, within $\pm 1 \mu \mathrm{g}$ of zero. The zero reading should be recorded.

All filters should be passed over the cylindrical Polonium spot to neutralize any charge on the face of the filter. The filters should be turned over to ensure that both sides have been neutralized. If $70 \mathrm{~mm}$ T60A20 filters are being used, then at least two $70 \mathrm{~mm}$ T60A20 reference filters should be weighed and compared to make sure that the average of the difference of their minimum and maximum weights are within $40 \mu \mathrm{g}$ for the filters for 1988-2006 standards. The new 2007 standards state that $47 \mathrm{~mm}$ filters should be within an average of $10 \mu \mathrm{g}$ for a difference between the minimum and maximum of any of their weighings. Reference filters should be changed each month. 
While inside the cleanroom, the person should refrain from scratching their face and making any abrupt movements. The person should try to keep their hands and face moisturized to minimize the amount of particle contamination. A notebook, designed to minimize particle contamination for use in cleanroom applications, is located inside the room to log what procedures have been completed, such as cleaning or any other events such as equipment malfunctions.

\subsection{Weighing Procedures}

The pre-weight and post-weight weighing procedures can be completed after the reference filters have been weighed and have been determined to be within the specifications as previously mentioned. The filters should first be neutralized before being placed onto the weighing platform. This is completed by passing the filters over the cylindrical Polonium spot to neutralize any charge on the face of the filter. The filters should be turned over to ensure that both sides have been neutralized. The filters should then be placed onto the weighing platform. After this filter has been placed onto the weighing platform, another filter set should be placed onto the Polonium spot to give a long duration for the static charge to be neutralized. The weight should be recorded as soon as the scale reaches a stable reading. It was found that reading the balance when it first becomes stable would help to minimize the effects of drifting [28]. After the weight has been recorded, the filter is removed from the weighing platform and placed back into its original Petri dish where it will be stored until being used or until being disposed. The filter set that was placed onto the Polonium spot will be waved over the Polonium spot to ensure that both sides are statically neutral and will then be placed onto the weighing platform. 
This process will take place for 10 minutes and then the zero value will be checked to ensure that the balance has not drifted to $\pm 1 \mu \mathrm{g}$. This process is completed by removing the filter from the weighing pan and closing the weighing chamber. The scale is then allowed to stabilize, in which this value will be recorded. After this value has been recorded, the tare button is pressed to zero the scale to begin the next 10 minute session and this value will also be recorded to show that the balance has been zeroed before weighing proceeds.

It has been determined that taking an average of two filter weighings will improve confidence in the determined weight. Therefore, a set of filters will be weighed in a 10 minute span, then the amount of drift will be checked and the balance will be tarred. The set of filters will be reweighed during the next 10 minute span. If the difference between the two weighings is greater than $5 \mu \mathrm{g}$, then a third weight will be taken to be included in the average.

A loaded filter has the possibility of being mishandled and losing some PM through the filter handling process. Therefore, if a second weight is taken and it is less than $5 \mu \mathrm{g}$, a third weight will be taken to determine if it is also less than $5 \mu \mathrm{g}$. If the second and third weighing are below $5 \mu \mathrm{g}$, then the initial weighing will be assumed to be the correct weight unless it is obvious that the first weight was in error.

\subsubsection{Buoyancy Correction}

Archimedes' principle states that a body experiences a loss in weight equal to the weight of the medium it displaces [51]. Therefore a filter is subjected to the force of buoyancy in the opposite direction of the force of weight. "This reduces the weight of the mass to be determined by an amount exactly equivalent to the weight of the displaced 
air" [52]. The buoyancy correction uses the dew point temperature to calculate the vapor pressure of water. The vapor pressure of water is then used to calculate the air density. The water $\left(\mathrm{H}_{2} \mathrm{O}\right)$ content of air is $3 \%$ at $30{ }^{\circ} \mathrm{C}$ and $0.5 \%$ at $0{ }^{\circ} \mathrm{C}$ by volume, where carbon dioxide $\left(\mathrm{CO}_{2}\right)$ accounts for $0.038 \%$ by volume. The molar mass of $\mathrm{CO}_{2}$ and $\mathrm{H}_{2} \mathrm{O}$ is 44 and $18 \mathrm{~g} / \mathrm{mol}$, respectively. $\mathrm{CO}$ is 2.44 times the mass of $\mathrm{H}_{2} \mathrm{O} . \mathrm{H}_{2} \mathrm{O}$ has a much higher percentage by volume than $\mathrm{CO}_{2}$ and therefore used in the calculation of the buoyancy correction.

The buoyancy correction is used to account for changes in barometric pressure, which affects air density. The affect of air density fluctuations on a $0.5 \mathrm{mg}$ particulate weight, with a filter of volume $60 \mathrm{~mm}^{3}$, can influence the weight by $\pm 4.8 \%$ [52]. However, the influence is only $0.06 \%$ with a filter of volume $25 \mathrm{~mm}^{3}$ and the same weight of $0.5 \mathrm{mg}$ is used. The following demonstrates an error propagation analysis to determine the largest source of error for the $70 \mathrm{~mm}$ T60A20, and the $47 \mathrm{~mm}$ Teflo filters $[53,54]$. Equation 3-3 will be examined to find the vapor pressure of liquid water by using the dew point temperature, which was calculated to be $1.1882 \mathrm{kPa}$. Table 4-1 illustrates the values that are being inputted into the following equations to determine the error propagation for the given filters.

Table 4-1: Values to be used in error propagation

\begin{tabular}{|c|c|c|c|c|c|c|c|c|}
\hline $\begin{array}{l}\text { Filter } \\
\text { Size } \\
(\mathrm{mm})\end{array}$ & $\begin{array}{l}\text { Filter } \\
\text { Type }\end{array}$ & $\begin{array}{c}\text { Barometer } \\
(\mathrm{kPa})\end{array}$ & $\begin{array}{c}\text { Chamber } \\
\text { Temp } \\
\left({ }^{\circ} \mathrm{C}\right)\end{array}$ & $\begin{array}{c}\text { Chamber } \\
\text { Dewpoint } \\
\left({ }^{\circ} \mathrm{C}\right)\end{array}$ & $\begin{array}{c}\text { Vapor } \\
\text { Pressure } \\
(\mathrm{kPa})\end{array}$ & $\begin{array}{c}\text { Air } \\
\text { Density } \\
\left(\mathrm{kg} / \mathrm{m}^{3}\right)\end{array}$ & $\begin{array}{l}\text { Weight } \\
\text { (mg) }\end{array}$ & $\begin{array}{l}\text { Buoyancy } \\
\text { Correction } \\
\text { (mg) }\end{array}$ \\
\hline 70 & T60A20 & 97.14 & 22.1 & 9.5 & 1.19 & 1.14 & 303.2927 & 303.4000 \\
\hline 47 & T60A20 & 97.14 & 22.1 & 9.5 & 1.19 & 1.14 & 60.5018 & 60.5234 \\
\hline 47 & Teflo & 97.14 & 22.1 & 9.5 & 1.19 & 1.14 & 171.4921 & 171.6806 \\
\hline
\end{tabular}


A derivative is taken of $\mathrm{P}_{\mathrm{W}}$ with respect to $\mathrm{T}_{\mathrm{dp}}$ to yield Equation 4-1.

$$
\frac{d P_{W}}{d T_{d p}}=0.6113 * 10^{\left(\frac{7.5 * T_{d p}}{237.3+T_{d p}}\right)} *\left(7.5 *\left(237.3+T_{d p}\right)-\frac{7.5 * T_{d p}}{\left(237.3+T_{d p}\right)^{2}}\right) * \log (10) \text { Equation 4-1 }
$$

The value of $\Delta \mathrm{T}_{\mathrm{dp}}$ is specified to be $\pm 0.2{ }^{\circ} \mathrm{C}$ as required by $40 \mathrm{CFR} 86$. This value is then placed into Equation 4-2 to calculate the amount of error in the $\mathrm{P}_{\mathrm{W}}$ term, in which it was determined that $\mathrm{dP}_{\mathrm{W}} / \mathrm{dT}_{\mathrm{dp}}$ is equal to 0.080 .

$$
\Delta P_{W}=\left[\left(\frac{d P_{W}}{d T_{d p}} * \Delta T_{d p}\right)^{2}\right]^{\frac{1}{2}}= \pm 0.016
$$

Equation 4-2

This process is used to determine the amount of errors in Equations 3-3, 3-4, and 3-5. Equation 3-4 is used to determine the air density for the buoyancy correction, which is calculated to be $1.14 \mathrm{~kg} / \mathrm{m}^{3}$ by using the values in Table $4-1$. Partial derivatives are taken of Equation 3-4 with respect to temperature $(\mathrm{T})$, vapor pressure of liquid water $\left(\mathrm{P}_{\mathrm{w}}\right)$, and barometric pressure (P), as shown in Equation 4-3 through Equation 4-5, to yield the values given in Table 4-2. The values shown in Table 4-2 are calculated by using T, P, and $\mathrm{P}_{\mathrm{w}}$ as shown in Table 4-1. The $\mathrm{P}_{\mathrm{w}}$ value was calculated from Equation 3-3.

$$
\begin{gathered}
\rho_{A}=\frac{3.484 * P-1.317 * P_{W}}{T+273.15} \\
\frac{\partial \rho_{A}}{\partial P}=\frac{3.484}{T+273.15} \\
\frac{\partial \rho_{A}}{\partial T}=\frac{-\left(3.484 P-1.317 P_{W}\right)}{(T+273.15)^{2}} \\
\frac{\partial \rho_{A}}{\partial P_{W}}=\frac{-1.317}{T+273.15}
\end{gathered}
$$

Equation 4-3

Equation 4-4

Equation 4-5 
The errors used in the air density calculation are illustrated in Table 4-2, in which these values are used in Equation 4-3 to determine a $\Delta \rho_{\mathrm{A}}$ value of 0.000248 . The error terms given in Table 4-2 are given as a \pm values.

Table 4-2: Values used to find error terms for Equation 4-6

\begin{tabular}{|c|c|c|c|}
\hline $\begin{array}{c}\text { Partial } \\
\text { Derivative }\end{array}$ & $\begin{array}{c}\text { Values for } \\
\text { Partial Der. }\end{array}$ & $\begin{array}{c}\text { Instrument } \\
\text { Error }\end{array}$ & $\begin{array}{c}\text { Error } \\
\text { Terms }\end{array}$ \\
\hline$\delta \rho_{\mathrm{A}} / \mathrm{dP}_{\mathrm{W}}$ & 0.0118 & 0.016 & 0.00019 \\
\hline$\delta \rho_{\mathrm{A}} / \delta \mathrm{T}$ & -0.0039 & 0.032 & 0.000124 \\
\hline$\delta \rho_{\mathrm{A}} / \delta \mathrm{P}$ & -0.0045 & 0.023 & 0.000104 \\
\hline
\end{tabular}

Equation 4-6 demonstrates how the error term is calculated for the air density. The $\Delta \mathrm{P}_{\mathrm{W}}$ term was calculated as shown in Equation 4-2, where the $\Delta \mathrm{T}$ and $\Delta \mathrm{P}$ error terms are found from Table $4-3$ as $\pm 0.2{ }^{\circ} \mathrm{C}$ and $\pm 0.023 \mathrm{kPa}$.

Table 4-3: Error associated with each instrument used in the buoyancy correction [55, 56, 57, 58]

\begin{tabular}{|l|c|c|c|c|}
\hline Instrument & $\begin{array}{c}\text { Edgetech } \\
\text { Model 200 } \\
\text { Dewtrack }\left({ }^{\circ} \mathrm{C}\right)\end{array}$ & $\begin{array}{c}\text { Druck RPT } \\
301 \text { Option A A } \\
(\mathrm{kPa})\end{array}$ & $\begin{array}{c}\text { Deban } \\
\text { Thermister } \\
\left({ }^{\circ} \mathrm{C}\right)\end{array}$ & $\begin{array}{c}\text { Sartorius } \\
\text { SE2-F } \\
(\mu \mathrm{g})\end{array}$ \\
\hline Z Value (95\%) & -- & -- & -- & 1.96 \\
\hline Non-linearity & -- & -- & -- & 0.90 \\
\hline Repeatability & -- & -- & -- & 0.25 \\
\hline Total Error & \pm 0.2 & \pm 0.023 & \pm 0.03175 & 1.39 \\
\hline
\end{tabular}

$$
\Delta \rho_{A}=\left[\left(\frac{\partial \rho_{A}}{\partial P_{W}} * \Delta P_{W}\right)^{2}+\left(\frac{\partial \rho_{A}}{\partial T} * \Delta T\right)^{2}+\left(\frac{\partial \rho_{A}}{\partial P} * \Delta P\right)^{2}\right]^{\frac{1}{2}}= \pm 0.000248 \text { Equation 4-6 }
$$

Equation 3-5 is the final equation used in the buoyancy correction. Partial derivatives are taken of Equation 3-5 with respect to air density $\left(\rho_{A}\right)$, calibration weight density $\left(\rho_{\mathrm{w}}\right)$, filter density $\left(\rho_{s}\right)$, and determined weight $(\mathrm{R})$. The air density used in the calculation of the partial derivatives is shown in Table 4-1. The calibration weight density was 7850 $\mathrm{kg} / \mathrm{m}^{3}$. The filter density used for the T60A20 filter media was $2300 \mathrm{~kg} / \mathrm{m}^{3}$ and 920 $\mathrm{kg} / \mathrm{m}^{3}$ was used for the Teflo filter media. The filter weights used for T60A20 $70 \mathrm{~mm}, 47$ $\mathrm{mm}$ and for $47 \mathrm{~mm}$ Teflo are shown in Table 4-1. 
The errors in the final calculation of the buoyancy correction of $70 \mathrm{~mm} \mathrm{T60A20,}$ $47 \mathrm{~mm} \mathrm{T60A20,} \mathrm{and} 47 \mathrm{~mm}$ Teflo filters are found by calculations of Equations 4-7 through Equation 4-10 and are shown in Table 4-4. It was determined that the industry standard is $\pm 10 \%$ in variation for filter density [59]. The 40 CFR 86 states that an acceptable value for PTFE coated borosilicate fiber filters is $2300 \mathrm{~kg} / \mathrm{m}^{3}$. Therefore, the variation in filter density, $\Delta \rho_{\mathrm{s}}$, will equal $\pm 230 \mathrm{~kg} / \mathrm{m}^{3}$. It was determined from a sample size of 20 single $47 \mathrm{~mm}$ T60A20 filters that the standard deviation was $7.9489 \mathrm{mg}$ with an average weight of $64.0838 \mathrm{mg}$.

The average density of the $47 \mathrm{~mm}$ Teflo filters is given by the 40 CFR 86 as 920 $\mathrm{kg} / \mathrm{m}^{3}$ [7]. The density given for the PTFE membrane ranged from $2200 \mathrm{~kg} / \mathrm{m}^{3}$ to 2400 $\mathrm{kg} / \mathrm{m}^{3}$. However, $95 \%$ of the weight of the Teflo filter is the polymethylpentene support ring and the polymethylpentene support ring has a density of $850 \mathrm{~kg} / \mathrm{m}^{3}$. As previously mentioned, the industry standard variation for filter density is $\pm 10 \%$ and by using the 40 CFR 86 average of $920 \mathrm{~kg} / \mathrm{m}^{3}$, a density variation of $\pm 92 \mathrm{~kg} / \mathrm{m}^{3}$ was used in the error propagation calculation [59]. The average value, stated by 40 CFR 86 , was used to determine the $\pm 10 \%$ error due to the lack of density testing of filters [59]. It was determined from a sample size of 960 single $47 \mathrm{~mm}$ Teflo filters that the standard deviation was $14.1122 \mathrm{mg}$ and an average weight of $186.8550 \mathrm{mg}$.

The stainless steel calibration weight can have a density of $8000 \mathrm{~kg} / \mathrm{m}^{3}$, as shown in the CFR buoyancy calculation example as stated in 40 CFR 86 . The class U stainless steel calibration weights located in the WVU CAFEE cleanroom have a density of 7850 $\mathrm{kg} / \mathrm{m}^{3}$. Therefore, the calibration weight density must be found for the microbalance to determine the buoyancy correction. The WVU CAFEE Sartorius SE2-F calibration 
weight has a density of $7850 \mathrm{~kg} / \mathrm{m}^{3}$. It is assumed that there is not a large variation in the calibration weigh density, where $\Delta \rho_{\mathrm{w}}$, was set equal to $\pm 10 \mathrm{~kg} / \mathrm{m}^{3}$ and was used to determine the error propagation.

$$
\begin{aligned}
& M=R * \frac{\left(1-\frac{\rho_{A}}{\rho_{W}}\right)}{\left(1-\frac{\rho_{A}}{\rho_{S}}\right)} \\
& \frac{\partial \mathrm{M}}{\partial \rho_{\mathrm{A}}}=\frac{-\mathrm{R}}{\rho_{\mathrm{W}} /\left(1-\rho_{\mathrm{A}} / \rho_{\mathrm{S}}\right)}+\frac{\mathrm{R}\left(1-\rho_{\mathrm{A}} / \rho_{\mathrm{W}}\right)}{\rho_{\mathrm{S}}\left(1-\rho_{\mathrm{A}} / \rho_{\mathrm{S}}\right)^{2}} \\
& \frac{\partial \mathrm{M}}{\partial \rho_{\mathrm{w}}}=\frac{\mathrm{R}^{*} \rho_{\mathrm{A}}}{\rho_{\mathrm{w}}^{2}\left(1-\rho_{\mathrm{A}} / \rho_{\mathrm{S}}\right)} \\
& \frac{\partial \mathrm{M}}{\partial \rho_{\mathrm{S}}}=\frac{-\mathrm{R}\left(1-\rho_{\mathrm{A}} / \rho_{\mathrm{W}}\right)\left(\rho_{\mathrm{A}} / \rho_{S}^{2}\right)}{\left(1-\rho_{\mathrm{A}} / \rho_{\mathrm{S}}\right)^{2}} \\
& \frac{\partial \mathrm{M}}{\partial R}=\left(1-\rho_{\mathrm{A}} / \rho_{\mathrm{W}}\right) /\left(1-\rho_{\mathrm{A}} / \rho_{\mathrm{S}}\right) \\
& \Delta M=\left[\left(\frac{\partial \mathrm{M}}{\partial \rho_{A}} * \Delta \rho_{A}\right)^{2}+\left(\frac{\partial \mathrm{M}}{\partial \rho_{W}} * \Delta \rho_{W}\right)^{2}+\left(\frac{\partial \mathrm{M}}{\partial \rho_{S}} * \Delta \rho_{S}\right)^{2}+\left(\frac{\partial \mathrm{M}}{\partial R} * \Delta R\right)^{2}\right]^{\frac{1}{2}} \text { Equation 4-11 }
\end{aligned}
$$

The errors associated with the instruments are found in Table 4-3, in which the error associated with the balance is $0.00139 \mathrm{mg}$ and is used in Equation $4-11$ as $\Delta \mathrm{R}$. 
Table 4-4: Error terms for different filter media and diameters

\begin{tabular}{|c|c|c|c|c|c|}
\hline $\begin{array}{l}\text { Filter } \\
\text { Media }\end{array}$ & $\begin{array}{c}\text { Partial } \\
\text { Derivative }\end{array}$ & $\begin{array}{l}\text { Values for } \\
\text { Partial Der. }\end{array}$ & $\begin{array}{c}\text { Instrument } \\
\text { Error }\end{array}$ & $\begin{array}{l}\text { Error } \\
\text { Units }\end{array}$ & $\begin{array}{l}\text { Error } \\
\text { Terms }\end{array}$ \\
\hline \multirow{4}{*}{ 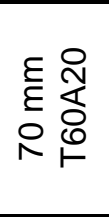 } & $\delta \mathrm{M} / \delta \rho_{\mathrm{A}}$ & 0.093300 & 0.00025 & $\mathrm{~kg} / \mathrm{m}^{3}$ & 0.000023 \\
\hline & $\delta \mathrm{M} / \delta \rho_{\mathrm{w}}$ & 0.000006 & 10 & $\mathrm{~kg} / \mathrm{m}^{3}$ & 0.000056 \\
\hline & $\delta \mathrm{M} / \delta \rho_{\mathrm{s}}$ & -0.000065 & 230 & $\mathrm{~kg} / \mathrm{m}^{3}$ & 0.015060 \\
\hline & $\delta \mathrm{M} / \delta \mathrm{R}$ & 1.000400 & 0.00139 & $\mathrm{mg}$ & 0.001391 \\
\hline \multirow{4}{*}{ 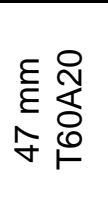 } & $\delta \mathrm{M} / \delta \rho_{\mathrm{A}}$ & 0.018600 & 0.00025 & $\mathrm{~kg} / \mathrm{m}^{3}$ & 0.000005 \\
\hline & $\delta \mathrm{M} / \delta \rho_{\mathrm{W}}$ & 0.000001 & 10 & $\mathrm{~kg} / \mathrm{m}^{3}$ & 0.000014 \\
\hline & $\delta \mathrm{M} / \delta \rho_{\mathrm{S}}$ & -0.000013 & 230 & $\mathrm{~kg} / \mathrm{m}^{3}$ & 0.003004 \\
\hline & $\delta \mathrm{M} / \delta \mathrm{R}$ & 1.000400 & 0.00139 & $\mathrm{mg}$ & 0.001391 \\
\hline \multirow{4}{*}{ 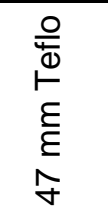 } & $\delta \mathrm{M} / \delta \rho_{\mathrm{A}}$ & 0.165000 & 0.00025 & $\mathrm{~kg} / \mathrm{m}^{3}$ & 0.000041 \\
\hline & $\delta \mathrm{M} / \delta \rho_{\mathrm{w}}$ & 0.000003 & 10 & $\mathrm{~kg} / \mathrm{m}^{3}$ & 0.000032 \\
\hline & $\delta \mathrm{M} / \delta \rho_{\mathrm{s}}$ & -0.000232 & 92 & $\mathrm{~kg} / \mathrm{m}^{3}$ & 0.021321 \\
\hline & $\delta \mathrm{M} / \delta \mathrm{R}$ & 1.001100 & 0.00139 & $\mathrm{mg}$ & 0.001392 \\
\hline
\end{tabular}

The total error for the buoyancy correction of a $70 \mathrm{~mm}$ T60A20 filter is \pm 16.9 $\mu \mathrm{g}$, as shown in Table 4-4. The total errors for the $47 \mathrm{~mm}$ T60A20 and Teflo filter are $\pm 5.0 \mu \mathrm{g}$ and $\pm 21.4 \mu \mathrm{g}$, respectively. The total errors depend on the determined weight and the density of the filters. The density of the filters and the weight of the filters are only present in the calculation of the buoyancy corrected weight as shown in Equation 35 , in which the errors listed for the air density and the dew point pressure are equal for all filters. The largest calculated error terms result from the variation in filter density as shown in Table 4-4. A potential limitation of the buoyancy correction is that it assumes an equal pre- and post-weight. This assumption is valid for 2007 particulate filter trap equipped exhaust due to the low amount of PM collection and therefore the collected PM density would not alter the filter density. This assumption would not be valid for pre2007 vehicles because the PM collected on the filter could be enough to have a small affect on the post-weight filter density. 
Table 4-5: Total error values for each calculated term in the buoyancy correction equation

\begin{tabular}{|c|c|c|c|c|}
\hline Terms & $\begin{array}{c}\text { Total Errors } \\
70 \mathrm{~mm} \text { T60A20 }\end{array}$ & $\begin{array}{c}\text { Total Errors } \\
47 \mathrm{~mm} \text { T60A20 }\end{array}$ & $\begin{array}{c}\text { Total Errors } \\
47 \mathrm{~mm} \text { Teflo }\end{array}$ & Units \\
\hline$\Delta \rho_{\mathrm{A}}$ & 0.00025 & 0.00025 & 0.00025 & $\mathrm{~kg} / \mathrm{m}^{3}$ \\
\hline$\Delta \mathrm{P}_{\mathrm{W}}$ & 0.01598 & 0.01598 & 0.016 & $\mathrm{kPa}$ \\
\hline$\Delta \mathrm{M}$ & 16.9 & 5.0 & 21.4 & $\mu \mathrm{g}$ \\
\hline
\end{tabular}

The variation of Teflo filter media density and the uncertainty of calibration weight density on the buoyancy correction were used to determine the buoyancy correction, which ranged from 1.00124 and 1.0099. It was determined that a linear relationship exists between the calibration weight density and Teflo filter media density on the buoyancy correction. Table 4-6 shows the calculation of the buoyancy corrected weight and compares it to the weight determined by the microbalance.

Table 4-6: Values used to determine buoyancy correction and buoyancy corrected values

\begin{tabular}{|c|c|c|c|c|c|c|c|c|}
\hline $\begin{array}{c}\text { Filter Size } \\
(\mathrm{mm})\end{array}$ & FilterType & $\begin{array}{c}\text { Barometer } \\
(\mathrm{kPa})\end{array}$ & $\begin{array}{c}\text { Chamber } \\
\text { Temp }\left({ }^{\circ} \mathrm{C}\right)\end{array}$ & $\begin{array}{c}\text { Chamber } \\
\text { Dewpoint }\left({ }^{\circ} \mathrm{C}\right)\end{array}$ & $\begin{array}{c}\text { Weight } \\
(\mathrm{mg})\end{array}$ & $\begin{array}{c}\text { Air Density } \\
\left(\mathrm{kg} / \mathrm{m}^{3}\right)\end{array}$ & $\begin{array}{c}\text { Buoyancy } \\
\text { Correction }(\mathrm{mg})\end{array}$ & $\begin{array}{c}\text { Weight } \\
\text { Difference }(\mathrm{mg})\end{array}$ \\
\hline 70 & T60A20 & 97.154 & 22.007 & 9.451 & 303.2939 & 1.142 & 303.4012 & 0.1073 \\
\hline 70 & T60A20 & 97.154 & 21.974 & 9.478 & 303.2944 & 1.142 & 303.4017 & 0.1073 \\
\hline 70 & T60A20 & 97.152 & 22.051 & 9.545 & 303.2936 & 1.141 & 303.4009 & 0.1073 \\
\hline 70 & T60A20 & 97.149 & 21.974 & 9.512 & 303.2935 & 1.142 & 303.4008 & 0.1073 \\
\hline 70 & T60A20 & 97.144 & 22.073 & 9.498 & 303.2927 & 1.141 & 303.4000 & 0.1073 \\
\hline
\end{tabular}

Figure 4-2 demonstrates the small affect of the barometric pressure on filter weight. It can be shown that the weight of the filter becomes less as the barometric pressure is lowered. This is completed over five weighings to allow a magnified view of the weight, and the barometric pressure. 


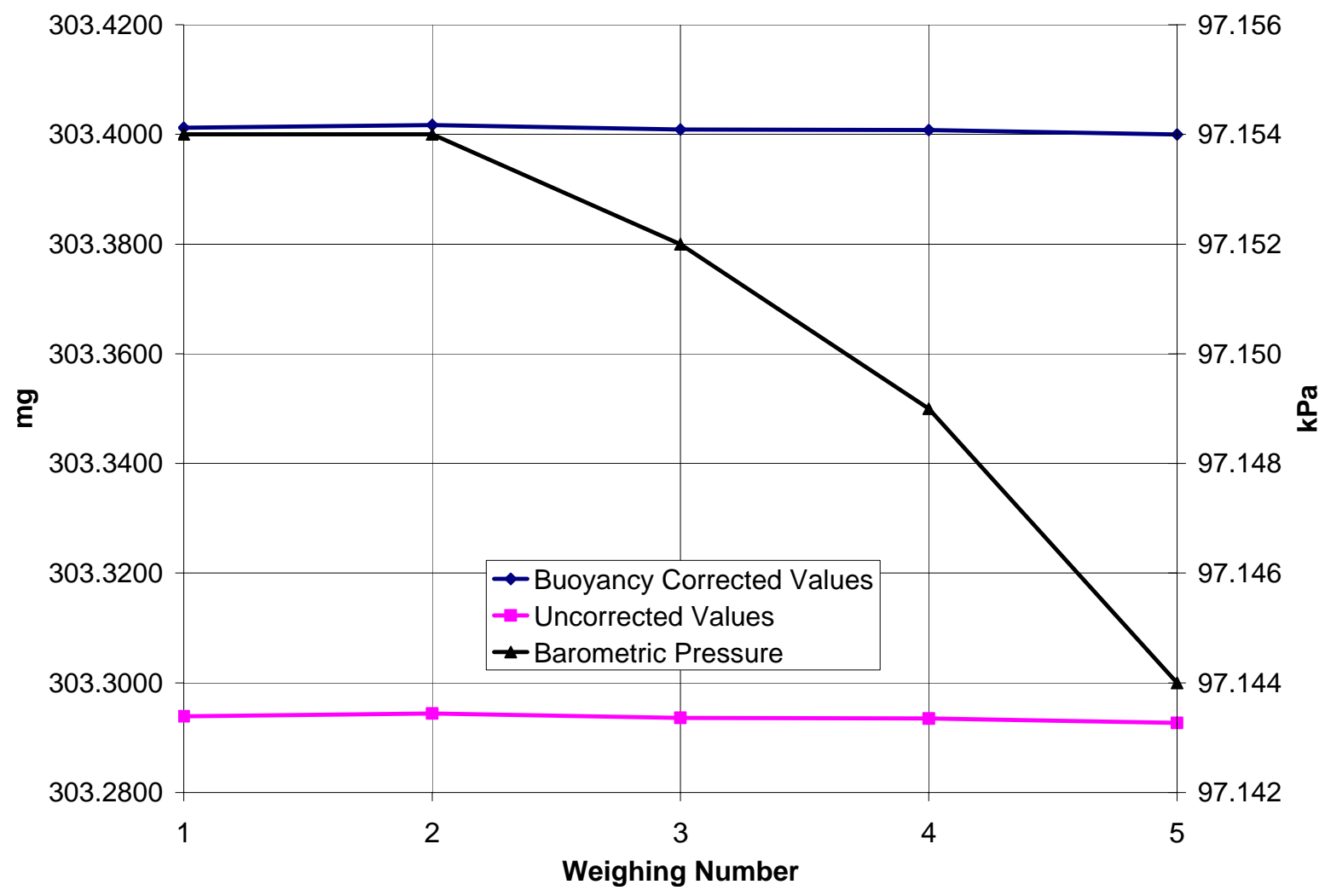

Figure 4-2: Illustrating the change in weight with the change in barometric pressure

Figure 4-3 shows the effects of barometric pressure on a PM loaded Teflo filter.

The figure illustrates the average for both the buoyancy corrected and uncorrected values to determine the fluctuations before and after the buoyancy correction is used. The daily buoyancy corrected average fluctuates from a high of $189.5773 \mathrm{mg}$ to a low of 189.5724 mg, which yields a difference of $4.9 \mu \mathrm{g}$. This difference falls within the clean filter precision requirement of $\pm 2.5 \mu \mathrm{g}$. 


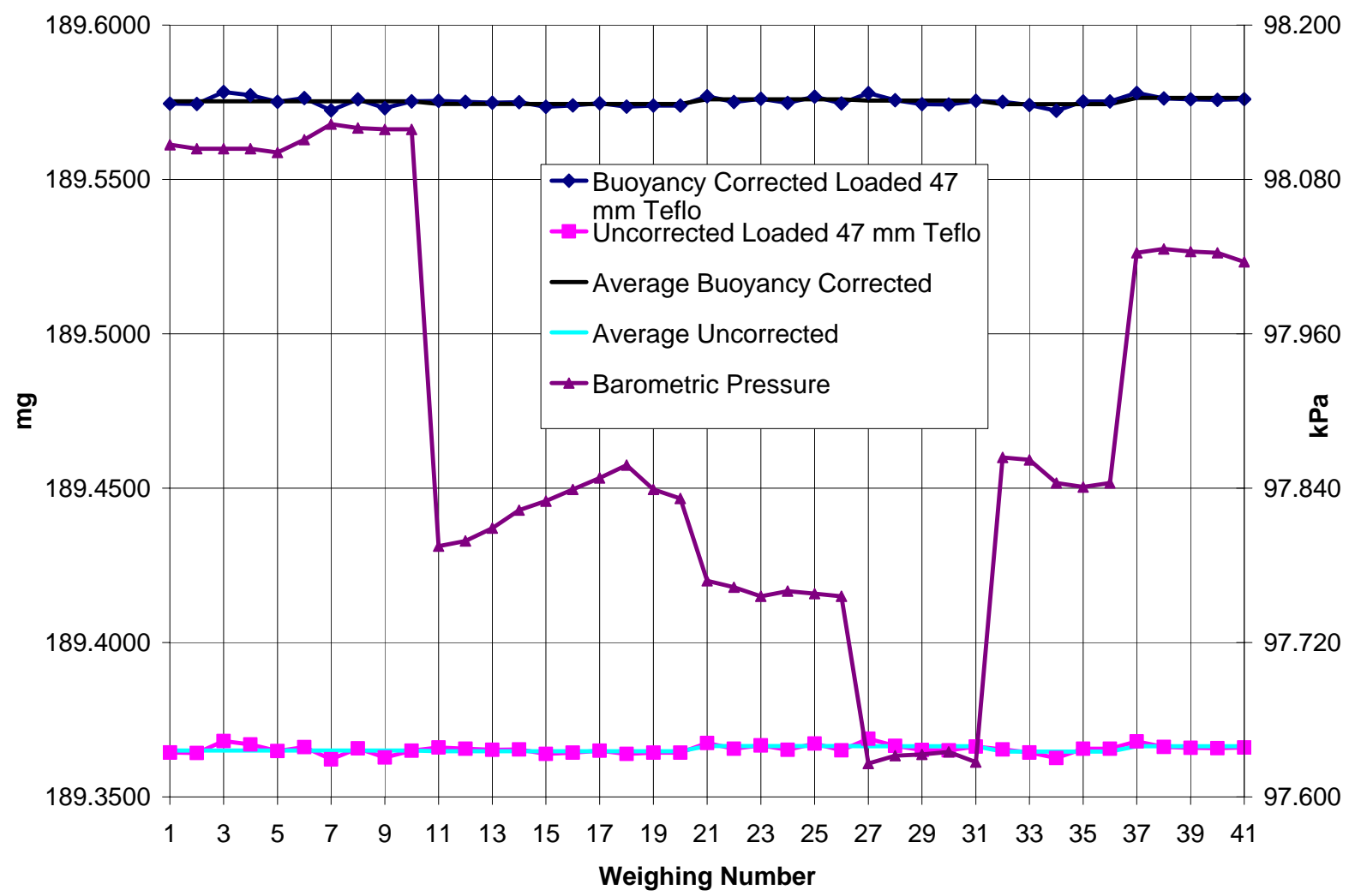

Figure 4-3: Demonstrates the buoyancy correction on a larger weighing sample

However, not all differences from the minimum and maximum values of the 47 $\mathrm{mm}$ Teflo and T60A20 filters were found to meet the precision requirement previously mentioned. Table 4-7 demonstrates the difference between maximum and minimum values obtained for the determined weight and the buoyancy corrected weight. In five cases it was found that the buoyancy correction had increased the difference between maximum and minimum values and in five cases the buoyancy corrected (BC) and uncorrected (UC) difference between maximum and minimum were equal. Five T60A20 filters and four Teflo filters were able to meet the clean filter precision requirement of 2.5 $\mu \mathrm{g}$. Therefore less than half of the total number of filters were able to meet this precision requirement. Seven of the filters that met this precision requirement were loaded filters, which indicates proposed filter handling procedures are able to minimize filter variation. 
However, it was found that one filter had a difference between minimum and maximum weight of $11.0 \mu \mathrm{g}$. This could possibly be caused by static charge buildup in which this filter was not allowed the proper amount of time to dissipate the static charge. These values are not acceptable when 2007 PM standards take effect, net weight may approximately be $60 \mu \mathrm{g}$. When the average of the differences in Table 4-7 are compared to this net mass, $8.6 \%$ and $8.9 \%$ of the determined weight could be filter variation for $\mathrm{BC}$ and $\mathrm{UC}$, respectively.

Table 4-7: Illustrates the difference between maximum and minimum values

\begin{tabular}{|c|c|c|c|}
\hline Filter Type & $\begin{array}{l}\text { Filter } \\
\text { Number }\end{array}$ & $\begin{array}{l}\text { BC Max \& Min } \\
\text { Difference }(\mu \mathrm{g})\end{array}$ & $\begin{array}{l}\text { UC Max \& Min } \\
\text { Difference }(\mu \mathrm{g})\end{array}$ \\
\hline \multirow{5}{*}{ 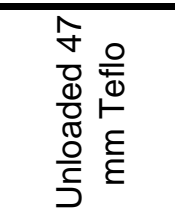 } & 1 & 3.8 & 3.6 \\
\hline & 2 & 5.9 & 6.6 \\
\hline & 3 & 5.9 & 6.6 \\
\hline & 4 & 6.3 & 6.7 \\
\hline & 5 & 7.8 & 8.6 \\
\hline \multirow{5}{*}{ 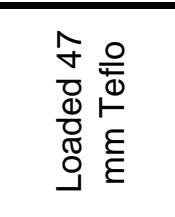 } & 6 & 3.3 & 3.5 \\
\hline & 7 & 2.7 & 2.7 \\
\hline & 8 & 8.5 & 9.4 \\
\hline & 9 & 3.7 & 3.7 \\
\hline & 10 & 5.8 & 6.2 \\
\hline \multirow{5}{*}{ 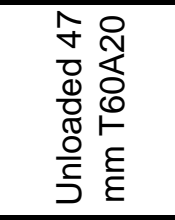 } & 11 & 3.0 & 2.9 \\
\hline & 12 & 11.0 & 11.0 \\
\hline & 13 & 6.1 & 6.2 \\
\hline & 14 & 6.6 & 6.6 \\
\hline & 15 & 5.7 & 5.8 \\
\hline \multirow{5}{*}{ 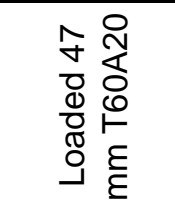 } & 16 & 5.3 & 5.3 \\
\hline & 17 & 3.5 & 3.6 \\
\hline & 18 & 3.1 & 3.0 \\
\hline & 19 & 2.7 & 2.6 \\
\hline & 20 & 2.3 & 2.2 \\
\hline \multicolumn{2}{|l|}{ Average } & 5.2 & 5.3 \\
\hline
\end{tabular}

Figure 4-4 and Figure 4-5 demonstrate the buoyancy corrected weight and determined weight compared to barometric pressure, respectively. It can be shown that the trend is nearly identical between both figures, except for weighing number 15 and 16 . The air density is higher for weighing number $15,1.152 \mathrm{~kg} / \mathrm{m}^{3}$ when compared to the air density of weighing number $16,1.149 \mathrm{~kg} / \mathrm{m}^{3}$ and this equates to a larger buoyancy 
corrected value when the determined weights are nearly identical, $171.492 \mathrm{mg}$ and $171.4924 \mathrm{mg}$.

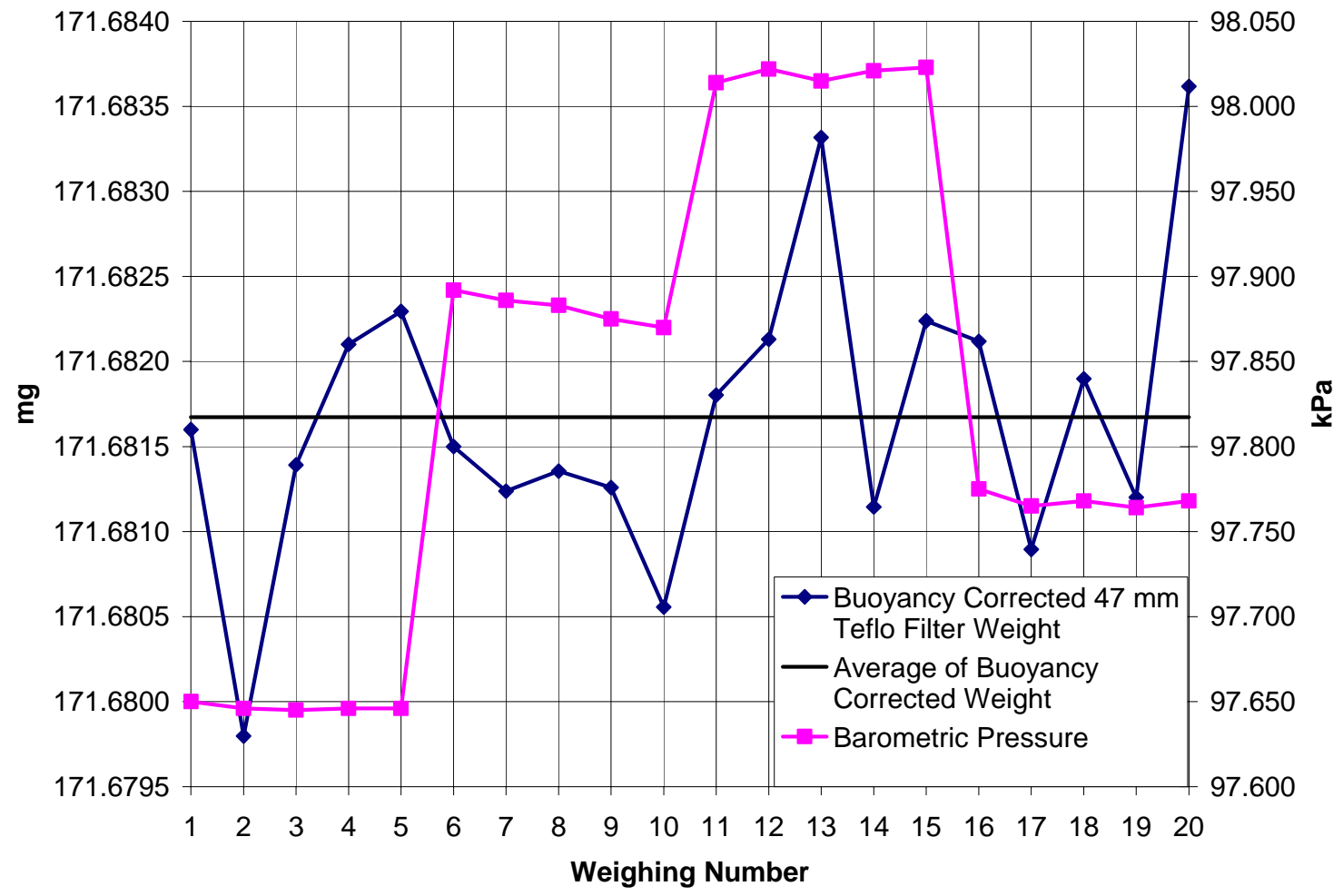

Figure 4-4: Buoyancy corrected weight for $47 \mathrm{~mm}$ Teflo filter compared to barometric pressure 


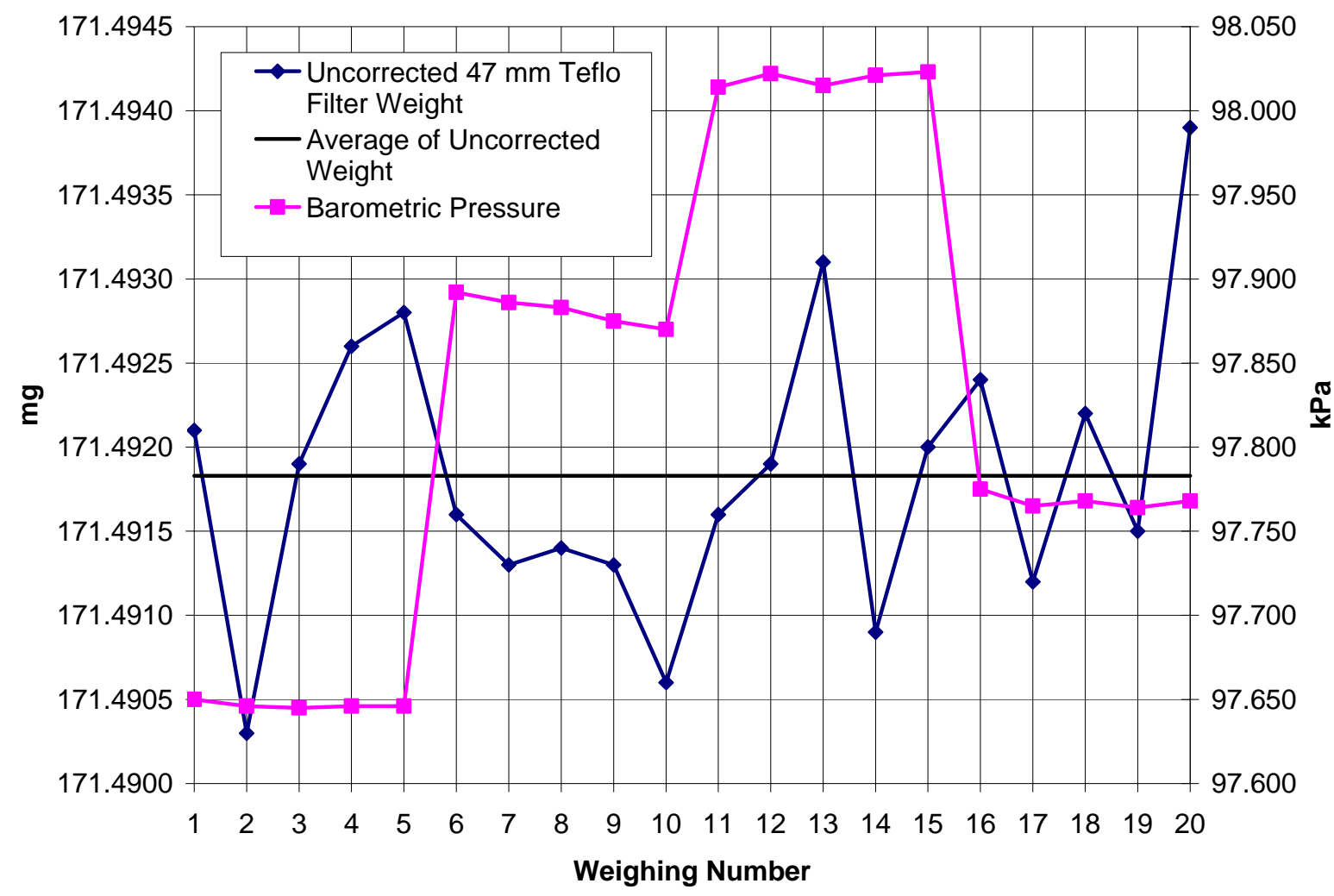

Figure 4-5: Uncorrected weight for $47 \mathrm{~mm}$ Teflo filter compared to barometric pressure

\subsubsection{Evaluation of Average Filter Weight}

The four days of weighings were evaluated to determine if an average weight should be taken. This was determined by taking the initial buoyancy corrected weight and comparing it to the average of the first two buoyancy corrected weights. Then the initial weight was compared to the average of the first three initial buoyancy corrected weights. This process was completed for all five weighings. It was found that the difference between the initial weight and the average of the five weighings nearly double the difference between the average of the first two weighings and the average of the five weighings, as shown in Table 4-8. The average of each difference is then compared to 60 $\mu \mathrm{g}$, which was the weight gain on a primary Teflo filter for a transient test at the 
Southwest Research Institute. This weight was chosen because it reflects the weight of

PM mass that will be collected after 2007 emissions standards take effect.

Table 4-8: Evaluation of average $47 \mathrm{~mm}$ T60A20 and Teflo filter weighing compared to the initial weight

\begin{tabular}{|c|c|c|c|c|c|c|}
\hline Difference Between & Day 1 & Day 2 & Day 3 & Day 4 & Average & $\%$ \\
\hline Initial weight and Average of five weighings, $(\mu \mathrm{g})$ & 1.6 & 0.8 & 1.6 & 0.5 & 1.1 & 1.87 \\
\hline Average of first 2 weighings and Average of five weighings, $(\mu \mathrm{g})$ & 0.8 & 0.5 & 0.7 & 0.4 & 0.6 & 0.95 \\
\hline Average of first 3 weighings and Average of five weighings, $(\mu \mathrm{g})$ & 0.3 & 0.3 & 0.7 & 0.3 & 0.4 & 0.69 \\
\hline Average of first 4 weighings and Average of five weighings, $(\mu \mathrm{g})$ & 0.1 & 0.2 & 0.8 & 0.3 & 0.3 & 0.58 \\
\hline
\end{tabular}

\subsubsection{Standard Deviations for Sartorius Microbalance}

The results of calculating the precision of the Sartorius microbalance are shown in Table 4-9 and Table 4-10. There are two sets of results in which one set had the tare key pressed before each weighing of the $200 \mathrm{mg}$ calibration weight, and the other set is when the zero value was recorded and the $200 \mathrm{mg}$ weight was replaced onto the weighing platform. Table 4-9 shows the precision average of each test number and then shows the average of the precision averages for the internal calibration and internal calibration and linearization. This data shows that the addition of the internal linearization to the internal calibration provides a better precision than just internal calibration alone. Table 4-10 shows that precision improves when the tare key is used between each weighing.

Table 4-9: Illustrates the precision of the microbalance when the tare key is not used

\begin{tabular}{|c|c|c|c|c|c|c|}
\hline Date & \multicolumn{3}{|c|}{ Internal Calibration } & \multicolumn{3}{c|}{ Internal Calibration \& Linearization } \\
\hline Test \# & $1(\mu \mathrm{g})$ & $2(\mu \mathrm{g})$ & $3(\mu \mathrm{g})$ & $1(\mu \mathrm{g})$ & $2(\mu \mathrm{g})$ & $3(\mu \mathrm{g})$ \\
\hline $6 / 1 / 2006$ & 0.24 & 0.26 & 0.20 & 0.20 & 0.25 & \\
\hline $6 / 2 / 2006$ & 0.44 & 0.39 & 0.17 & 0.29 & 0.13 & 0.13 \\
\hline $6 / 5 / 2006$ & 0.12 & 0.10 & 0.13 & 0.31 & 0.13 & 0.24 \\
\hline $6 / 6 / 2006$ & 0.25 & 0.24 & 0.15 & 0.38 & 0.15 & 0.13 \\
\hline Average & 0.26 & 0.25 & 0.16 & 0.30 & 0.16 & 0.17 \\
\hline Average & & 0.22 & & & 0.21 & \\
\hline
\end{tabular}

Table 4-10: Demonstrating the precision of the microbalance when the tare key is used

\begin{tabular}{|c|c|c|c|c|c|}
\hline Date & \multicolumn{3}{|c|}{ Internal Calibration } & \multicolumn{2}{c|}{ Calibration \& Linearization } \\
\hline Test \# & $1(\mu \mathrm{g})$ & $2(\mu \mathrm{g})$ & $3(\mu \mathrm{g})$ & $1(\mu \mathrm{g})$ & $2(\mu \mathrm{g})$ \\
\hline $6 / 1 / 2006$ & & & & & 0.08 \\
\hline $6 / 7 / 2006$ & 0.10 & 0.17 & 0.31 & 0.14 & 0.13 \\
\hline Average & & 0.19 & & & 0.16 \\
\hline
\end{tabular}


A percent difference is used to calculate the difference between the precision averages shown in Table 4-9 and Table 4-10. The percent difference equation is shown below as Equation 4-6 and is used to calculate Table 4-11.

$$
\text { Percent Difference }=\frac{\text { measured }_{1}-\text { measured }_{2}}{\left(\frac{\text { measured }_{1}+\text { measured }_{2}}{2}\right)} * 100 \%
$$

Equation 4-6

The determination of percent difference, shown in Table 4-11, illustrates the percent difference when the precision averages from when the tare key is not used, as shown in Table 4-9 is compared to the precision averages when the tare key is used between each weighing, as shown in Table 4-10. The largest percent difference compares the precision average when only the internal calibration is used, to the precision average of when the internal calibration and internal linearization is used along with pressing the tare key in between each weighing.

Table 4-11: Determination of percent difference by using Equation 4-6

\begin{tabular}{|l|c|c|c|}
\hline \multicolumn{1}{|c|}{ Difference Between Measurement Techniques } & $\begin{array}{c}\text { Avg. Std. } \\
\text { Dev. }(\mu \mathrm{g})\end{array}$ & $\begin{array}{c}\text { Avg. Std. } \\
\text { Dev. }(\mu \mathrm{g})\end{array}$ & \% difference \\
\hline Internal Cal. - Internal Cal. \& Lin. With Tare key used & 0.22 & 0.21 & 6.62 \\
\hline Internal Cal. \& Lin. - Internal Cal. with Tare key used & 0.21 & 0.19 & 8.33 \\
\hline Internal Cal. with Tare - Internal Cal.\& Lin. with Tare key used & 0.19 & 0.16 & 15.37 \\
\hline Internal Cal. \& Lin. - Internal Cal. \& Lin. with Tare key used & 0.21 & 0.16 & 23.63 \\
\hline Internal Cal - Internal Cal. \& Lin. with Tare key used & 0.22 & 0.16 & 30.14 \\
\hline
\end{tabular}

\subsubsection{Linearization of Sartorius Microbalance}

This linearization test had a step of $100 \mathrm{mg}$. The test was run from $100 \mathrm{mg}$ to 500 mg and then back to $100 \mathrm{mg}$. Table 4-12 illustrates the results that were obtained when the weight was placed onto the weighing platform and the microbalance was allowed to stabilize. After stabilization, the tare key was pressed and then the weight was taken off the weighing platform for five seconds and replaced onto the weighing platform. There are no 300 and $400 \mathrm{mg}$ calibration weights and therefore a combination of class U 200 
and $100 \mathrm{mg}$ weights were weighed to determine the linearity at $300 \mathrm{mg}$. A combination of class U $200 \mathrm{mg}$ and class $1200 \mathrm{mg}$ weights were weighed to determine the linearity at $400 \mathrm{mg}$. Class U calibration weights were used to determine the linearity at 100, 200, and $500 \mathrm{mg}$. As seen in this table, variations in weighing the calibration weights can be as high as $0.7 \mu \mathrm{g}$ but are typically within the $\pm 0.25 \mu \mathrm{g}$ requirement.

Table 4-12: Results obtained from linear testing of Sartorius microbalance

\begin{tabular}{|c|c|c|c|c|}
\hline Weight $(\mathrm{mg})$ & Test 1 $(\mu \mathrm{g})$ & Test 2 $(\mu \mathrm{g})$ & Test 3 $(\mu \mathrm{g})$ & Average $(\mu \mathrm{g})$ \\
\hline 100 & 0.4 & 0.1 & -0.2 & 0.2 \\
\hline 200 & 0 & -0.1 & -0.4 & 0.2 \\
\hline 300 & -0.2 & 0.1 & -0.1 & 0.1 \\
\hline 400 & -0.3 & -0.7 & 0.1 & 0.4 \\
\hline 500 & -0.2 & -0.2 & -0.2 & 0.2 \\
\hline 400 & -0.1 & -0.1 & -0.6 & 0.3 \\
\hline 300 & -0.3 & -0.2 & 0.2 & 0.2 \\
\hline 200 & 0 & 0.3 & -0.3 & 0.2 \\
\hline 100 & -0.2 & 0.2 & 0.2 & 0.2 \\
\hline
\end{tabular}

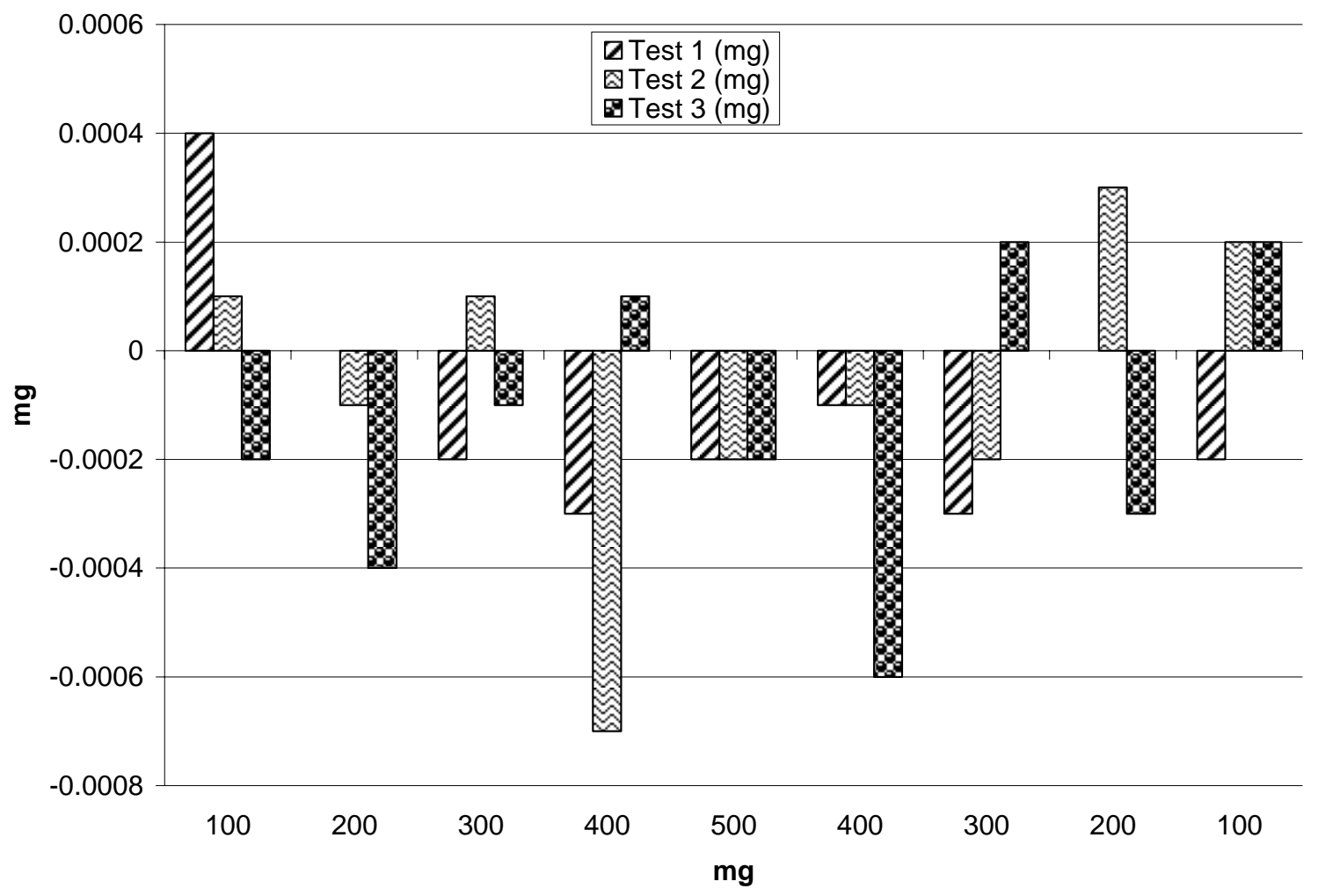

Figure 4-6: Results from running linearity test 


\subsection{Filter Comparison Results}

A study of filters was conducted to determine the difference in PM mass when using T60A20 $70 \mathrm{~mm}$ and $47 \mathrm{~mm}$ filters, and Teflo $47 \mathrm{~mm}$ filters. This study used the reduced data to determine the PM mass emitted by a 1992 Detroit Diesel DDC Series S60, as calculated in 40 CFR 86, Subpart N.

Figure 4-7 illustrates the results of the comparison of the calculated PM for dual $70 \mathrm{~mm}$ T60A20 filter and single $47 \mathrm{~mm}$ Teflo filters. The figure demonstrates that the overall trend is the same between each filter. However, tests 1 and 7 had the largest and smallest differences in calculated PM between the $47 \mathrm{~mm}$ Teflo and dual $70 \mathrm{~mm}$ filters, 0.330 and $0.149 \mathrm{~g} /$ testphase, respectively. The average difference for the calculated PM is $4.9 \%$, which equates to $0.259 \mathrm{~g} /$ testphase.

The $47 \mathrm{~mm}$ filter is collecting less PM than the $70 \mathrm{~mm}$ filter. This could be due to the organic vapor deposition onto the $70 \mathrm{~mm}$ filters and calibration errors. A study by Chase et al. found that OV accounts for $10-20 \%$ of the total PM measurement for the Teflo filters and $30-50 \%$ for the TX40 filter [24]. The TX40 filter is very similar to the T60A20 filter in that they both are made of Borosilicate glass and contains PTFE [60]. Calibration errors could have an effect on the outcome of this as well in which only one flow rate was chosen throughout the study. Different flow rates could have possibly matched the data, from the $70 \mathrm{~mm}$ T60A20 filters to the $47 \mathrm{~mm}$ filters, better. This difference in PM collection could also be a result of a backup filter not being used. The average difference between the PM collected on the $70 \mathrm{~mm}$ filters and the $47 \mathrm{~mm}$ Teflo filters is $4.9 \%$. The lower amount of calculated PM could be attributed to the filter 
handling could of the first filter since this was the first time this type of filter and filter holder were used.

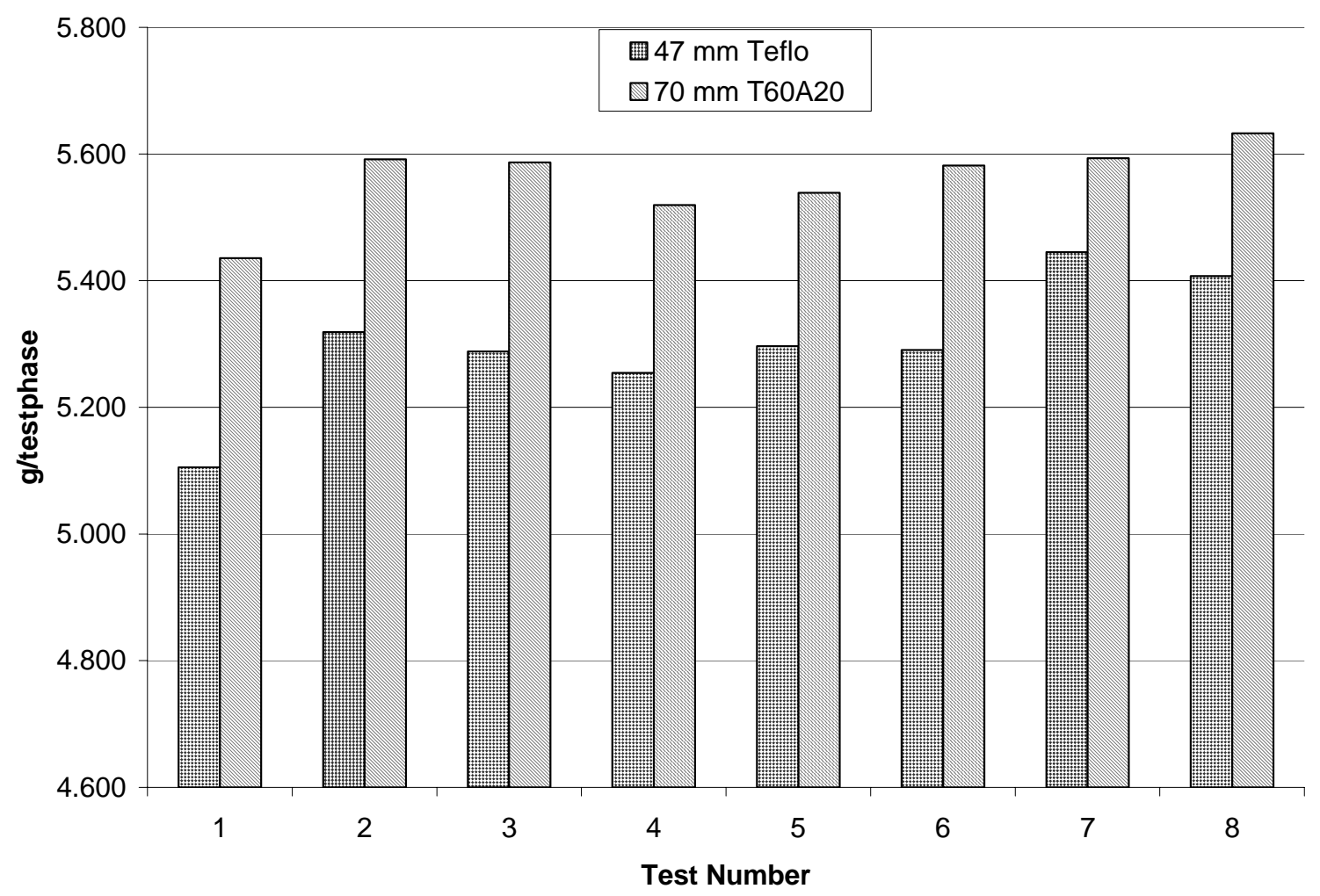

Figure 4-7: Results when a single $47 \mathrm{~mm}$ Teflo filters are compared with dual $70 \mathrm{~mm}$ T60A20 filters

Figure 4-8 illustrates the results of the comparison of the calculated PM for dual $70 \mathrm{~mm}$ T60A20 filter and single $47 \mathrm{~mm}$ T60A20 filters. The overall trend is the same between each filter, except for Test Number 6 in Figure 4-8, where there is a $10 \%$ difference, which equates to $0.525 \mathrm{~g} /$ testphase, in weights. This value is the largest difference. The smallest difference is 0.068 and the average is $0.205 \mathrm{~g} /$ testphase. The average without the $0.525 \mathrm{~g} /$ testphase value was determined to be $0.159 \mathrm{~g} /$ testphase. The second largest value was $0.280 \mathrm{~g} /$ testphase, which is $47 \%$ less than the largest value.

The $47 \mathrm{~mm}$ filter is collecting less PM than the $70 \mathrm{~mm}$ filter. This could be due to the absence of a backup filter. The backup filter will accumulate more OV than PM because the primary filter efficiency increase with time as it collects more PM. However, 
the $47 \mathrm{~mm}$ filter was a single filter and therefore will not collect as much PM initially since there is no backup filter to collect PM. This lack of backup filter for the $47 \mathrm{~mm}$ setup does not allow as much absorption of OV. The average difference between the PM collected on the $70 \mathrm{~mm}$ filters and the $47 \mathrm{~mm}$ T60A20 filters is $3.9 \%$, which equates to $0.205 \mathrm{~g} /$ testphase. This value is a smaller difference than found in the comparison of single $47 \mathrm{~mm}$ Teflo filters to dual $70 \mathrm{~mm}$ T60A20 filters. However, this is higher due to test number 6 shown in Figure 4-8, where this test had a difference of 10.7\%. The average difference is $2.9 \%$ if test number 6 is not included in this average.

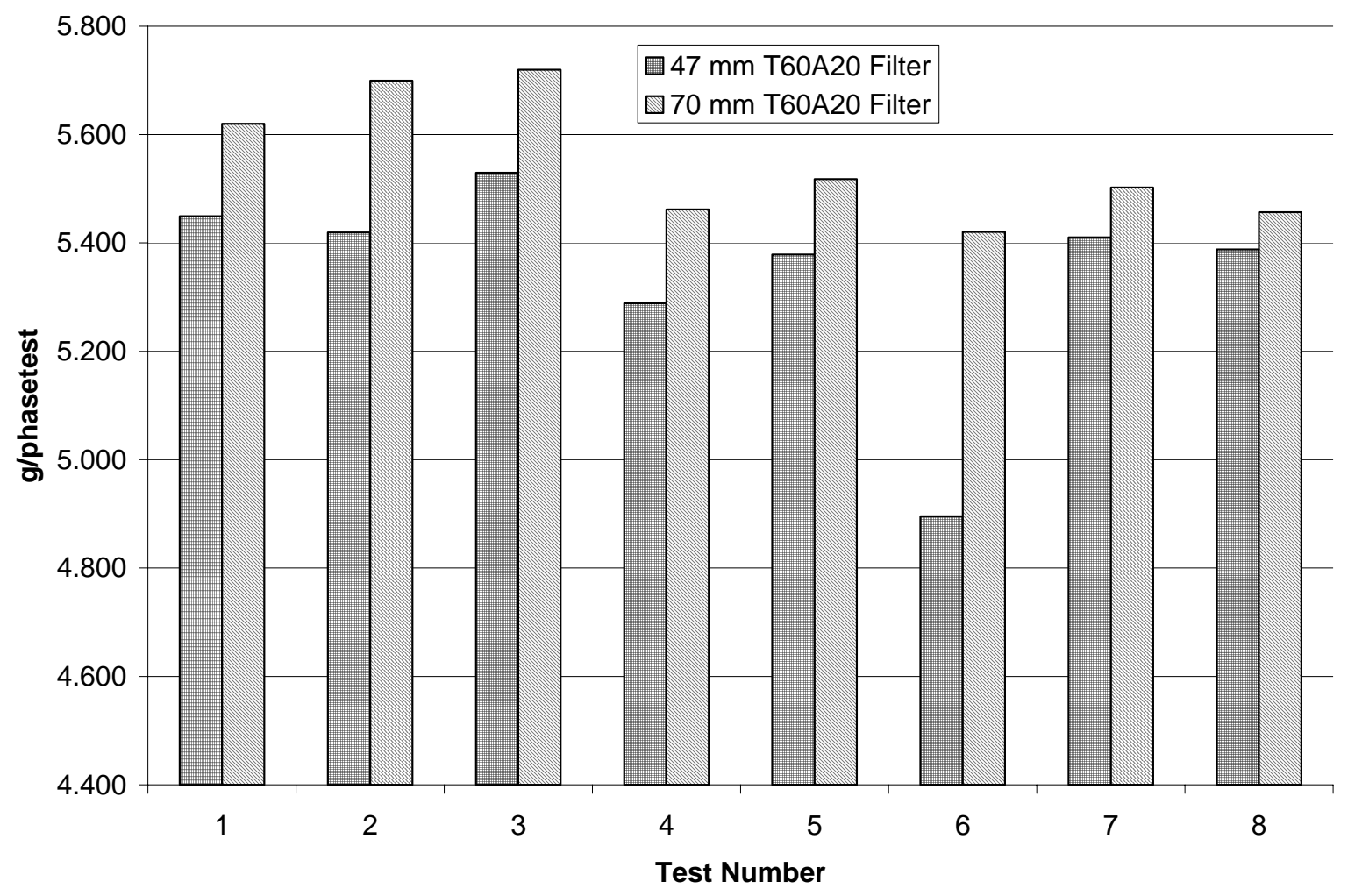

Figure 4-8: Comparison of results from single $47 \mathrm{~mm}$ and dual $70 \mathrm{~mm}$ T60A20 


\section{CONCLUSIONS AND RECOMMENDATIONS}

\subsection{Cleanroom Cleaning Procedures}

The cleaning procedures are listed in section 4.2. These procedures were taken from ISO 14644 and the TourAndoverControls manual. The cleaning procedures that are outlined in section 4.2 are more stringent than the EPA cleanroom cleaning procedures. The WVU CAFEE cleaning procedures were adopted in an effort to minimize dust and to maintain the cleanliness requirements of the cleanroom. These procedures are based on the amount of activity in the cleanroom and the cleanroom classification.

\subsection{Determination of Weighing Procedures}

The addition of the internal linearization to the procedures did improve (reduce) the standard deviation slightly and therefore it was chosen to be implemented in the weighing procedures. The recommended procedure would be to include pressing the tare key in between each weighing of a filter. This proved to be the best precision, however this would increase the amount of time, approximately a minute a filter, taken to weigh filters and its standard deviation difference is small, $\pm 0.03 \mu \mathrm{g}$, when compared to the net mass of PM collected on a filter.

It was also found that weighing the filters twice in the same weighing session and taking the average would be a good practice, as shown in Table 4-8. Taking the average of five weighings would yield higher precision results, however five weighings would significantly increase the time and cost needed to weigh filters. This illustrated a difference of $0.6 \mu \mathrm{g}$ from the average attained from five filters. The difference from the 
first filter and average of five weighings was found to be $1.1 \mu \mathrm{g}$. Therefore, weighing the filter twice and taking the average, could reduce the variability to nearly half of only using the initial weighing. Taking an average of two filter weights could also be used to verify that a filter has been properly weighed and that the filter was statically neutral. Table 4-7 illustrates the effect of one weighing affecting the results in which one weighing produced a result where the difference between the maximum and minimum was $11 \mu \mathrm{g}$. This large amount of variation would greatly affect the results if weights of $60 \mu \mathrm{g}$ were considered. The difference in maximum and minimum would be $3.3 \mu \mathrm{g}$ without this one large difference in maximum and minimum weight.

\subsection{Buoyancy Correction}

The buoyancy correction appears to fluctuate with the weight in most cases as demonstrated in Figure 4-3, Figure 4-4, and Figure 4-5. The barometric pressure does have a small effect on the weight of the filter, which can be seen in Figure 4-2. The buoyancy correction does not appear to smooth the fluctuations in filter weights taken in different barometric pressure conditions, as shown in Figure 4-3, Figure 4-4 and Figure 4-5. The correction did not minimize variations of the maximum and minimum filter weights in ten of the twenty filter weights that are illustrated in Table 4-7. It was found through error propagation that the filter density is the largest contributor to error for the buoyancy correction. All values listed in Table 4-7 would fall into the $\pm 26.4 \mu \mathrm{g}$ error range determined by the buoyancy correction error propagation analysis. However, the values listed in Table 4-7 for the uncorrected weights have nearly the same minimum and maximum differences as the buoyancy corrected values and therefore the buoyancy correction cannot be held entirely accountable for the large differences. In five cases it 
was found that the buoyancy correction increased this difference and therefore the filter density error could be increasing the minimum and maximum difference, through the buoyancy correction calculation, when compared to the minimum and maximum difference of the uncorrected filter weights.

\subsection{Filter Comparison}

The results obtained from the filter comparison show that neither single Teflo or T60A20 $47 \mathrm{~mm}$ filters will obtain the same results as the primary and backup $70 \mathrm{~mm}$ filter set, as shown in Figure 4-7 and Figure 4-8. As previously mentioned, the most probable cause is that neither had a backup filter, as the backup filter will often collect OV and will therefore increase the weight of collected PM. Various errors could have also affected the results, such as calibration, filter handling, and weighing errors. It was found that the $47 \mathrm{~mm}$ T60A20 had a smaller average difference in weight with dual 70 $\mathrm{mm}$ T60A20 filters, $0.205 \mathrm{~g}$ /testphase, when compared to the $47 \mathrm{~mm}$ Teflo average difference with dual $70 \mathrm{~mm}$ T60A20 filters, $0.259 \mathrm{~g} /$ testphase. This could be attributed to the collection of OV by different filter media types, in which the T60A20 filter media is thought to collect a larger amount of OV.

It would be recommended to study the effect of using a backup filter for the 47 mm T60A20 and Teflo. A study should be conducted to determine whether the $47 \mathrm{~mm}$ and 70mm T60A20 would collect a similar amount PM when a background filter is used since they are made of the same filter media. It would be expected for the Teflo filter to not collect as much PM as the T60A20 filter even though a backup filter is used due to previous findings demonstrating that the Teflo filter media does not adsorb as much OV as the T60A20 filter media. The 2007 dilution tunnel should be compared to the pre- 
2007 dilution tunnel and determine the variability with the move to a new dilution tunnel due to the changes in the secondary dilution tunnel for the 2007 dilution tunnel. 


\section{REFERENCES}

1. Lies, K. H., Postulka, A., and Gring, H., "Particulate Emissions from Diesel Engines - Evaluation of Measurement and Results," Warrendale, PA, SAE Paper No. 830455, 1983

2. Lev-On, M., LeTavec, C., Ulhlein, J., Kimura, K., Gautam, M., Thompson, G. J., Wayne, W. S., Clark, N., Okamoto, R., Rieger, P., Yee, G., Zielinska, B., Sagebiel, J., Chatterjee, S., and Hallstrom, K., "Speciation of Organic Compounds from the Exhaust of Trucks and Buses: Effect of Fuel and After-Treatment on Vehicle Emission Profiles," Warrendale, PA, SAE Paper No. 2002-01-2873, 2002

3. "California Diesel Risk Reduction Program," DieselNet, Ecopoint Inc., Brampton, ON, Canada, $2004<\mathrm{http}: / /$ www.dieselnet.com/standards/us/ca_diesel.php\#intro>

4. Montajir, R. M., Kusaka, T., Bamba, Y., and Adachi, M., "A New Concept for RealTime Measurement of Particulate Matter (Soot and SOF)," Warrendale, PA, SAE Paper No. 2005-01-3605, 2005

5. Wick, C., "Diesel Retrofit Technology," EPA Office of Transportation and Air Quality, $2006<\mathrm{http}: / /$ www.epa.gov/cleandiesel/documents/420s06002.pdf $>$

6. Lindhjem, C. and Jackson. T., "Update of Heavy Duty Emission Levels (Model Years 1998-2004+) for Use in MOBILE6," U.S. EPA Office of Mobile Sources, Assesment and Modeling Division, 2002 $<$ http://www.epa.gov/otaq/models/mobile6/r02018.pdf>

7. Code of Federal Regulations, Title 40, Office of the Federal Register National Archives and Records Administration, Washington, DC, 2004

8. HEI Program Summary, "Research on Diesel Exhaust and Other Particles," Health Effects Institute, Charleston Navy Shipyard, Boston, MA, 2003

9. Foster, D. E., Stetter, J. C., and Schauer, J. J., "Modern Diesel Particulate Matter Measurements and the Application of Lessons Learned to 2007 Levels and Beyond," Warrendale, PA, SAE Paper No. 2005-01-0194, 2005

10. Majewski, A., "Diesel Particulate Matter," DieselNet, Ecopoint Inc., Brampton, ON, Canada, $2002<\mathrm{http}: / /$ www.dieselnet.com/tech/dpm.html $>$

11. McMillian, M., Cui, M., Gautam, M., Keane, M., Ong, T., Wallace, W., and Robey, E., "Mutagenic Potential of Particulate Matter from Diesel Engine operation on Fischer-Tropsch Fuel as a Function of Engine Operating Conditions and Particle Size,” Warrendale, PA, SAE Paper No. 2002-01-1699, 2002 
12. Kittelson, D. B., "Engines and Nanoparticles: A Review," Journal Aerosol Science. 5/6 (29), pg. 575-588, 1998

13. Saegusa, S. and Senda, F., "Preliminary Evaluation of Health Effects of Diesel Exhaust Particles with Future Automobile and Fuel Technologies - JCAP Health Effects Working Group Report,“ Warrendale, PA, SAE Paper No. 2003-01-1906, 2003

14. Walsh, M. P., "Global Trends in Diesel Emissions Regulation - A 2001 Update," Warrendale, PA, SAE Paper No. 2001-01-0183, 2001

15. Majewski, W. A., and Burtscher, H., "PM Measurement: Collecting Methods," DieselNet, Ecopoint Inc., Brampton, ON, Canada, 2004.

$<$ http://www.dieselnet.com/tech/measure_pm_col.html $>$

16. Vogt, R., Chase, R. E., and Maricq, M., “Technical Difficulties with PM Measurement at Euro V Level," Research and Advanced Engineering Ford Motor Company, Dearborn, MI, 2003

$<$ http://ies.jrc.cec.eu.int/Units/eh/events/EURO5/PROCEEDINGS/Session\%20I\%20 Presentations/Session\%20I\%20-\%20D1\%20M/2EURO\%20V\%20ISPRA\%2028112003-Vogt.pdf>

17. Waldenmaier, D. A., Gratz, L. D., Bagley, S. T., Johnson, J. H., and Leddy, D. G., "The Influence of Sampling Conditions on the Repeatability of Diesel Particulate and Vapor Phase Hydrocarbon and PAH Measurements," Warrendale, PA, SAE Paper No. 900642,1990

18. De Lucas, A., Duran, A., Carmona, M., and Lapuerta, M., "Characterization of Soluble Organic Fraction in DPM Optimization of the extraction Met," Warrendale, PA, SAE Paper No. 1999-01-3532, 1999

19. Tan, P., Deng, K., and Lu, J., "Analysis of Particulate Matter Composition From A Heavy-Duty Diesel Engine,” Automobile Engineering, 218, pg. 1325-1331, 2004

20. ASTM International, "Standard Test Method for Determination of Mass Concentration of Particulate Matter from Stationary Sources at Low Concentrations (Manual Gravimetric Method), West Conshohocken, PA, Paper No. D6331-98, 2005

21. Khalek, I. A., Stewart, D. W., and Ullman, T. L., "2007 Diesel Particle Measurement Research," Southwest Research Institute, San Antonio, Texas, 2005

22. Zervas, E., Dorlene, P., Forti, L., Perrin, C., Momique, J.C., Monier, R., Pingal, D., and Lopez, B., "Development of an Improved Gravimetric Method for the Mass Measurement of Diesel Exhaust Gas Particles," Warrendale, PA, SAE Paper No. 2005-01-2145, 2005 
23. Akard, M., Oestergaard, K., Chase, R., Richert, J. F. O., Adachi, M., and Fukushima, H., "Comparison of an Alternative Particualte Mass Measurement with Advanced Microbalance Analysis," Warrendale, PA, SAE Paper No. 2004-01-0589, 2004

24. Chase, R. E., Duszkiewcz, G. J., Richert, J. F. O., Lewis, D., Maricq, M. M., and Xu, N., "PM Measurement Artifact: Organic Vapor Deposition on Different Filter Media,” Warrendale, PA, SAE Paper No. 2004-01-0967, 2004

25. Allen, R., Box, M., Lee-Jane, S., and Larson, T. V., "A Cost Effective Weighing Chamber for Particulate Matter Filters," Journal of the Air \& Waste Management Association, Volume 51, Pages 1650-1653, 2001

26. Steinman, A., "Static Charge: It's a Killer," Semiconductor International, Volume 17, No. 10, Pages 73-76, 1994

27. Hanninen, O. O., Koistinen, K. J., Kousa, A., Keski-Karhu, J., and Jantunen, M. J., "Quantitative Analysis of Environmental Factors in Differential Weighing of Blank Teflon Filters," Journal of the Air \& Waste Management Association, Volume 52, Pages 134-139, February 2002

28. Chase, R. E., Duszkiewicz, G. J., Lewis, D., and Podsiadlik, D. H., "Reducing PM Measurement Variability by Controlling Static Charge," Warrendale, PA, SAE Paper No. 2005-01-0193, 2005

29. Andersson, J. D., Clarke, D. P., and Watson. J. A., "UK Particulate Measurement Programme: A Near US 2007 Approach to Heavy Duty Diesel Particulate Measurements -Comparison with the Standard European Method," Warrendale, PA, SAE Paper No. 2004-01-1990, 2004

30. Clark, N., Gautam, M., Xu, S., and Wayne, W. S., "Comparison of Heavy-Duty Truck Diesel Particulate Matter Measurement: TEOM and Traditional Filter," Warrendale, PA, SAE Paper No. 2005-01-2153, 2005

31. Dionnet, B., Daviau, R., Dorlhene, P., and Zervas, E., "Repeatability of Fine Particle Measurement of Diesel and Gasoline Vehicles Exhaust Gas," Warrendale, PA, SAE Paper No. 2004-01-1983, 2004

32. Kim, D., Gautam, M., and Gera, D., "Effect of Ambient Dilution on Coagulation of Particulate Matter in a Turbulent Dispersing Plume," Warrendale, PA, SAE Paper No. 2002-01-0652, 2002

33. Gautam, M., Clark, N. N., Metha, S., Boyce, J., Rogers, F., and Gertler, A., "Concentrations and Size Distributions of Particulate Matter Emissions from a Class8 Heavy-duty Diesel Truck Tested in a Wind Tunnel," Warrendale, PA, SAE Paper No. 2003-01-1894, 2003 
34. Lieberman, A., "Particulate Contamination Control Specifications and Procedures to Implement Parenteral Fluids Preparation," Measurement Science Conference: Pasadena Convention Center, Pasadena, California, January 23 and 24, 1997

35. Mielke, R. L., "Common Misconceptions About The Differences between ISO 14644-1 and -2 and Fed-Std 209E- What You Don't Know Could Cost You," IEST, Mount Prospect, IL, 2002

36. Lieberman, A., "Airborne Particulate Cleanliness Classification Via ISO 14644-1 and FED-STD 209E," Contamination Control: the ICCCS 14th International Symposium on Contamination Control: the Symposium on Cleanrooms for the Healthcare Industry, pgs 548-555, ISSN 00739227, 1998

37. Federal Standard 209E, "Airborne Particulate Cleanliness Classes in Cleanrooms and Clean Zones," Institute of Environmental Sciences and Technology, Mount Prospect, IL, 1992

38. ISO 14644-1, "Cleanrooms and Associated Environments - Classification of Air Cleanliness," International Organization for Standardization, Geneve, Switzerland, 1999

39. ISO 14644-2, "Cleanrooms and Associated Environments -Specifications for Testing and Monitoring to Prove Continued Compliance with ISO 14644-1," International Organization for Standardization, Geneve, Switzerland, 2000

40. ISO 14644-3, "Cleanrooms and Associated Environments - Test Methods," International Organization for Standardization, Geneve, Switzerland, 2005

41. ISO 14644-4, "Cleanrooms and Associated Environments - Design, Construction and Startup,” International Organization for Standardization, Geneve, Switzerland, 2001

42. ISO 14644-5, "Cleanrooms and Associated Environments - Operations," International Organization for Standardization, Geneve, Switzerland, 2004

43. EPA National Vehicle and Fuel Emissions Laboratory, "Particulate Filter Weighing," Ann Arbor, MI, 2006 $<$ http://www.epa.gov/OMSWWW/emisslab/testproc/714d.pdf>

44. Operating Instructions, "Mettler Toledo MT/UMT Operating Instructions," MettlerToledo GmbH, Greifensee, Switzerland, 1999

45. EPA National Vehicle and Fuel Emissions Laboratory, "Particulate Mass Filter Setup and Transport Procedure," Ann Arbor, MI, 2006

$<$ http://www.epa.gov/otaq/emisslab/testproc/608.pdf $>$

46. Procedures CAFEE Emissions Laboratory Standard Procedures, Calibration Procedures and Scheduled Maintenance Checks, "PM Filter Handling and Weighing," West Virginia University, Morgantown, WV, 2005 
47. Berli, U. and Bonzli, M., "Electronic Weighing Principles," Mettler Toledo AG, Griefensee, Switzerland, 1991

48. Operation \& Maintenance Manual "Lab Dressing Procedure," TourAndoverControls, Lebanon, OH, 2005

49. WeighAhead 8, "Emissions Testing of Diesel Fuels," Sartorius, Goettingen, Germany, Issue 8, pg 16, 2004

50. List of Tolerances for Testing Metrological Specifications Supplement, Sartorius, Goettingen, Germany, 2004

51. Weighing the Right Way with Mettler Toledo, "The Proper Way to Work With Electronic Analytical and Microbalances," Mettler-Toledo GmbH, Greifensee, Switzerland, 2001

52. Air Buoyancy Correction During High Precision Filter Weighing, "Maximum Accuracy for Particulates Emissions by Diesel Powered Vehicles," Sartorius Corporation, Edgewood, NY, 2004

53. Velosa, J., "Error Analysis of the Vehicle Exhaust Emission Measurement System," Warrendale, PA, SAE Paper No. 930393, 1993

54. Cunningham, P. and Meckl, P., "Measuring Particulate Load in a Diesel Particulate Filter," Warrendale, PA, SAE Paper No. 2006-01-0868, 2006

55. Model 200 Dewtrack, Humidity Transmitter Operator Manual, EdgeOne LLC, Marlborough, MA, $2003<$ www.edgetech.com $>$

56. RPT Digital Output Pressure Transducer User Manual K177, Druck Limited, Leicester, England, Druck Publications Department, 1998

57. Calibration Certificate, Deban Enterprises, Beavercreek, OH, 2005 $<$ www.deban.com $>$

58. Operating Instructions ME and SE Series, Sartorius AG, Goettingen, Germany, 2005, $<$ www.sartorius.com>

59. Mary Burwell, Whatman Incorporated, Florham Park, NJ, 2006

60. Pallflex Filter Specifications, Pall Corporation, East Hills, NY, 2002 $<$ www.pall.com $>$ 


\section{APPENDIX A}

\section{TPM Filter Weighing - 2007 and Later Model Year Engines (SOP- 0270-A)}

\section{Overview}

A precision microbalance, with readability of $0.1 \mu \mathrm{g}$ and a precision of $0.25 \mu \mathrm{g}$, is used to measure filter weights. Environment, calibration and weighing information is recorded by software on the cleanroom computer. Many precautions need to be taken to prevent contamination of sample filters due to the small mass of collected PM.

\section{References}

40 CFR Parts 86.1312-2007

\section{Conditions}

Ensure that the conditions of the weighing and storage area are within the following specifications.

- Each filter must be placed in a partially open Petri dish and exposed to the conditioning environment for a minimum of 30 minutes prior to pre or post test weighing.

- Filters must be stored in covered Petri dishes or sealed filter holders in the conditioned storage area when not being pre or post test conditioned.

- Used filter pairs being conditioned for post use must be stored face-to-face in covered Petri dishes. Otherwise, single filters must be stored face up.

- If the sample on the filters contacts the Petri dish or any other surface, the associated test is void and must be re-run.

- At least two unused reference filters must be stored next to the microbalance at any given time. If the average weight of the reference filter pairs changes between sample filter weighings by more than $10 \mu \mathrm{g}$, then all the associated sample and background filters being stabilized are void and their respective emissions tests must be re-run.

- A filter post weight must be determined within 60 hours of the start of the stabilization period.

- Test filters must be weighed within 2 hours of reference filters but preferably during the same session.

- The reference filters should be changed once a month. A minimum of two reference filters must be associated with a test filter pre and post weight.

- The zero/tare drift of the scale must not exceed $\pm 1 \mu \mathrm{g}$ during any drift check. The zero/tare drift must be checked after weighing for 10 minutes and at the conclusion of a weighing session.

The filter weighing room must be maintained at the following conditions

- Temperature: $22^{\circ} \pm 1{ }^{\circ} \mathrm{C}$ 
- Dew Point: $9.5^{\circ} \pm 1^{\circ} \mathrm{C}$

where the temperature and dew point are averaged over 5 minutes intervals. If these conditions are not met the room conditions must be brought to within the above specifications and allowed to remain in that state for 30 minutes prior to performing filter weighing operations. If the room exceeds the environmental specifications, then the filters will be required to condition in the room for 30 minutes after the environmental conditions have been corrected.

\section{Procedures}

1. Ensure that balance is level.

2. Place the anti-static wristband on your wrist to minimize static charge buildup on filters.

3. Start the filter weighing software.

4. Log on to begin the weighing session.

5. Observe any discrepancies in the room conditions from those listed above. If problems exist, contact the laboratory supervisor.

6. Follow the weighing program prompts through the initial calibration and reference filter weighing steps.

a. Complete the onscreen instructions to complete the internal calibration and internal linearization functions.

b. The program will check that the zero/tare reading is within $\pm 1 \mu \mathrm{g}$. The program will record the zero/tare reading from the scale and will re-zero the scale if required and record the new zero value.

c. Place the reference weight onto the weighing pan and record the reading. The program will ensure that the weight will be within $\pm 1 \mu \mathrm{g}$. The program will not allow the weighing process to progress if the reference weight is out of the previous specification.

d. Remove the reference weight and allow the program to check that the zero/tare reading is $\pm 1 \mu \mathrm{g}$. The user will need to complete steps 6 to 7 if the zero/tare reading exceeds specifications. Contact a laboratory supervisor if, after a third attempt, the zero cannot meet the specifications.

e. Pass each side of the reference filter over the Polonium spot before placing the reference filter onto the weighing pan.

f. Measure and record the weight of the reference filter.

g. Continue to measure additional reference filter, ensure step 6e is followed for each filter.

h. After 10 minutes or at the completion of the reference filter weighing, the program will check that the zero/tare reading is within $\pm 1 \mu \mathrm{g}$. The program will record the zero/tare reading from the scale and will re-zero the scale if required and record the new zero value. If the zero/tare is outside the allowable range, the reference filters weighed between the last valid zero/tare check and invalid zero/tare check will be re-weighed.

7. Follow the weighing program prompts through the test filter weighing steps.

a. For post-test filter weighing, the program will check that the difference in the average change in weight of the reference filters is less than $10 \mu \mathrm{g}$ 
between the pre and post test weighing sessions. If the average change is greater than $10 \mu \mathrm{g}$ then all tests associated with those reference filters are invalid and must be re-run.

b. Pass each side of the sample filter over the Polonium spot before placing the sample filter onto the weighing pan.

c. Measure and record the weight of each sample filter.

d. Continue to measure additional test filter, insure step $7 \mathrm{~b}$ is followed for each filter.

e. After 10 minutes or at the completion of the filter weighing, the program will check that the zero/tare reading is within $\pm 1 \mu \mathrm{g}$. The program will record the zero/tare reading from the scale and will re-zero the scale if required and record the new zero value. If the zero/tare is outside the allowable range, the filters weighed between the last valid zero/tare check and invalid zero/tare check will be re-weighed.

f. All filters will be reweighed to determine an average of the filter weight, in which the program will ensure that the filter weight is within $\pm 2.5 \mu \mathrm{g}$, A third weighing will be taken if the program finds that the filter is outside the $\pm 2.5 \mu \mathrm{g}$.

\section{Corrective Actions}

If the room conditions are not met, wait until the room conditions are within specifications. If the scale is unable to meet the zero, spans, or reference filter requirements, ensure that the room conditions are stable. If problems persist, contact the laboratory supervisor. 


\section{APPENDIX B}

\section{WVU CAFEE Cleanroom Cleaning Procedures (SOP-0271)}

\section{Schedule}

To be completed in between weighing periods, as close to once a month as possible

\section{$\underline{\text { Overview }}$}

A precision microbalance, with readability of $0.1 \mu \mathrm{g}$ and a precision of $0.25 \mu \mathrm{g}$, is used to measure filter weights. Many precautions need to be taken to prevent contamination of sample filters due to the small mass of collected PM. Therefore, cleaning procedures must be maintained to ensure that particles are minimized and class 1000 status can be maintained. The frequency of cleaning is determined by the amount of activity in a cleanroom and the classification of the cleanroom. The cleaning method is to work from top to bottom. The ceiling panels are removed to wipe the upper side of the panels and panel tracks to ensure that no dust is being pushed into the room.

\section{References}

FED-STD 209E, ISO 14644-5, TourAndoverControls, and EPA Cleanroom

\section{Materials}

Certain materials are needed to clean the cleanroom thoroughly and to access the ceiling panels. It is preferred that two people are able to clean the cleanroom as this allows the ceiling panels to be removed, cleaned and replaced more carefully and with much more ease.

- Step Ladder, or Stool

- Isopropyl/Water saturated cleanroom wipes

- Tacky Roller

\section{Procedures}

1. Ensure that any stepladder or stool taken into the cleanroom is thoroughly wiped from top to bottom with Isopropyl/Water saturated cleanroom wipes before taken into the cleanroom

2. Place booties over shoes to minimize the introduction of particles into the cleanroom

3. Cover all Petri Dishes when accessing cleanroom to minimize particles being introduced to filter and interior of petri dish

4. Clean the ceiling panels

- Be careful when removing ceiling panels, as the edges are sharp and can cut skin and can scratch the wall surface, while the ceiling panel over the door to access the cleanroom might have objects resting on the ceiling panel 
- Do not allow ceiling panels to touch the floor since the floor has not been cleaned

- Use one Isopropyl/Water saturated cleanroom wipe to clean upper side of panel, and use one Isopropyl/Water saturated cleanroom wipe to wipe the bottom

- Wipe ceiling panel tracks

- Be careful when replacing ceiling panels as the edges are sharp and can cut skin and can scratch the wall surface

- Complete cleaning of all ceiling panels that can be removed

- The ceiling panels that can not be removed should have the underside cleaned with one Isopropyl/Water saturated cleanroom wipe per panel

5. Wipe the walls from the ceiling to the floor with overlapping strokes,

- Replace Isopropyl/Water saturated cleanroom wipe when needed to ensure that the wipes are not spreading particles

- Wipe horizontal surface as working from ceiling to floor before proceeding towards the floor

a. Wipe wire shelves and posts as much as possible, without moving all petri dishes and items on the shelves

b. Wipe out pass through and horizontal and vertical surfaces of pass through

c. Wipe chairs from top to bottom

d. Wipe marble tables from top to bottom, use tacky roller to remove loose particles on marble table top, where keyboard is placed

6. Use tacky roller on the floor to remove any large particles

7. Wipe floor with Isopropyl/Water saturated cleanroom wipes

- Be sure to clean behind the computer and in among the wires directly beneath balances

- Be sure to clean base of air returns

- Be sure to clean underneath the static dissipative chair mat

8. Use tacky roller another time to ensure that loose particles are removed from the floor

9. Remove top tacky mat before leaving the cleanroom

10. Return an hour later to remove lids to Petri dishes

\section{Corrective Actions}

Contact the laboratory supervisor if cleaning supplies and/or tacky mats are needed. 


\section{APPENDIX C}

\section{WVU CAFEE Gowning Room Cleaning Procedures (SOP-0272)}

\section{Schedule}

To be completed once a month

\section{Overview}

A precision microbalance, with readability of $0.1 \mu \mathrm{g}$ and a precision of $0.25 \mu \mathrm{g}$, is used to measure filter weights. Precautions need to be taken to prevent contamination of sample filters due to the small mass of collected PM. Therefore, cleaning procedures must be maintained to ensure that particles are minimized and class 1000 status can be maintained. The frequency of cleaning is determined by the amount of activity in a cleanroom and the classification of the cleanroom. The cleaning method is to work from top to bottom. The ceiling panels are removed to wipe the upper side of the panels and panel tracks to ensure that no dust is being pushed into the room. The gowning room has to be kept as clean as possible to minimize the particles being introduced to cleanroom.

\section{References}

FED-STD 209E, ISO 14644-5, TourAndoverControls, and EPA Cleanroom

\section{Materials}

Certain materials are needed to clean the gowning room thoroughly and to access the ceiling panels. It is preferred that two people are able to clean the gowning room as this allows the ceiling panels to be removed, cleaned and replaced more carefully and with much more ease.

- Step Ladder, or Stool

- Isopropyl/Water saturated cleanroom wipes

- Tacky Roller

\section{Procedures}

1. Place booties over shoes to minimize the introduction of particles into the cleanroom

2. Thoroughly wipe the stepladder or stool from top to bottom with Isopropyl/Water saturated cleanroom wipes before being used in the gowning room

3. Clean the ceiling panels, starting near the entrance to the cleanroom and working towards the entrance to the gowning room

4. Be careful when removing ceiling panels, as the edges are sharp and can cut skin and can scratch the wall surface

5. Do not allow ceiling panels to touch the floor since the floor has not been cleaned

6. Use one Isopropyl/Water saturated cleanroom wipe to clean upper side of panel, and use one Isopropyl/Water saturated cleanroom wipe to wipe the bottom 
- Wipe ceiling panel tracks

- Be careful when replacing ceiling panels as the edges are sharp and can cut skin and can scratch the wall surface

- Complete cleaning of all ceiling panels that can be removed

- The ceiling panels that can not be removed should have the underside cleaned with one Isopropyl/Water saturated cleanroom wipe per panel

7. Wipe the walls from the ceiling to the floor with overlapping strokes, starting closest to the entrance to the cleanroom and work towards the entrance to the gowning room

- Replace Isopropyl/Water saturated cleanroom wipe when needed to ensure that the wipes are not spreading particles

- Wipe horizontal surface as working from ceiling to floor before proceeding towards the floor

a. Wipe wire shelves and posts as much as possible, without moving all items on the shelves

b. Wipe out pass through and horizontal and vertical surfaces of pass through

8. Use tacky roller on the floor to remove any large particles

9. Wipe floor with Isopropyl/Water saturated cleanroom wipes, working from cleanroom entrance toward gowning room entrance

- Be sure to clean base of air returns

- Be sure to clean underneath gowning bench

10. Use tacky roller another time to ensure that loose particles are removed from the floor

11. Remove top tacky mats before leaving the gowning room

\section{Corrective Actions}

Contact the laboratory supervisor if cleaning supplies and/or tacky mats are needed. 


\section{APPENDIX D}

\section{WVU CAFEE Cleanroom and Gowning Room Cleaning Procedures (SOP-0273)}

\section{Schedule}

To be completed weekly, or as conditions dictate.

\section{Overview}

A precision microbalance, with readability of $0.1 \mu \mathrm{g}$ and a precision of $0.25 \mu \mathrm{g}$, is used to measure filter weights. Precautions need to be taken to prevent contamination of sample filters due to the small mass of collected PM. Therefore, cleaning procedures must be maintained to ensure that particles are minimized and class 1000 status can be maintained. The frequency of cleaning is determined by the amount of activity in a cleanroom and the classification of the cleanroom. The cleaning method is to work from top to bottom. The gowning room has to be kept as clean as possible to minimize the particles being introduced to cleanroom.

\section{References}

FED-STD 209E, ISO 14644-5, TourAndoverControls, and EPA Cleanroom

\section{Materials}

Certain materials are needed to clean the gowning room and cleanroom. The tacky roller and Isopropyl/Water saturated cleanroom wipes are needed to remove large particles and hair from the cleanroom and gowning floor.

- Isopropyl/Water saturated cleanroom wipes

- Tacky Roller

\section{Procedures}

1. Place booties over shoes to minimize the introduction of particles into the cleanroom

2. Cover all Petri Dishes when accessing cleanroom to minimize particles being introduced to filter and interior of petri dish

3. Wipe the walls from the ceiling to the floor with overlapping strokes,

- Replace Isopropyl/Water saturated cleanroom wipe when needed to ensure that the wipes are not spreading particles

- Wipe horizontal surface as working from ceiling to floor before proceeding towards the floor

a. Wipe wire shelves and posts as much as possible, without moving all items on the shelves

b. Wipe out pass through and horizontal and vertical surfaces of pass through 
c. Wipe chairs from top to bottom

d. Wipe marble tables from top to bottom, use tacky roller to remove loose particles on marble table top, where keyboard is placed

4. Use tacky roller on the floor to remove any large particles

5. Wipe floor with Isopropyl/Water saturated cleanroom wipes

- Be sure to clean behind the computer and in among the wires directly beneath balances

- Be sure to clean base of air returns

- Be sure to clean underneath the static dissipative chair mat

6. Use tacky roller another time to ensure that loose particles are removed from the floor

7. Remove top tacky mat before leaving the cleanroom

8. Return an hour later to remove lids to Petri dishes

9. Move to gowning room

10. Wipe the walls from the ceiling to the floor with overlapping strokes, starting closest to the entrance to the cleanroom and work towards the entrance to the gowning room

- Replace Isopropyl/Water saturated cleanroom wipe when needed to ensure that the wipes are not spreading particles

- Wipe horizontal surface as working from ceiling to floor before proceeding towards the floor

a. Wipe wire shelves and posts as much as possible without moving items on shelves

b. Wipe out pass through and horizontal and vertical surfaces of pass through

11. Use tacky roller on the floor to remove any large particles

12. Wipe floor with Isopropyl/Water saturated cleanroom wipes, working from cleanroom entrance toward gowning room entrance

- Be sure to clean base of air returns

- Be sure to clean underneath gowning bench

13. Use tacky roller another time to ensure that loose particles are removed from the floor

14. Remove top tacky mats before leaving the gowning room

\section{Corrective Actions}

Contact the laboratory supervisor if cleaning supplies and/or tacky mats are needed. 